\title{
DIVERSITY OF OCEANIC ISLAND FLORAS: A FUNCTIONAL AND \\ TAXONOMIC APPROACH ALONG GRADIENTS OF ENVIRONMENTAL HETEROGENEITY AND ACROSS SPATIAL SCALES
}

\author{
Dissertation \\ to attain the doctoral degree (Dr. rer. nat.) \\ of the Faculty of Forest Sciences and Forest Ecology \\ Georg-August-Universität Göttingen
}

Submitted by

Martha Paola Barajas Barbosa

Born in Bogotá

Göttingen, 2021 
1. Referee: Prof. Dr. Holger Kreft

University of Goettingen

2. Referee: Prof. Dr. Kerstin Wiegand

University of Goettingen

Additional referee:

Prof. Dr. Catrin Westphal

University of Goettingen

Date of oral examination: June $10^{\text {th }}, 2021$ 


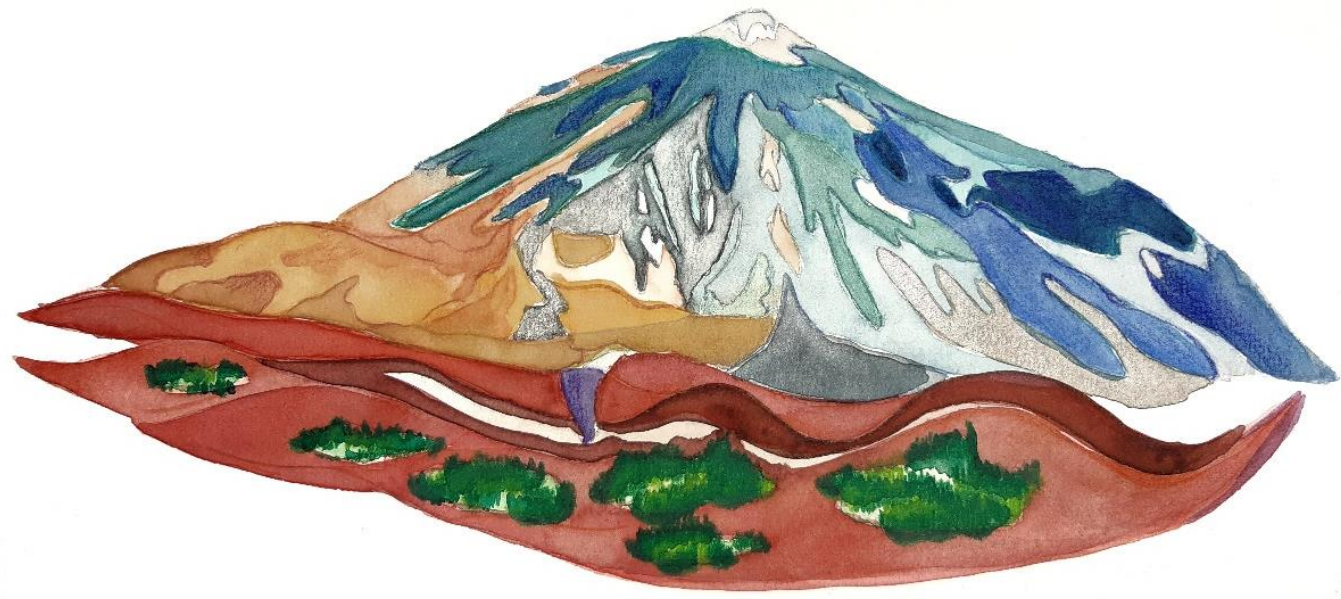

Mount Teide Tenerife

From explosive melting rocks, with hot gas and burning ashes, to the apparent tranquility of oceanic islands, how do plants make their way and thrive on such isolated volcanoes? 


\section{ABSTRACT}

Oceanic islands are recognized for their unique biota, which include remarkable examples of trait evolution. This makes them excellent model systems for testing biogeographical and evolutionary hypotheses, as well as for linking geodiversity to plant diversity patterns. Functional island biogeography is an emerging research field, which based on trait-based approaches can provide deeper insights about dynamics and patterns of insular plant diversity. Yet empirical measurements of plant functional traits are scarce for oceanic islands. Consequently, our knowledge about functional diversity of insular environments and island trait syndromes remains limited. To fill this research gap, I selected Tenerife (Spain, Canary Islands) as a model system, an oceanic island with high environmental heterogeneity and well-described flora, and systematically sampled eight plant traits for nearly all Tenerife native seed plants (80\%). I investigated how biogeography, evolution, and the environment shape the assembly of Tenerife flora by applying a functional trait-based approach. I then explored plant trait syndromes of the oceanic island and compared them to global plant trait syndromes. Furthermore, I investigated the scale dependence of functional diversity of Tenerife to understand the ecological processes shaping plant diversity patterns across space, from regional to local scales. Additionally, I investigated how the complexity and temporal dynamics of insular environmental heterogeneity affect plant diversity on oceanic islands globally. My results expand the understanding about the importance of biogeography (via dispersal), evolution (via speciation), and the environment in determining the functional diversity of island flora. Dispersal, both long distance and among islands, increases functional diversity, while speciation limits it. Importantly, the arid environmental conditions of Tenerife, which has a predominantly Mediterranean climate, have resulted in plant species converging to a shrubby growth form. I further show the scale dependency of functional diversity. Regional patterns of functional diversity percolate down to local scales, but the processes that determine the emerging patterns of functional diversity differ among local grains. While at large spatial grains climate and topography affect plant functional diversity, at fine local grains species interactions affect it. Finally, I show that the environmental heterogeneity of oceanic islands is highly dynamic over geological time. Environmental heterogeneity reaches its maximum levels faster than previously thought, i.e., upon the emergence of an island from the ocean, and progressively decreases with time. This dynamic strongly influences insular plant diversity and endemism levels. The results of this PhD work evidence that trait-based approaches in island biogeography research provide key insights into the spatio-temporal patterns of insular floras. Such approaches also allow us to unravel and understand the importance of biogeography, evolution and ecology in determining how insular plants assemble. Assessing the patterns of functional and 
taxonomic diversity at different spatial scales, allow us to understand which factors govern plant diversity across space. Finally, to better understand species richness and endemism of oceanic islands, it is key to assess the temporal dynamic and the effect of insular environmental heterogeneity, because ecological opportunities and island carrying capacity are linked to heterogeneity levels of an environment. 


\section{ZUSAMMENFASSUNG}

Ozeanische Inseln sind bekannt für ihre einzigartige Biota, die bemerkenswerten Beispiele der Merkmalsentwicklung enthält. Dies macht sie zu ausgezeichneten Modellsystemen für das Testen biogeographischer und evolutionärer Hypothesen sowie für die Verknüpfung von Geodiversität mit Mustern der Pflanzendiversität. Die funktionale Inselbiogeographie ist ein aufstrebendes Forschungsfeld, das auf der Grundlage von merkmalsbasierten Ansätzen tiefere Einblicke in die Dynamik und Muster der insularen Pflanzendiversität liefern kann. Empirische Messungen von funktionalen Pflanzenmerkmalen sind für ozeanische Inseln jedoch rar. Folglich bleibt unser Wissen über die funktionelle Diversität insularer Umgebungen und Inselmerkmalssyndrome begrenzt. Um diese Forschungslücke zu schließen, habe ich Teneriffa (Spanien, Kanarische Inseln) als Modellsystem gewählt, eine ozeanische Insel mit hoher Umweltheterogenität und gut beschriebener Flora, und systematisch acht Pflanzenmerkmale für fast alle auf Teneriffa heimischen Samenpflanzen (80\%) erfasst. Anschließend untersuchte ich, wie Biogeographie, Evolution und die Umwelt den Aufbau der Flora Teneriffas formen, indem ich einen auf funktionalen Merkmalen basierenden Ansatz angewendet habe. Anschließend untersuchte ich Pflanzenmerkmals-Syndrome der ozeanischen Insel und verglich sie mit globalen Pflanzenmerkmals-Syndromen. Darüber hinaus untersuchte ich die Skalenabhängigkeit der funktionellen Diversität auf Teneriffa, um die ökologischen Prozesse zu verstehen, die die Muster der Pflanzendiversität über den Raum hinweg formen, von regionalen bis zu lokalen Skalen. Zusätzlich untersuchte ich, wie die Komplexität und zeitliche Dynamik der insularen Umweltheterogenität die Pflanzenvielfalt auf ozeanischen Inseln global beeinflusst. Meine Ergebnisse erweitern das Verständnis über die Bedeutung der Biogeographie (durch Ausbreitung), der Evolution (durch Artbildung) und der Umwelt bei der Bestimmung der funktionellen Vielfalt der Inselflora. Die Ausbreitung, sowohl über große Entfernungen als auch zwischen Inseln, erhöht die funktionelle Vielfalt, während die Speziation sie begrenzt. Wichtig ist, dass die trockenen Umweltbedingungen auf Teneriffa, das ein überwiegend mediterranes Klima hat, dazu geführt haben, dass Pflanzenarten zu einer strauchartigen Wuchsform konvergieren. Ich zeige außerdem die Skalenabhängigkeit der funktionellen Diversität. Regionale Muster der funktionalen Diversität sickern bis zu lokalen Skalen hinunter, aber die Prozesse, die die entstehenden Muster der funktionalen Diversität bestimmen, unterscheiden sich zwischen den lokalen Körnern. Während auf großen räumlichen Körnern Klima und Topographie die funktionelle Diversität von Pflanzen beeinflussen, sind es auf feinen lokalen Körnern Arteninteraktionen. Schließlich zeige ich, dass die Umweltheterogenität ozeanischer Inseln im Laufe der geologischen Zeit sehr dynamisch ist. Die Umweltheterogenität erreicht ihr Maximum schneller als bisher angenommen, d.h. bei der Entstehung einer Insel aus dem Ozean, und nimmt mit der Zeit 
immer mehr ab. Diese Dynamik beeinflusst stark die insulare Pflanzenvielfalt und den Grad des Endemismus. Die Ergebnisse dieser Doktorarbeit zeigen, dass eigenschaftsbasierte Ansätze in der Inselbiogeographie-Forschung wichtige Einblicke in die räumlich-zeitlichen Muster der Inselflora liefern. Solche Ansätze erlauben es uns auch, die Bedeutung von Biogeographie, Evolution und Ökologie bei der Bestimmung des Aufbaus insularer Pflanzen zu entschlüsseln und zu verstehen. Die Bewertung der Muster der funktionalen und taxonomischen Vielfalt auf verschiedenen räumlichen Skalen ermöglicht es uns zu verstehen, welche Faktoren die Pflanzenvielfalt im Raum bestimmen. Um schließlich den Artenreichtum und Endemismus ozeanischer Inseln besser zu verstehen, ist es von entscheidender Bedeutung, die zeitliche Dynamik und die Auswirkungen der Heterogenität der Inselumwelt zu bewerten, da die ökologischen Möglichkeiten und die Tragfähigkeit der Insel mit dem Heterogenitätsgrad der Umwelt verbunden sind. 


\section{CONTENTS}

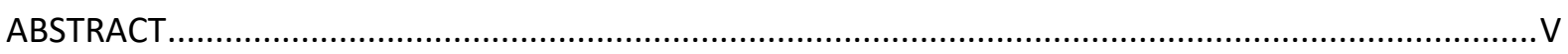

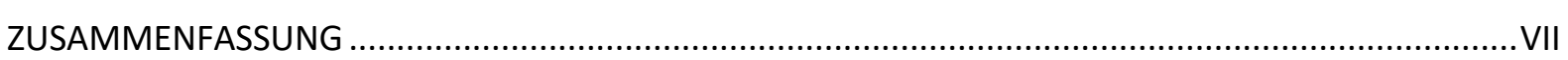

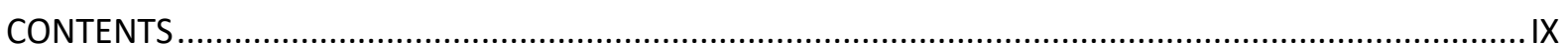

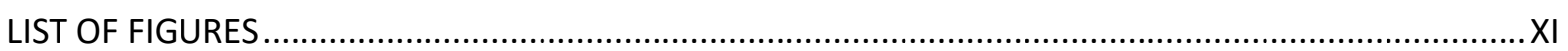

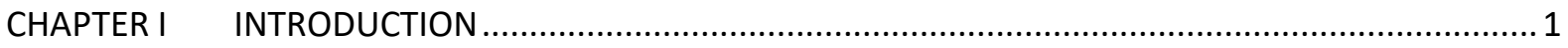

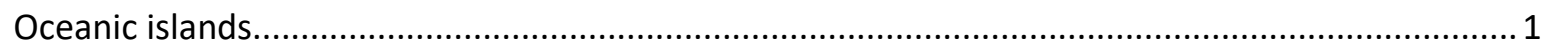

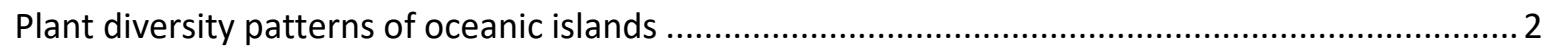

Functional diversity broadens the understanding about insular plant assembly............................. 3

The environment of oceanic islands: how does it affect plant diversity ......................................... 5

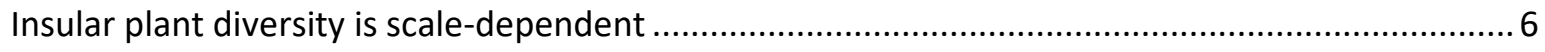

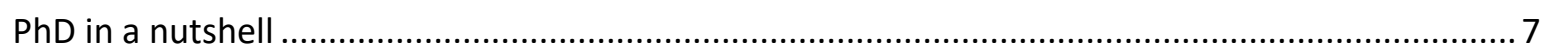

CHAPTER II ASSEMBLY OF FUNCTIONAL DIVERSITY OF AN OCEANIC ISLAND FLORA .................... 11

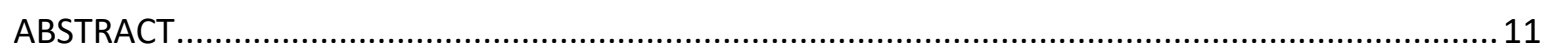

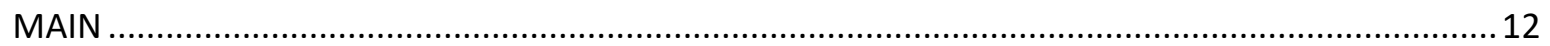

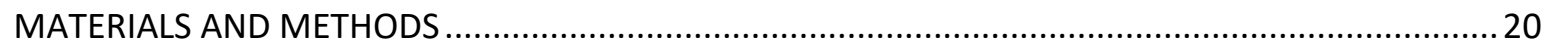

CHAPTER III PLANT FUNCTIONAL DIVERSITY ON AN OCEANIC ISLAND VARIES ACROSS SPATIAL SCALES 27

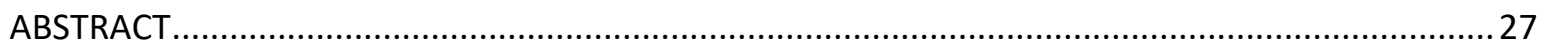

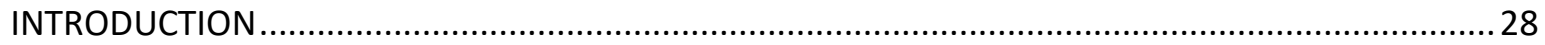

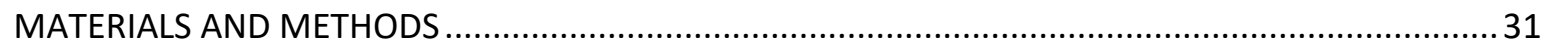

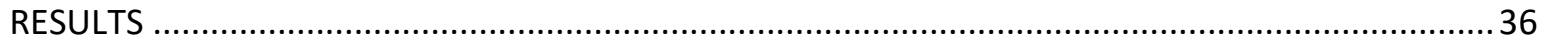

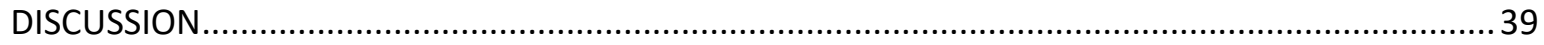

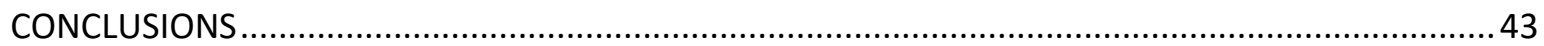

CHAPTER IV ENVIRONMENTAL HETEROGENIETY DYNAMICS DRIVE PLANT DIVERSITY ON OCEANIC ISLANDS $\quad 45$

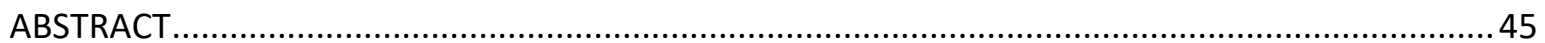

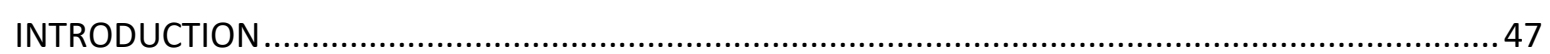

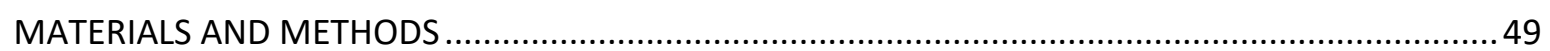

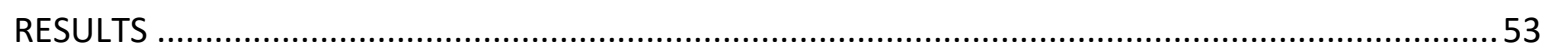

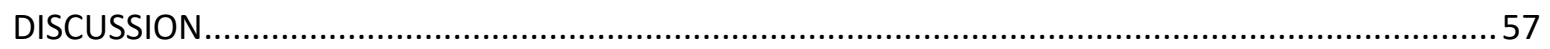

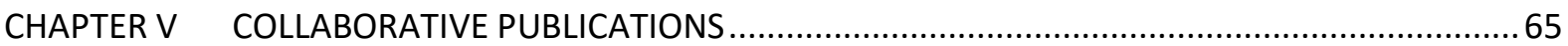

Scientific floras can be reliable sources for some trait data in a system with poor coverage in global

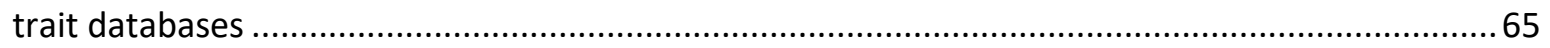

Climatic and biogeographic drivers of functional diversity in the flora of the Canary Islands .........67

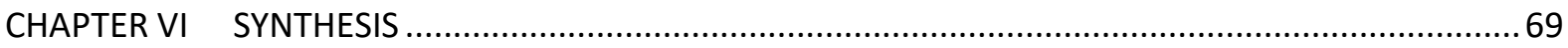


The assembly of an oceanic island flora from a functional diversity perspective .69

Functional diversity of an oceanic island across different spatial scales

Temporal dynamic of environmental heterogeneity on oceanic islands and its effect on plant diversity. .73

The importance trait-based approaches and future perspectives ............................................... 74

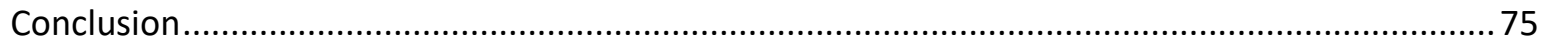

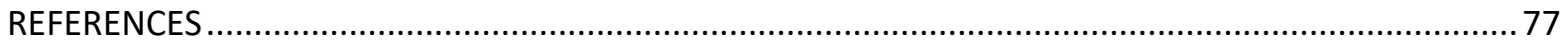

APPENDIX

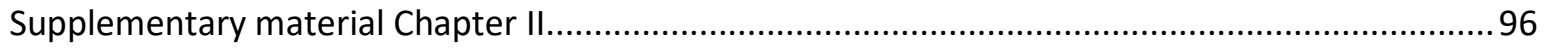

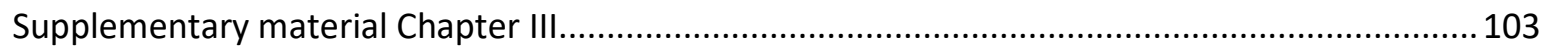

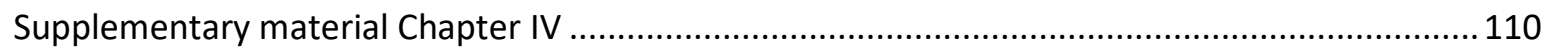

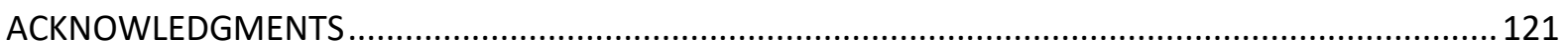

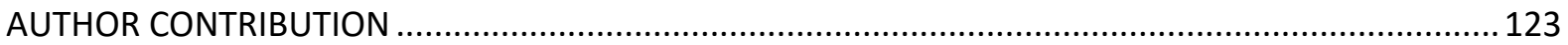

DOKTORANDEN-ERKLÄRUNG DER GEORG-AUGUST-UNIVERSITÄT GÖTTINGEN ............................. 124 


\section{LIST OF FIGURES}

Figure I-1 Map of the Macaronesia region, Canary Islands and Tenerife. Tenerife is the largest island of the Canary archipelago and Macaronesia.

Figure II-1 Hypothetical depiction of biogeography via dispersal and environmental filters and evolution via speciation shaping an oceanic island plant trait space.

Figure II-2 Trait syndromes of the complete native flora of Tenerife are subjected to the same constraints as in the global spectrum of plant form and function, but are biased towards mediumstatured species with intermediate seed size. (a)

Figure II-3 Functional trait space of (a) the Tenerife oceanic island flora (436 native species) based on eight functional traits.

Figure II-4 Functional contribution and originality for a) biogeographical and b) evolutionary groups.

Figure III-1 Conceptual diagram of study, illustrating the spatial scales and grains at which we examine patterns and drivers of plant functional diversity on Tenerife.

Figure III-2 Functional diversity accumulation curves of native plant communities on Tenerife at two

spatial grains

Figure III-3 Functional diversity patterns of Tenerife vegetation types from within local (alpha) and regional (gamma) spatial scales

Figure III-4 Scale-dependent environmental effects on functional diversity computed at plot grain (a) and at cell grain (b).

Figure IV-1 Workflow of quantifying environmental heterogeneity (EH) for 135 oceanic islands worldwide

Figure IV-2 Temporal trends of environmental heterogeneity (EH) over island age (in millions of years i.e., Ma) based on data for 135 oceanic islands. .55

Figure IV-3 Effects of environmental heterogeneity (EH) components and metrics, island area and age on species richness and endemism of vascular plants .56 


\section{CHAPTER I INTRODUCTION}

\section{Oceanic islands}

Oceanic islands are ideal model systems for testing ecological and evolutionary hypotheses (Wardle 2002; Gillespie 2007). Over centuries, oceanic islands have inspired western scientists to formulate central concepts about evolution and ecology (Darwin 1859; MacArthur \& Wilson 1967). The effect of the geographical context of an insular system, in terms of its area and isolation, governing species diversity (MacArthur \& Wilson 1967) exemplify this. Since then and despite certain critics (Meiri 2017), oceanic islands have continuously provided key insights into the intricate relationship between biota and the environment (MacArthur \& Wilson 1967; Whittaker \& Fernández-Palacios 2007; Weigelt et al., 2015; Triantis et al., 2016; Craven et al., 2019).

Originating through volcanic activity and being small landmasses, oceanic islands have particular characteristics that make them excellent natural laboratories (Whittaker et al., 2017). They emerge devoid of life, have an unusual geographical isolation and simpler biota compared to the mainland ones (Vitousek \& Benning 1995; Gillespie 2007; Whittaker et al., 2017). Furthermore, their geological origin and global distribution make oceanic islands spatially independent and replicated systems, with various sizes, geological ages and distinct environmental conditions (Wardle 2002). Examples of this are the Canary Islands, in the Atlantic Ocean, and Hawaiian Islands in the Pacific Ocean. Both archipelagos are composed of young islands, i.e., $0.53 \mathrm{Ma}$ (Ma: million years) to $20 \mathrm{Ma}$ old islands and of small to large islands, i.e., from 100 to $10.000 \mathrm{~km}^{2}$. Such characteristics allow comparisons of biota at local, regional and global scale and how biota change over time (Wardle 2002). In fact, through macroecological and biogeographical studies, oceanic islands have improved the understanding about how environmental conditions and evolutionary processes shape assemblies of floras (Kreft et al., 2008; Weigelt et al., 2015). The study of oceanic island biota has been mainly focused on two main biodiversity facets, taxonomic and phylogenetic diversity. Although studies investigating functional diversity (Tillman 2001), i.e., the component of biodiversity that influences organisms, species and ecosystem functions, are rapidly increasing (Westerband et al., 2021; Kühn et al., 2021; Taylor et al., 2021). This is important, because functional diversity allows us to quantify the ecological strategies performed by species in an 
assembly, communities and ecosystem (Díaz \& Cabido 2001), which will improve the general understanding about evolution and ecology of insular systems (Ottaviani et al., 2020).

Besides being excellent model systems, oceanic islands and other island systems are biodiversity hotspots (Myers et al., 2000). At a global scale, islands harbour a large proportion of endemic species, one quarter of known extant vascular plants are endemic to islands (Kier et al., 2009). The high endemism level of islands combined with the intensification of human activities make their biota vulnerable (Graham et al., 2017). Island biota are undergoing severe habitat loss and biological invasions (Whittaker et al., 2017), which is a significant detriment for biodiversity in general. Thus, island research will not only deepen and aid understanding how evolution and ecology act on species diversity but it will allow us to preserve their outstanding biodiversity levels.

\section{Plant diversity patterns of oceanic islands}

Central to the understanding of plant diversity patterns of insular environments is The Theory of Island Biogeography (MacArthur \& Wilson 1963; MacArthur \& Wilson 1967), which explains how key evolutionary and biogeographical processes affect species distribution and assembly processes. The theory states that species colonization, speciation and extinction rates determine the number of species existing on an island. Colonization and extinction reach a dynamic equilibrium, in which the number of species remains constant while species identities are replaced over time. In the Theory of Island Biogeography, both island size and distance to the colonist's source affect species replacement. Thus, larger islands host more species, while isolated islands receive less colonists. However, the concept of island biota reaching a dynamic equilibrium is not plausible, because island size (area) is dynamic over time (Whittaker et al., 2007; Whittaker et al., 2008). Along the geological life-span an oceanic island changes from a high and smooth, to a highly rugged volcano marked by erosion, to a flat small island remnant (Paulay 1994; Price \& Clague, 2002). During island life-span, also termed as 'island ontogeny' (Heaney 2007; Whittaker et al., 2007; Whittaker et al., 2008), very young islands have relatively low environmental diversity, which reaches its maximum at about mid-age. Over time old islands become eroded, flat and small, with a homogeneous environment (Whittaker et al., 2008). This dynamic influence island carrying capacity and species richness, which rates are expected to be humped-shaped over time (Whittaker et al., 2008). These dynamics affecting island biota have been synthesized in the Dynamic theory of oceanic island biogeography (Whittaker et al., 2008), which together with The Theory of Island Biogeography are pillars for understanding how island floras assemble. 
Nevertheless, both theories assume that plants have equal probabilities to colonize and establish an oceanic island, which implies that species are functionally equivalent. Yet in reality, species have different morphological, chemical, physiological characteristics (i.e., functional traits sensu Lavorel \& Garnier 2002 \& Violle et al., 2007) that play key roles in plant colonization, establishment, speciation and extinction on islands (Jacquet et al., 2016). A holistic understanding of the ecology and evolution of island biota should therefore include species identities, i.e., taxonomic diversity, species evolutionary relationships, i.e., phylogenetic diversity and also species ecological performance, i.e., functional diversity (Patiño et al., 2017).

\section{Functional diversity broadens the understanding about insular plant assembly}

Plant functional traits are distinct morphological and physiological characteristics that can be measured from individuals, communities to ecosystems (Violle et al., 2007). Functional traits are the means to understand plant ecological strategies, which impact growth, reproduction and survival of individuals (Violle et al., 2007), affect organism responses to the environment (Lavorel \& Garnier 2002) and influence community assembly (Kraft \& Ackerly 2014).

Functional traits mediate biogeographical (e.g., dispersal) and evolutionary (e.g., speciation) processes (Emerson \& Guillespie 2008; Kraft \& Ackerly 2014), as well as environmental filters (Carvajal-Endara et al., 2017), which are responsible for the variation and compositions of island floras (Mouchet et al., 2010; Spasojevick et al., 2012; Weigelt \& Kreft 2013). Plants are constantly dispersing and colonizing new environments. On oceanic islands, colonization rates are regulated by both long and inter-island dispersal (Weigelt \& Kreft 2013), which naturally occur through water currents, wind or animal aid (Whittaker \& Fernández-Palacios 2007). Yet plants depend on their traits combinations to disperse and establish in such far away environments (Weigelt et al., 2015; Taylor et al., 2019). For instance, palms with large seeds dispersed by animals, undergo negative dispersal filters, as a consequence such plants are absent on oceanic islands (Weigelt et al., 2015). New island environments constitute strong abiotic filters for plants. Thus, plants require functional traits combinations that allow them to cope with the new environment and guarantee their survival (Weigelt et al., 2015; Patiño et al., 2017). For instance, the arid conditions of the Canary Islands, a volcanic archipelago characterized by a Mediterranean climate, have filtered functional traits combination of plants that survive drought, such as high leaf thickness related to 
succulence (Shmida \& Werger 1992) and high stem density related to woodiness (Lens et al., 2013). Once established on an oceanic island, speciation can initiate by fragmentation of populations (i.e., through geographic isolation), which leads to allopatric speciation without emergence of new trait combinations (Stuessy et al., 2006); or by divergent selection with individuals exploiting alternative island niches (Chase \& Leibold 2009), which can lead to new trait combinations (Givnish et al., 2009). The latter process is termed adaptive radiation, in which species modify their traits to adapt to a different ecological and environmental condition (Givnish et al., 2009). Therefore, along the geological, evolutionary and ecological history of oceanic islands, plant functional traits and ecological strategies play a key role in determining the identity, abundance and distributional patterns of plants that occur on them (Carlquist 1974; König et al., 2021).

Using functional traits, it is possible to quantify ecological differences among species (Díaz \& Cabido 2001; Cadotte et al., 2013). Such differences determine the species role in a community and how they respond to the environment (Mason et al., 2005; Spasojevic \& Sundig 2012; Reich 2014). A straightforward example of two ecologically distinct species are herbaceous plants versus trees. Both plant types have disparate functional traits combinations related to their size that evolved to optimize growth, survival and reproduction (Lande 1982; Wright et al., 2004). Furthermore, functional traits relate to the way plants acquire and use resources (Westoby et al., 2002; Wright et al., 2004, Reich 2014) also referred to as the fast-slow continuum. It relates to the life history variation of plants, where on one side are plants with fast development rates, high mortality and high fecundity rates, and generally short life cycles, and on the other side are plants with slow growth rates, low mortality and low fecundity rates and long-life cycles are (Franco \& Silvertown 1996). The fast-slow continuum encompasses the distinct ecological strategies responsible for the diverse life histories found in plants, in which contrasting strategies have proven throughout evolution to be equally successful (Moles 2018).

A functionally diverse community is composed of functionally distinct plants with contrasting trait combinations (Mouchet et al., 2010). Functional diversity can be quantified using complementary indices (Villéger et al., 2008; Mouchet et al., 2010): functional, richness, dispersion and evenness. Functional diversity indices can detect processes involved in assembly rules, such as habitat filtering and biotic interactions (Götzenberger et al., 2012). For instance, a low functional richness value links to strong habitat filtering, such as high aridity or too high competition (Spasojevic \& 
Suding 2012). Contrarily, high functional richness values link to species coexistence and high habitat diversity (Mouchet et al., 2010). To date, there are two approaches currently used to quantify functional diversity. Firstly, the trait-value-based approach, which considers the position and extent of species within a multidimensional functional space and calculates the volume occupied by species to estimate functional diversity. Most prominent approaches within the traitvalue-based approach are convex hulls (Cornwell et al., 2006) and probabilistic hypervolumes (Blonder et al., 2018). The latter has overcome limitations of the convex hull because multidimensional trait spaces have empty areas caused by extreme trait values or dominance of a particular trait combination (Blonder 2016). Secondly, the distance-based approach, which uses a set of functional traits to calculate a functional pairwise distance matrix in order to estimate functional diversity (Villéger et al., 2008; Chao et al., 2019). Most recent distance-based approaches are very sensitive to species abundances and to species-pairwise distances, and therefore generate more accurate functional diversity estimates (Chao et al., 2019).

\section{The environment of oceanic islands: how does it affect plant diversity}

Climate and elevation are the main drivers of plant diversity (Rahbek 1995; Kreft \& Jetz 2007). For plants, climatic conditions, in terms of precipitation and temperature, influence water and energy availability (Clarke \& Gaston 2006) and are responsible for the observed plant diversity gradients at regional and global scales (Kreft \& Jetz 2007). The geological history and landscape configuration of oceanic islands determine the range and complexity of climate and topography (Barajas-Barbosa et al., 2020). This translates into levels of habitat and environmental heterogeneity found on islands, which tightly relates to island carrying capacity, species richness and endemism levels (Whittaker et al., 2008; Irl et al., 2015; Borregaard et al., 2017).

Environmental heterogeneity is a main factor governing plant diversity (Stein et al., 2014; Keppel et al., 2016) and encompasses spatial variation of abiotic and biotic factors, such as climate and topography, as well as land cover, soil and vegetation (Stein \& Kreft 2015). Environmental heterogeneity positively influences plant diversity (Stein et al., 2014), because heterogeneous environments have different habitat types where large numbers of species can coexist, provide refugia during adverse climatic fluctuations where species can persist (Keppel et al., 2015) and promote diversification as certain species will adapt to contrasting environmental conditions 
(Rosenzweig 1995; Hortal et al., 2013). The different levels of environmental heterogeneity on oceanic islands are defined by its climatic ranges and topographic complexity (Barajas-Barbosa et al., 2020). For instance, high climatic ranges intrinsic of high elevation islands (e.g., the highest points of Hawai'i and Tenerife are 4,207 and 3,718 m a.s.l, respectively) create step and variable temperature and rain gradients, which in turn increases environmental heterogeneity. In parallel, topographic complexity, (i.e., island ridges and valleys) produces local changes in temperature and rain. This increases habitat diversity and available niches for species to coexist and speciate (Hortal et al., 2009; Irl et al., 2015). Yet, the effect of environmental heterogeneity on plant diversity is not always simple to detect. First because environmental heterogeneity is tightly related to the island area (Triantis et al., 2003), that is, on large islands environmental heterogeneity is higher than on small islands, simply because large areas have a higher amount of resources and energy available (Hortal et al., 2013). Island area has always emerged among the strongest predictors of insular diversity (MacArthur \& Wilson 1967; Rosenzweig 1995; Kreft et al., 2008); whereby the relation between area and species numbers is one of the few laws in ecology (Arrhenius 1921; Lomolino 2000), which states that the number of species increases with area and conceptualized as the 'species-area relationship' (Triantis et al., 2012). Importantly, area and environmental heterogeneity are not mutually exclusive but mutually supplementary because both influence species diversity (Triantis et al., 2003).

\section{Insular plant diversity is scale-dependent}

Generally, biodiversity changes across space and time (Chase \& Leibold 2002; Chase et al., 2018). It is expected that the different facets of insular plant diversity, i.e., taxonomic, phylogenetic and functional diversity, are scale-dependent too. Concretely, the scale dependency of diversity refers to the number of species and functionally distinct species increasing nonlinearly with space; that is with spatial grain (i.e., size of sampling unit) and extent (i.e., total area sampled of a study) (Scheiner et al., 2011; Viana \& Chase 2018). Scale-dependent patterns emerge because the mechanisms shaping plant diversity act differently from regional to local scales (Zobel 1997; Chase \& Leibold 2002). At regional scales, processes such as dispersal and environmental filters influence species numbers and functional groups of communities and ecosystems (Zobel 1997). At local scales, species interactions, such as competition and adaptation, determine species numbers and functional groups of communities (Ricklefs 1997). Both regional and local processes are in a 
constant interplay, determining the patterns of plant diversity that emerge from different scales (Ricklefs 1997).

In ecology, plant assemblies and communities are commonly studied from a single spatial scale and with single facets of biodiversity, e.g., species richness, mainly due to logistics constraints or limited data availability (Chase et al., 2018). However, plant diversity needs to be assessed including multiple biodiversity facets and at different spatial scales to answer fundamental ecological questions, such as at which spatial scale the processes balancing coexistence have a clear effect on species number and functional diversity and plant strategies? Or at which spatial scale environmental conditions have a clear effect on species functional diversity? Certainly, in small areas, species coexistence becomes restricted due to limited habitat diversity and resource availability (Chase 2014; Schrader et al., 2019) and in large areas habitat diversity may boost functional diversity at regional scales (Bond \& Chase 2002; Spasojevic et al., 2012). There are suitable methods to study the scale dependency of diversity. A commonly used method is rarefaction curves (Scheiner et al., 2011), which informs about how diversity varies with increasing spatial grain or sampling effort (Gotelli \& Colwell 2001; Chase \& Knight 2013). Among rarefaction curves, sample-based rarefaction allows identifying how plant diversity varies with increasing area (Gotelli \& Colwell 2001). Furthermore, plant diversity can be examined in a spatially explicit context by partitioning it into local (alpha-diversity) and regional (gamma-diversity) diversity. The scaling factor between the local and regional, that is beta-diversity can be additionally calculated to infer diversity variation (turnover) over space (Chase \& Knight 2013).

\section{$\mathrm{PhD}$ in a nutshell}

Given the importance of including functional diversity in island biogeography research (Whittaker et al., 2014; Ottaviani et al., 2019) and the current lack of quantification of key plant functional traits for island floras (but see Schrader et al., 2020; Westerband et al., 2021; Kühn et al., 2021), I used a trait-based approach and Tenerife island (Spain - Canary Islands, which belong to Macaronesia biogeographical region) as model system (Figure I-1) in my PhD work to improve the understanding about how plants assemble (Chapter II) and which processes govern plant functional diversity patterns across space (Chapter III). To this end, I collected and measured eight fundamental functional plant traits (Díaz et al., 2016) for $80 \%$ of Tenerife native seed plants. 
Furthermore, given that the complexity and temporal dynamic of island environments strongly affect plant diversity, and the fact that there was not a comprehensive quantification of environmental heterogeneity of oceanic islands (but see Keppel et al., 2016), in my PhD work, I the assessed the environmental heterogeneity of oceanic island at a global scale, their temporal dynamic over time and how this dynamic affect insular plant diversity and endemism (Chapter IV).
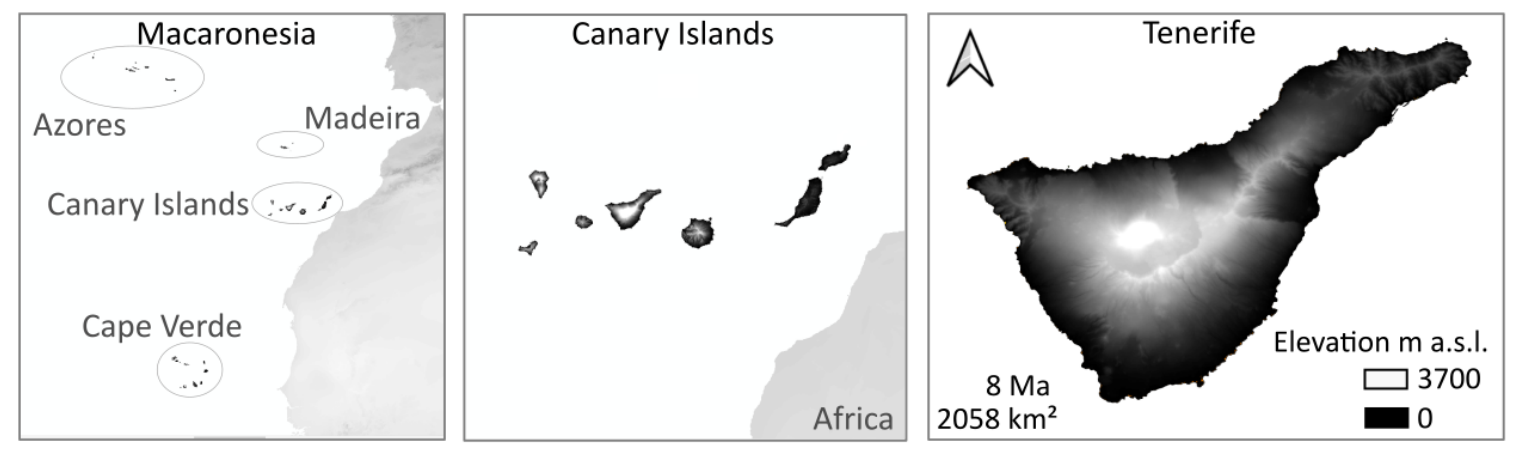

Figure I-1 Map of the Macaronesia region, Canary Islands and Tenerife. Tenerife is the largest island of the Canary archipelago and Macaronesia. Tenerife highest point is Mount Teide and it is the second largest volcanic island in the world.

In Chapter II I aimed to understand how biogeography, evolution and island environment shape Tenerife's plant functional diversity. To this end, I first assessed the functional diversity of different species groups related to species biogeographical ranges (e.g., single island endemics, canary endemics and native non-endemics) and speciation processes (i.e., cladogenetic species). Second, I explored matches and mismatches between island and global plant trait syndromes.

In Chapter III I studied the variation of plant diversity in space and how it relates to the abiotic conditions of Tenerife. For this, I tested the spatial scale dependency of functional and taxonomic diversity from regional to local scale and across local grains and related the environmental conditions of Tenerife to two local spatial grains.

In Chapter IV I assessed the complexity and temporal dynamic of the environmental heterogeneity, in terms of climate and topography, for 41 archipelagos, composed by 135 oceanic islands, distributed across the globe. I related the dynamics of environmental heterogeneity along the oceanic island's life-span to plant diversity. For the analysis, I integrated information from the Global Inventory of Floras and Traits (GIFT) database (Weigelt et al., 2019) and Climatologies at high resolution for the earth's land surface areas i.e., CHELSA (Karger et al., 2017).

Concretely, in my PhD I addressed the following research questions: 
Chapter II: are the trait syndromes of an oceanic island flora similar to those previously documented for the globe? And how biogeography, macroevolution and the environment shape functional diversity of an oceanic island native flora?

Chapter III: are Tenerife functional diversity patterns scale-dependent and do functional diversity patterns percolate down from regional to local scales, i.e., from vegetation types (regional scale) down to two local spatial grains $\left(1 \mathrm{~m}^{2}\right.$ and $\left.1 \mathrm{~km}^{2}\right)$ ? And how do climate and topography impact local scale functional diversity, and are these impacts consistent across local spatial grains?

Chapter IV: does environmental heterogeneity exhibit a hump-shaped relationship with island age? And what is the effect of environmental heterogeneity on plant diversity of oceanic islands?

Lastly, In Chapter V I present the abstracts of the collaborations I did during my PhD with two PhD students Dagmar Hanz from the Goethe University Frankfurt and Vanessa Cutts from University of Nottingham. The collaborations lead to my co-authorship of two projects related to plant functional diversity on the Canary Islands. 


\section{CHAPTER II ASSEMBLY OF FUNCTIONAL DIVERSITY OF AN OCEANIC ISLAND FLORA}

Martha Paola Barajas-Barbosa ${ }^{1}$, Dylan Craven $^{1,3}$, Patrick Weigelt ${ }^{1}$, Pierre Denelle ${ }^{1}$, José María Fernández-Palacios ${ }^{2}$, Rüdiger Otto ${ }^{2}$, Sandra Díaz ${ }^{4}$, Jonathan Price 5 and Holger Kreft $^{1,6}$.

\section{AFFILIATIONS}

1 Biodiversity, Macroecology \& Biogeography, University of Goettingen, Göttingen, Germany

2 Island Ecology and Biogeography Research Group, La Laguna University, Tenerife, Spain.

3 Centro de Modelación y Monitoreo de Ecosistemas, Universidad Mayor, Santiago, Chile.

${ }^{4}$ Instituto Multidisciplinario de Biología Vegetal (IMBIV), Consejo Nacional de Investigaciones Científicas y Técnicas and Facultad de Ciencias Exactas, Físicas y Naturales, Universidad Nacional de Córdoba, Casilla de Correo 495, 5000 Córdoba, Argentina.

${ }^{5}$ Department of Geography and Environmental Science, University of Hawai'i at Hilo, Hawaii.

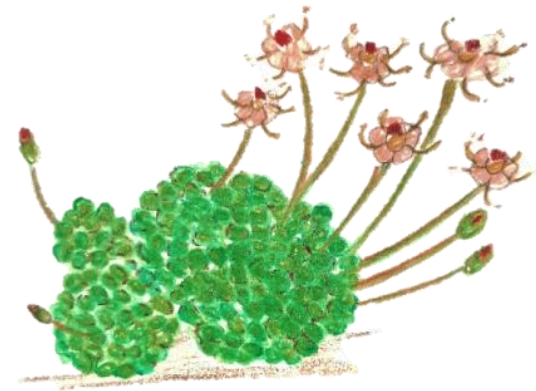

Monanthes pallens

This chapter is a manuscript in preparation. Target journal: Nature

\section{ABSTRACT}

Oceanic island floras are well-known for their morphological oddities and exhibit striking examples of trait evolution (Carlquist, 1966; Darwin, 1859). These morphological shifts are related to insularity, whose peculiar biogeographical and evolutionary history have shaped island biota (Carlquist, 1966; Burns 2019). However, the pathways in which evolution and biogeography had shaped island plant traits remain unclear. Here, we describe the functional trait space of an entire oceanic island flora and relate it to plant trade-offs previously documented for the globe (Díaz et al., 2016). We find the island trait space concentrated in a functional hotspot dominated by shrubby plants. By dissecting the island flora into species with different isolation levels, colonization and speciation events our results reveal that dispersal and speciation jointly shape the functional diversity of an entire island flora. Biogeography via long-distance dispersal and inter-island dispersal drive functional divergence and consequently expands the island trait space. Contrarily, evolution via species splitting and in-situ speciation drive a strong functional convergence, which highly packs the island trait space. 


\section{MAIN}

Oceanic islands have served as natural laboratories in biogeography (Patiño et al., 2017; Whittaker et al., 2017) to study the drivers of the assembly of floras and faunas (Losos \& Ricklefs 2009; Craven et al., 2019). A long-standing paradigm in island biogeography centers on the notion that island isolation and the geoenvironmental processes linked to island ontogeny led to evolutionarily unique (Gillespie \& Baldwin 2010; Weigelt et al., 2015) and functionally distinct biota (Loiseau et al., 2020). However, empirical tests of fundamental concepts in evolution and ecology use islands as model systems (Darwin 1859; MacArthur \& Wilson 1967) under the assumption that results can be generalizable to non-island contexts.

In contrast to neutral theories, such as the theory of island biogeography (MacArthur \& Wilson 1967) or the general dynamic model of oceanic island biogeography (Whittaker et al., 2008), where all arriving species have the same chances to occur on an island irrespective of their traits; a trait-based perspective considers functional differences among species to disentangle processes and identify mechanisms that have shaped island biota (Jacquet et al., 2016; Ottaviani et al., 2020). In a trait-based framework, differences among species are quantified using functional traits, i.e., morphological and physiological characteristics that impact how plants respond to environmental factors, affect other trophic levels and influence ecosystem properties (Lavorel \& Garnier 2002, Violle et al., 2007). Trade-offs among traits elucidate fundamental ecological strategies that structure plant life from individuals to communities. Prominent among these are the fast-slow continuum, which describes a trade-off in how species acquire and conserve resources for growth (Wright et al., 2004; Reich 2014), and the size-recruitment trade-off, which differentiates between plants with large stature that grow slow and live long and those that are short-statured, live short time and produce many offspring (Grime 1979). For quantifying the diversity and distribution of ecological strategies in an assemblage, functional diversity (Díaz \& Cabido 2000; Mason et al., 2005; Mouchet et al., 2010) can be used to identify factors that shape communities, such as abiotic conditions (Wieczynski et al., 2018, Bruelheide et al., 2018) and dispersal filters (Weigelt et al., 2015), which may expand or restrict an island trait space and drive functional divergence or convergence (Mason et al., 2005). However, shortfalls in trait and distribution data (Konig et al., 2019, Cornwell et al., 2019) usually restrict the geographic extent, spatial grain, and taxonomic coverage of such studies, leading to an incomplete knowledge of the factors that underpin a complete plant assemblage, such a complete island flora. 
Crossing large expanses of ocean and adapting to island environments are considerable challenges that likely filter trait values that enhance dispersal and establishment (Weigelt et al., 2015). Thus, biogeographical factors are expected to cluster island trait space, potentially leading to functional convergence (Figure II-1 Hypothetical depiction of biogeography via dispersal and environmental filters and evolution via speciation shaping an oceanic island plant trait space.). In contrast, evolutionary events, such as speciation via splitting of species (cladogenesis) (Stuessy 1990), are expected to expand trait space (Cornwell \& Ackerly 2009; Emerson \& Gillespie 2008), due to novel shifts of trait combinations that facilitate the occupation of vacant island trait space. The Hawaiian silverswords and Canary Echium adaptive radiations exemplify this (Böhle et al., 1996; Givnish et al., 2009). However, the relative importance of biogeographical and evolutionary processes in shaping trait diversity and ecological strategies on oceanic islands remains elusive (Ricklefs \& Jenkins 2011).

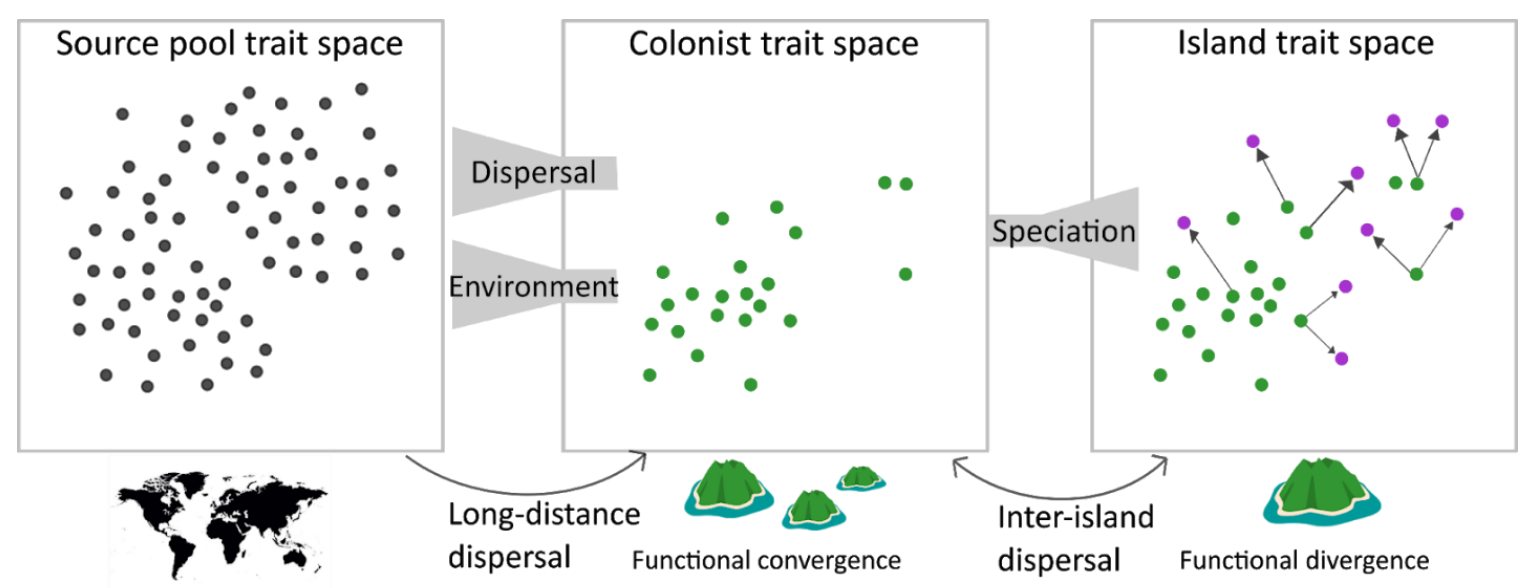

Figure II-1 Hypothetical depiction of biogeography via dispersal and environmental filters and evolution via speciation shaping an oceanic island plant trait space. Both biogeographical and evolutionary processes determine levels of island functional diversity. While dispersal and environmental filters drive functional convergence as they constrain island traits space, speciation via adaptive radiation expands island trait space via occupation of vacant island trait space and causes functional divergence.

Here, using a quantitative trait-based approach we explore matches and mismatches in trait syndromes between a complete native flora of an oceanic island and the global spectrum in plant form and function (Díaz et al., 2016). We use Tenerife (Canary Islands, Spain) as a model system, an oceanic island located in Macaronesia with stunning ranges of environmental conditions, from arid coastal succulent scrub vegetation, to humid Laurel forests, to arid alpine vegetation (Fernández-Palacios, 1992). Tenerife well-described flora comprises 436 native seed plants 
(Acebes Ginovés et al., 2010), for which we collected and measured $80 \%$ of eight plant functional traits (Figure II-3a). This includes species with different biogeographic ranges, e.g., endemic to Tenerife, and distinct evolutionary histories, e.g., adaptive radiations with iconic examples of island syndromes. This allowed us to understand imprints of biogeographical and evolutionary processes on the functional diversity of the island flora.

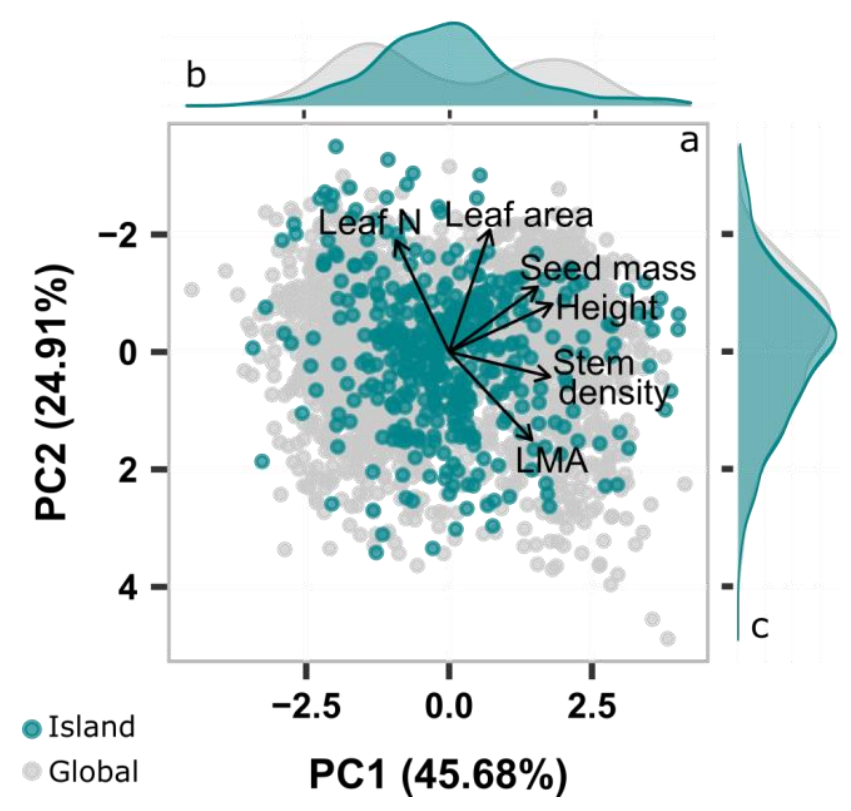

Figure II-2 Trait syndromes of the complete native flora of Tenerife are subjected to the same constraints as in the global spectrum of plant form and function, but are biased towards medium-statured species with intermediate seed size. (a) Trait space of the native flora of the oceanic island of Tenerife (i.e., 436 native species of Tenerife, green dots) in relation to the global plant trait space (2199 species, gray dots, from Díaz et al., 2016). Projections of the two first dimensions of variation from the principal component analysis (PCA) of six plant functional traits: leaf area $\left(\mathrm{mm}^{2}\right)$, leaf mass per area (LMA, $\mathrm{g} \mathrm{m}^{-2}$ ), leaf Nitrogen content (Leaf $\mathrm{N}, \mathrm{mg} \mathrm{g}^{-1}$ ), maximum plant height (Height, $\mathrm{m}$ ), stem specific density (Stem density, $\mathrm{mg} \mathrm{mm}^{-3}$ ) and seed mass (mg). Density distributions of the first (b) and second (c) dimensions of island and global trait spaces.

\section{An oceanic island flora faces similar functional constraints as other plants on Earth}

We compared Tenerife with the global spectrum of plant form and function (Díaz et al., 2016)

(Figure II-2) and found a considerable overlap between the island and the worldwide trait space (Jaccard similarity coefficient $=0.52$, based on hypervolume overlap-statistics for both trait spaces see Methods). This indicates that on an oceanic island, i.e., Tenerife, plants largely experience similar ecological, environmental and evolutionary constraints as plants reported for the globe. However, the density distribution of species of Tenerife trait space strikingly deviated along the first dimension of variation (Figure II-2b). The majority of island species are located between the two global hotspots (Figure II-2a): small statured, light-seeded plants and tall, heavy-seeded trees. This embedded position of Tenerife plants in the center of the global trait space evidences the 
underrepresentation of herbs and trees and the dominance of shrubs, i.e., plants with intermediate stature (maximum plant height $=1-3 \mathrm{~m}$ ), moderate to high wood density $(0.3-0.6$ $\mathrm{mg} \mathrm{m}^{-3}$ ), light seeds (seed mass $=0.5-8 \mathrm{mg}$ ), and leaves with intermediate sizes, leaf mass per area (LMA) and nitrogen content (leaf area $=300-2000, \mathrm{~mm}^{2}, \mathrm{LMA}=60-100 \mathrm{~g} \mathrm{~m}^{-2}$ and Leaf Nitrogen $=15-20 \mathrm{mg} \mathrm{g}^{-1}$, respectively) (Supplementary Figure 1 and 2). The shrub dominance highlights the functional convergence of Tenerife flora towards the shrub growth form (Figure II2 and II-3a). Arguably, Tenerife's Mediterranean climate marked by drought seasons and aridity at high elevations favours shrubs (Carlquist 1974; Van Huysduynen et al., 2020), for both colonists and endemic plants. In arid environments shrubby stems are more resistant than their herbaceous counterparts. Such stem trait prevents plants from hydraulic failure and drought-induced mortality (Dória et al., 2018). In fact, the origin of several shrubby plants on the Canary Islands (i.e., $80 \%$ of insular woody lineages) coincides with the onset of major aridification events 7 million year ago on these islands (Dória et al., 2018; Lens et al., 2013). Further, the taller stature of shrubs compared to herbaceous plants make them stronger competitors on an island (Darwin 1859; Givnish 1995). While there are alternative hypotheses for insular shrubbiness, e.g., increased competition, reduced herbivory (Whittaker \& Fernández-Palacios, 2007), which we did not test for specifically, our results provide strong empirical support for shrubbiness as an island syndrome.

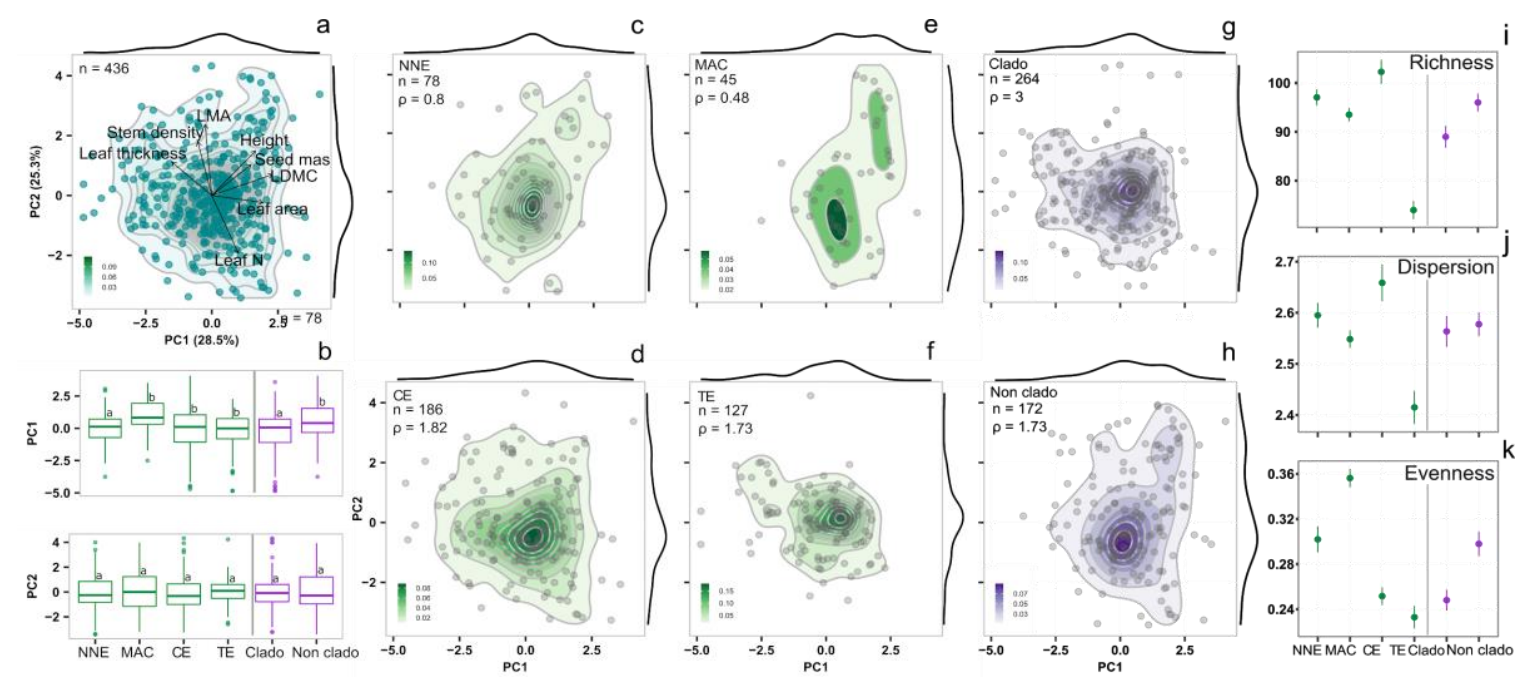

Figure II-3 Functional trait space of (a) the Tenerife oceanic island flora (436 native species) based on eight functional traits. Biogeographical groups representing dispersal and environmental filters in green (c-f) where ' $n$ ' is the number of species contained in each group and ' $\rho$ ' is the estimated mean hypervolume divided by the number of species of each group. Evolutionary groups representing speciation processes in purple (g-h) cladogenetic species and non-clado are non-cladogenetic species. Contours are built using 2D kernel density estimation. Gradient legends (bottom-left side) correspond to the proportion of data contained in a contour break. Comparison of the two first dimensions of variation from a principal component analysis (b), identical letters indicate no significant difference (Kruskal-Wallis text, $\mathrm{P}>0.05$ ). NNE stands for native non-endemics, MAC is Macaronesian-endemics, CE is Canary-endemics and TE is Tenerifeendemics. Contribution of different biogeographical groups to the functional diversity of Tenerife island (i-k). Functional richness (i), functional dispersion (j) and functional evenness ( $k$ ) were calculated based on $n$-dimensional hypervolumes 
(see Methods). Dots and error bars correspond to the mean values and 95\% confidence intervals, based on speciesrichness based rarefaction values. See observed and standardized values in Extended Figure 3.

The dominance of shrubs combined with lack of trees on Tenerife is generally consistent with the island rule (Foster 1967; Biddick et al., 2019), which predicts that small herbaceous (colonizer) species evolve into taller species and increase stem density to avoid competition with other species. These colonizing species likely filled un-occupied trait spaces on the island, which on mainland would have been already occupied by trees. The island rule also predicts that tall individuals tend to become smaller. Indeed, large trees are underrepresented on Tenerife, its tallest trees (Laurus novocanariensis and Pinus canariensis) reach about 30 to 50 meters. However, the lack of tall trees on Tenerife is best explained by dispersal filters and reduced environmentally suited areas (e.g., Tenerife's humid area, where Laurel forest occurs, covers $16 \%$ of the island) to sustain viable tree populations. Lastly, beyond the six traits used to compare Tenerife and the global spectrum, we included two additional traits: leaf thickness $\left(L_{\text {th }}\right)$ signaling succulence, a successful plant adaptation to the Canary Islands arid conditions (Shmida \& Werger 1992; Landrum 2002) and lead dry matter content (LDMC) signaling plant strategies.

\section{Biogeography and evolution have shaped the island plant trait space}

To disentangle how biogeographical and evolutionary processes have shaped the assembly of functional diversity of Tenerife, we analyzed the relationship of the eight plant functional traits (Figure II-3a) for four groups of species according to their endemism levels: endemics to Tenerife, Canary Islands, Macaronesia and Native non-endemics, hereafter 'biogeographical groups' (Figure II-3c-f). These four groups reflect different colonization and speciation pathways. Within the endemics we defined two groups of species related to diversification processes, hereafter 'evolutionary groups. One group comprises cladogenetic species, i.e., diversified immigrant lineages resulting in several distinct species sometimes with distinct traits (Stuessy et al., 1990). The other group comprises all other endemic species (i.e., non-cladogenetic endemics) (Figure II$3 g-h)$.

Trait spaces of almost all biogeographical groups showed broadly similar patterns and were highly aggregated in the center of island trait space (Figure II-3c, d, I). The trait space of native nonendemic species, which represent species that colonized Macaronesia without undergoing subsequent speciation (Price et al., 2018), encompasses a large range of trait combinations from 
light seeded and short plants to tall plants with heavy seeds (on average $0.01 \mathrm{~g}-5 \mathrm{~g}$ heavy seeds and 0.1 - $30 \mathrm{~m}$ tall plants). The trait space of Canary endemic species is dominated by shrubs and extends towards species with high leaf thickness (succulents) and leaf nitrogen content (on average $8 \mathrm{~mm}$ thick leaves and $45 \mathrm{mg} \mathrm{g}^{-1} \mathrm{~N}$ ), as well as toward species with opposite trait combination, i.e., low leaf thickness and leaf nitrogen content (on average $0.05 \mathrm{~mm}$ thick leaves and $7 \mathrm{mg} \mathrm{g}^{-1} \mathrm{~N}$ ). The trait space of Tenerife endemic species is highly dominated by shrubs and succulent species. In contrast, the Macaronesian endemics trait space has a bimodal distribution (Figure II-3e) associated with the presence of herbs/shrubs and trees. Trait combinations of tree species within the Macaronesian endemics, e.g., Laurus novocanariensis with large stature and seed mass (i.e., on average $25 \mathrm{~m}$ and $5 \mathrm{~g}$ ), have not emerged from in-situ speciation but from 'relictualization' (De Nascimento et al., 2009); a process that results from survival of species on islands after their extinction elsewhere. The trait spaces of both cladogenetic species and noncladogenetic species are also centered in the island trait space (Figure II-3g-h). In particular, cladogenetic species have a high aggregation of species (Figure II-3g) with small stature, light seeds, low leaf dry matter content and thick leaves, similar to the Tenerife endemics. This result is expected because most Tenerife endemics emerged via cladogenesis. The group of noncladogenetic endemics (Figure II-3h) consists of species with distinct evolutionary and biogeographical histories, for instance species resulting from anagenesis or relictualization. Consequently, this trait space includes trait combinations of species that expand the trait space towards large relictual trees, as the Macaronesian endemics trait space, as well as species located in the core of the island trait space.

\section{Imprints of biogeography and evolution on the island functional diversity}

We calculated three major independent components of functional diversity corrected for species richness: functional richness, evenness and dispersion (Mason et al., 2005; Mammola \& Cardoso 2020), which capture different aspects of trait distributions among biogeographical and evolutionary groups. Further, we tested the contribution (if a group increases island trait space or not) and unique position of each group within the island trait space (if a group has a unique 'position' it has unique trait combinations relative to the island) by calculating functional contribution and originality (Mammola \& Cardoso 2020). 
We found functional richness (Figure II-3i), i.e., the total amount of trait space covered (Mouchet et al., 2010), significantly varying among biogeographical groups and was highest for Canary endemics. This result is consistent with the idea that species evolved to take advantage of newunfilled island habitats, thereby avoiding direct competition (Givnish et al., 2009). Functional dispersion (Figure II-3j), which quantifies the sparseness or density of species in trait space, and thus, identifies functional divergence or convergence, exhibited a similar pattern as functional richness among groups. The high functional richness and dispersion, and the significant functional contribution and originality of the Canary endemics (Figure II-4a-iii) indicates the group has unique trait combinations and increases island trait space (i.e., species located at the margins of the Tenerife trait space, such as Spartocytisus supranubius a 4 meter shrub with very dense stems 0.7 $\mathrm{mg} \mathrm{mm} \mathrm{m}^{-3}$, and Dracunculus canariensis a 1.5 meter herb with thin leaves with high Nitrogen content, $\left.28 \mathrm{mg} \mathrm{g}^{-1}\right)$. In contrast, we found Tenerife endemic species having the lowest values for functional richness and dispersion (Figure II-3i, j). These results indicate that newly evolved species occurring on the Canary Islands have different trait combinations (e.g., from tiny herbs to tall shrubs), while Tenerife species share similar traits (e.g., small succulents and shrubs). The high habitat diversity plus the influence of inter-island dispersal across Canary Islands drive the high levels of functional diversity of the Canary endemics. Contrarily, the low functional diversity of Tenerife endemics suggests these species have a low degree of niche differentiation, whereby most species occupy restricted island habitats, e.g., coast and summit scrub. Functional evenness (Figure II-3k), i.e., the regularity of distribution of the species across the trait space, related to dominance of certain trait combinations, was the highest for Macaronesian endemics. This even distribution suggests that the number of herbs/shrubs and trees present in the Macaronesian endemics are equally represented, i.e., no dominance of a functional strategy in the group. Further, the significant functional originality values of Macaronesian endemics (Figure II-4a-vi) indicate the unique trait combinations in the group with respect to the island. Such traits combinations are from the relictual trees present in Macaronesia. Overall, our analysis of the four biogeographical groups indicates that while inter-island and long-distance dispersal (represented by Canary and native non-endemic species) expanded trait space on Tenerife, in-situ speciation (represented by Tenerife endemics) notably did not. 


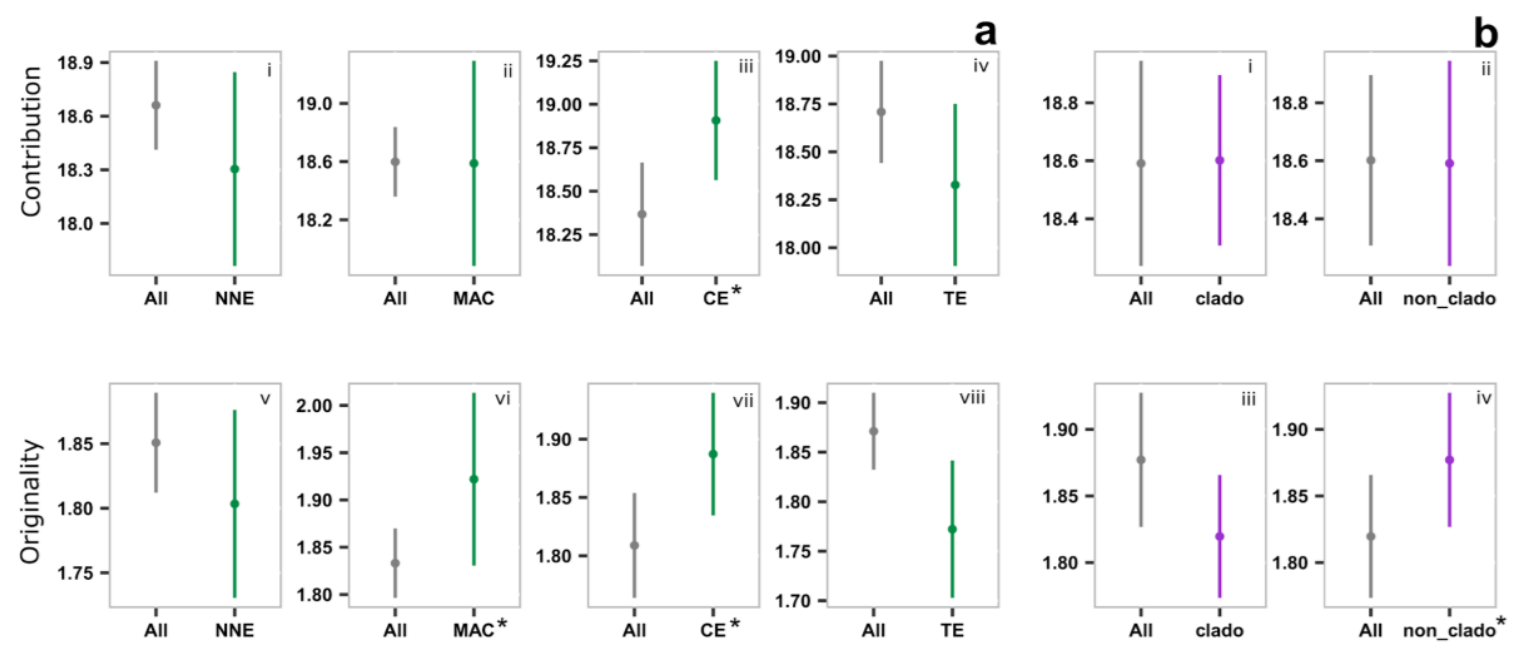

Figure II-4 Functional contribution and originality for a) biogeographical and b) evolutionary groups. Group abbreviations followed Figure II-2. "All" indicates all species except for species contained in the group of comparison. Dots and error bars correspond to the mean values and 95\% confidence intervals. Asterisk "*" indicate that groups have significantly contributed or have original values to the island trait space, using Kruskal-Wallis, with alpha level 0.05. Functional contribution and originality are based on hypervolumes calculation, which were estimated using eight plant functional traits sampled for 436 native species of Tenerife.

Counter to our expectation that species splitting (via cladogenesis) would expand island trait space by filling empty island habitats, we found that cladogenetic species did not expand Tenerife trait space (Figure II-3i, j). This result relates to the limited trait combinations of cladogenetic species. First, most lineages present in the Tenerife are composed by few species (most lineages comprise 3-4 species and only four lineages comprise more than 10 species, e.g., Echium and Aeonium lineages comprise 11 and 31 species, respectively). Second, non-adaptive radiation (i.e., allopatric speciation via isolation of populations) occurs more often than adaptive radiation (Rundell \& Price 2009) and leads to functionally similar species. As non-adaptive radiation is not driven by ecological speciation (Rundell \& Price 2009), plant traits do not necessarily shift as species may be coping with similar environmental conditions. Contrarily, in adaptive radiation species traits commonly adapt to cope with a changing environment (Givnish et al., 2009). Third, the highly uneven trait space of cladogenetic species (Figure II-3j) is consistent with the idea that strong environmental filters resulted in species converging around similar trait combinations. We attribute the dominance of arid conditions of Tenerife to be driving the functional convergence of cladogenetic species, and also the general functional convergence observed for the island. Lastly, we found non-cladogenetic species having relatively high values of richness and intermediate values for evenness and dispersion, and also high functional originality (Figure II-4b-iii) (mainly driven by the relictual trees shared with the Macaronesian endemics). 


\section{How radiated lineages contribute to the island functional trait space}

To understand how speciation, in relation to adaptive radiation processes, has shaped the functional trait space of Tenerife island, we quantified the functional contribution and originality of 21 major radiated lineages present in Tenerife (Supplementary Figure 4 and 5). We observed that, with the exception of the Aeonium lineage, most lineages did not significantly contribute to the expansion of island trait space (Supplementary Table 3). This result relates to both nonadaptive radiation being the speciation event more frequently occurring and the low number of species comprising each single lineage.

Our results provide evidence that plant form and function of an oceanic island are shaped by the same constraints as plants in general. Yet there is a clear mismatch between the Tenerife island and global trait space in terms of predominance of shrubby growth forms, which is driven by the arid Mediterranean environment of the island. We conclude that at the Canary Islands archipelago level evolution via speciation followed by biogeographical process via inter-island dispersal are expanding Tenerife trait space and therefore increasing the plant functional diversity of the island. On the other hand, evolution via lineage splitting (cladogenesis) and in-situ speciation within Tenerife are leading to a high packing of species in the core of the island trait space, with a modest extension towards succulent plants. These conserved trait combinations signal the strong environmental filter on Tenerife trait space, as plants have to cope with the arid conditions of the island. Overall, our results show how trait diversity and functional diversity levels of an oceanic island emerged due to larger scale biogeographical and evolutionary processes. Our approach offers a first step towards understanding, from a trait-based perspective, how dispersal and speciation jointly shaped an entire native flora.

\section{MATERIALS AND METHODS}

\section{Tenerife as a model system}

Tenerife $\left(2058 \mathrm{~km}^{2}\right)$ is the largest of the Canary Islands, which belongs to the Macaronesian floristic province off the coast of Northern Africa. The island is of volcanic origin, its oldest substrate is about 8 million years old (Troll \& Carracedo 2016). Tenerife is the second highest volcanic structure on the planet (after the island of Hawai'i). Its impressive topography and 
dynamic geological history (Troll \& Carracedo 2016) and interaction with the northeastern trade wind systems creates a great climatically and environmental heterogeneity (Barajas-Barbosa et al., 2020) with a wide range of different habitats (Fernández-Palacios \& Nicolás, 1995).

\section{Plant species data and their biogeographical and evolutionary status}

Tenerife has a well-known flora. We analyzed all native seed plant species of Tenerife, which are listed in the latest version of the vascular plant species checklist of the Canary Islands (Acebes Ginovés et al., 2010). Since the native status of several Canary Islands species remain unresolved (Price et al., 2018), we included species that are exclusively categorized as native, yielding a total of 436 species (Acebes Ginovés et al., 2010). We classified the species into the four biogeographical groups following the species the endemism status from the checklist (Acebes Ginovés et al., 2010) at the levels of Canary Islands and Macaronesia archipelago: native nonendemic (78 spp.), Macaronesian endemic (45 spp.), Canary Islands endemic (186 spp.) and singleisland endemic to Tenerife (127 species). We classified the species into two evolutionary groups, the first being cladogenetic species (264 spp.), containing 21 major lineages (with more than 3 species) that have radiated across the Canary Islands and Macaronesian (Price et al., 2018). The remaining endemic species (95 spp.) were categorized as anagenetic-neoendemics and palaeoendemics together, due the lack of fossil records.

\section{Trait sampling and measurement}

We collected and measured fundamental leaf and stems traits (Wright et al., 2004; Diaz et al., 2016) for $82 \%$ of the entire Tenerife native seed plants (361 species): leaf area (LA $\mathrm{mm}^{2}$ ) as the one-side surface area of individual lamina, leaf dry matter content (LDMC $\mathrm{mg} \mathrm{g}^{-1}$ ) as the leaf dry mass per unit of water-saturated fresh mass, leaf mass per area (LMA g m${ }^{-2}$ ) as the leaf dry mass per unit of lamina surface area, leaf Nitrogen content $\left(N_{\text {mass }} \mathrm{mg} \mathrm{g}^{-1}\right)$ as the nitrogen content per unit of lamina dry mass, leaf thickness ( $L_{\text {th }} \mathrm{mm}$ ), stem specific density (SSD $\mathrm{mg} \mathrm{mm}^{-3}$ ) as dry mass per unit of fresh stem volume. We collected the plants across the entire island in more than 500 different sites (Supplementary Figure 6), covering the full elevational gradient of Tenerife from sea level to $2700 \mathrm{~m}$ a.s.l. To include as much abiotic variability as possible, we sampled species with large distributions on multiple sites. We sampled rare species (when possible) in only one site and certain species (when possible) in botanical gardens (Jardín de aclimatación de La Orotava in Tenerife and Jardín Botánico Canario Viera y Clavijo in Gran Canaria). We confirmed species 
identity with a botanical expert. We collected three replicates (individual per species) for $60 \%$ of all 361 sampled species, one to two replicates for $16 \%$, and four to five replicates for $6 \%$ of all sampled species.

Measurement and quantification of trait values for leaves, stems and seeds were done following standardised protocols (Pérez-Harguindeguy et al., 2013). We collected healthy, adult and fully expanded sunny leaves from individual plants. Depending on leaf size, we collected between 10 (for $>1 \mathrm{~cm}^{2}$ leaves) to 100 (for $<1 \mathrm{~cm}^{2}$ leaves) leaves per individual. To measure stem traits and ensure that plants were not damaged, we collected for $>90 \%$ the first adjacent branch of the main plant stem. We stored the fresh plant material in coolers to prevent dehydration and measured fresh leaf mass using an analytical balance $(0.01 \mathrm{mg}$ precision from PCB $2500-2$ Kern \& Sohn) within 24 hours after collection. Leaf thickness and leaf area (leaves smaller than $1 \mathrm{~cm}^{2}$ were scanned at 300 and larger than $1 \mathrm{~cm}^{2}$ leaves at $600 \mathrm{dpi}$ ) were also measured within the 24 hours after collection. Leaf area was calculated using WinFOLIA software. To measure the volume of fresh stems, we first measured its length and diameter with a digital caliper. As stems are not perfect cylinders, we measured diameter in three different stem sections and used mean value per single stem. We computed fresh stem volume using the following formula for cylinders: $V=\Pi r^{2} h$, where $\Pi$ is $\mathrm{Pi}, \mathrm{r}$ is radio, $\mathrm{h}$ is height. We oven dried leaves and stems for 48 hours, or until a stable weight was reached, at $80^{\circ} \mathrm{C}$, and then measured leaf and stem dry mass using the same analytical balance. Nitrogen content of the dry leaves was determined by a $\mathrm{C} / \mathrm{N}$ elemental analyser (Vario EL III, elementar, Hanau, Germany) (Hertel 2011).

We sampled and measured seed mass (SM mg) for $74 \%$ of all native seed plants of Tenerife, as mass of an individual seed or spore at the seed bank from the Jardín Botánico Canario "Viera y Clavijo" in Gran Canaria. We counted between 5 to 200 seeds per species and weighed them using an analytical balance $(0.001 \mathrm{mg}$ precision). We obtained individual seed mass by dividing the total mass of the weighted seeds by the number of seeds. For very small seeds $(<0.1 \mathrm{~mm})$, we calculated seed mass using a test tube containing a volume of seeds for which the seed count was known. We obtained maximum plant height $(\mathrm{H} \mathrm{m})$, which is the upper boundary of the main photosynthetic tissue at maturity in meters, for $90 \%$ of all native species of Tenerife (Muer et al., 2016). 
In total we collected and gathered for all Tenerife native flora (i.e., 436 species) $80 \%$ of all eight traits values. Previous to the analysis, we checked the density distribution of single traits and correlation among traits (Supplementary Figure 2). To handle missing values, we used trait imputation. In total, we imputed trait values for $20 \%$ of leaf trait values, $24 \%$ of stem density, $26 \%$ of seed mass and $3 \%$ of maximum plant height. We used the phylogenetic imputation by Penone et al., (2014). To this end, we first constructed the phylogeny using the mega-phylogeny of Smith and Brown (2018) and conservatively bound species onto the backbone using dating information from congeners in the tree with the 'congeneric.merge' function in the R package 'pez' (Pearse et al., 2015). We then used the 'missForest' function from the R package (Stekhoven \& Buehlmann 2012 ) to predict missing trait values (see density distribution of original and imputed trait values in Supplementary Figure 2). We tested the prediction performance of the random forest algorithm that included phylogenetic relationship among species against a naïve prediction (i.e.,with no phylogenetic information). We found that phylogenetically informed imputation was superior to that of the naive imputation, as measured by out-of-bag error rates (Supplementary Table 1).

\section{The global trait data}

We used the global trait data via from Díaz et al., 2016, which has complete information for six plant traits (Leaf traits: LA mm², LMA g m${ }^{-2}, \mathrm{~N}_{\text {mass }} \mathrm{mg} \mathrm{g}^{-1}$; Stem trait: SSD mg mm${ }^{-3}$; Seed trait: SM mg; whole plant trait: $\mathrm{H} \mathrm{m}$ ) for 2214 plant species. Before comparison among Tenerife and global trait space, we removed all species from the global trait data that belonged to Tenerife flora. That is, we compared 2199 species from the global trait data with 436 Tenerife species.

\section{Functional trait space}

We performed a principal component analysis (PCA) on the log and z-transformed (centered and rescaled to unit variance) mean trait values. For the comparison of Tenerife versus global trait space of plant forms and function (Figure II-1), we used six plant functional traits, LA, LMA, H, $\mathrm{N}_{\text {mass, }}, \mathrm{SM}$ and SSD. For the trait space analysis of Tenerife island with its biogeographical and evolutionary groups (Figure II-2), we used eight plant functional traits LA, LMA, LDMC and $L_{t h}, H$, $\mathrm{N}_{\text {mass }}, \mathrm{SM}$ and SSD. We visualized the trait space of each biogeographical and evolutionary origin group. 


\section{Functional diversity}

We calculated the three components of functional diversity (Figure II-3) using functional hypervolumes, which quantify a trait space as the $n$-dimensional Hutchinsonian niche (Blonder et al., 2018). This approach to functional diversity is thought to be more accurate than traditional approaches (e.g., functional richness; Laliberté \& Legendre 2010) because it accounts for holes in trait space and, in doing so, avoids overestimation of functional diversity. To compute the hypervolumes, we used a fixed kernel bandwidth for all groups using the 'estimate_bandwidth' function in the R package Hypervolume (Blonder 2019). We used the gaussian method to build the hypervolumes, as it is the least sensitive method to variation in bandwidth and fits the data loosely, which is suitable for functional diversity and fundamental niche modelling applications (Blonder et al., 2018). We calculated hypervolume-based functional richness, evenness and dispersion using the function 'kernel.alpha', 'kernel.evenness' and 'kernel.dispersion' in the R package 'BAT' (Mammola \& Cardoso 2020). Functional richness is the total volume of a trait space. Functional dispersion quantifies how spread or dense a given trait space is, by calculating the average difference between the trait space centroid and random points within the boundaries of the hypervolume (Mamola \& Cardoso 2020). Functional evenness quantifies how regular a given trait space is, by calculating the overlap between the observed hypervolume and a theoretical, perfectly even hypervolume (Mamola \& Cardoso 2020). We computed the Jaccard similarity coefficient for comparing the global and island trait space in Figure II-1 (Supplementary Table 2) by first building gaussian hypervolumes with a fixed bandwidth, for both global and island data and second, we computed hypervolume overlap statistics, using the R package Hypervolume (Blonder et al., 2018). We calculated functional contribution and originally, as the net contribution of each single species to the total island hypervolume and as the average dissimilarity difference between a given species and a sample of random points ( $10 \%$ of the total random points) within the boundaries of the island hypervolume (Mamola \& Cardoso 2020).

\section{Data analysis}

We used Kruskal-Wallis-test to assess differences among the first and second principal components of the biogeographical and evolutionary group trait spaces (Figure II-2), as well as for assessing the statistical significance of functional contribution and originality to the island trait space of the groups and 21 radiated lineages (Figure II-4). Because the number of species commonly affects functional diversity metrics, we performed species-richness based rarefaction to ensure that values were comparable across biogeographical and evolutionary groups, which 
varied markedly in species richness. To this end, we fixed a minimum number of species $(n=30)$, which we randomly sampled 99 times, and calculated the functional diversity metrics each time per group. We computed mean values and $95 \%$ confidence intervals from all samples.

\section{Authors contributions}

HK conceived the idea. MPBB, DC and PW further developed the conceptual idea. MPBB collected and measured plant trait data and performed the analysis. PD supported the analysis. RO supported plant trait data collection. All authors contribute to the results interpretation and writing of the paper.

\section{Acknowledgments}

MPBB and HK acknowledge funding by the German Research Foundation (DFG) Research Training Group 1644 'Scaling Problems in Statistics', grant no. 152112243. MPBB and HK thank the Jardín Botánico Canario "Viera y Clavijo" in Gran Canaria for allowing measurements in the seed bank as well as for the samples taken of the (10) rare species that were not possible to find in the field. MPBB thanks the field assistants in Tenerife, who made possible the successful collection and the laboratory work of almost all Tenerife native plants, Nora Strassburger, Mercedez Vidal Rodríguez and Arnau Andreu Diez, as well as Rubén Barone Tosco for helping identify plant species. 


\section{CHAPTER III PLANT FUNCTIONAL DIVERSITY ON AN OCEANIC ISLAND VARIES ACROSS SPATIAL SCALES}

Martha Paola Barajas Barbosa ${ }^{1}$, Dylan Craven ${ }^{2}$, Patrick Weigelt ${ }^{1}$, Rüdiger Otto ${ }^{3}$, Joshua Erkelenz ${ }^{1}$, Amanda Taylor ${ }^{1}$, Dagmar $\mathrm{Hanz}^{4}$, Pierre Denelle ${ }^{1}$, José María Fernández Palacios $^{3}$, Manuel Steinbauer ${ }^{5}$ and Holger Kreft ${ }^{1}$

\section{AFFILIATIONS}

${ }^{1}$ Biodiversity, Macroecology and Biogeography, University of Goettingen, Göttingen, Germany.

2 Centro de Modelación y Monitoreo de Ecosistemas, Universidad Mayor, Santiago, Chile.

3 Island Ecology and Biogeography Research Group, La Laguna University, Tenerife, Spain.

${ }^{4}$ Geozentrum, Goethe-Universität Frankfurt, Frankfurt am Main, Germany.

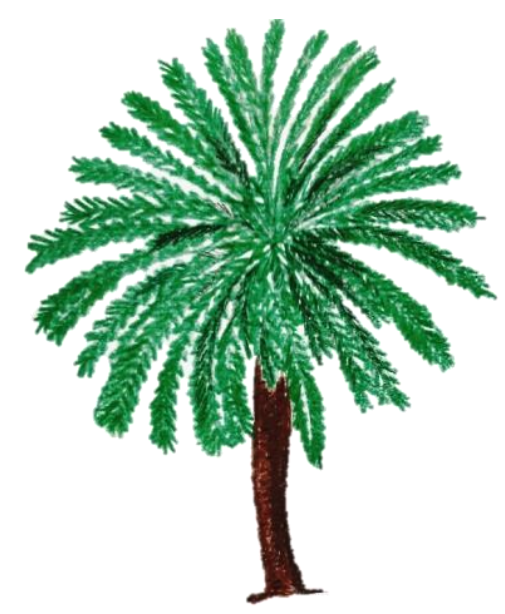

Phoenix canariensis

5 Institut für Sportwissenschaft, University of Bayreuth, Bayreuth, Germany.

This chapter is a manuscript in preparation. Target journal: Ecology letters

\section{ABSTRACT}

Functional diversity is a major component of biodiversity that reveals how the variation of traits in communities relate to ecosystems functions. As other biodiversity components, functional diversity is expected to be scale dependent, but our knowledge about how the two components of scale, i.e.,spatial grain and extent, affect functional diversity is limited. In this study, we assessed how functional diversity of an insular flora varies across spatial grains $\left(100 \mathrm{~m}^{2}\right.$ vs $\left.1 \mathrm{~km}^{2}\right)$ and extents (local and regional). Our functional diversity estimates are based on plant functional traits we measured for nearly a complete oceanic island flora. We found that functional diversity is scale dependent and that the spatial dependence of functional diversity patterns is determined by environmental filters at larger grains, and by biotic factors at smaller spatial grains. Climate and elevation had a strong effect on the functional diversity of the island at the larger spatial grain, but these effects vanished at the smaller spatial grain of community. Our study improves our understanding about functional diversity changes with spatial grain and scale and as the taxonomic diversity is not a surrogate of functional diversity, studying both biodiversity facts is important. 


\section{INTRODUCTION}

Functional diversity, a major component of biodiversity, provides insights into how species traits mediate ecological strategies, respond to the environment and influence ecosystem processes (Díaz \& Cabido 2001; Kattge et al., 2011). Species identities and functional traits, in particular, influence ecosystem processes because traits determine how species compete, modify and adapt to the biotic and abiotic environment (Díaz \& Cabido 2001; Cadotte et al., 2011). For instance, drought resistance of ecosystems is modulated by plant traits, such as high leaf thickness and wood density, which allow plants to cope with water scarcity (Díaz \& Cabido 2001; Lens et al., 2013). Primary productivity, nutrient and water cycling are also mediated by plant functional traits (Díaz \& Cabido 2001). Such processes regulate the provision of ecosystem services, which are key for the human well-being and can be studied through functional diversity frameworks (Díaz et al., 2007; Díaz et al., 2019).

Biodiversity is scale dependent (Chase \& Knight 2013; Chase et al., 2018) because ecological processes shaping it act at different spatial scales and are interconnected, as local communities are contained within regional biota (Leibold et al., 2004). Commonly used metrics that quantify species diversity, such as species richness or dissimilarity (i.e., alpha and beta diversity), are highly influenced by two main components of scale, spatial grain (i.e., size of sampling unit) and extent (i.e., total area sampled of a study) (Scheiner et al., 2011; Viana \& Chase 2018). There is a (relative) good understanding about the interconnections and factors governing patterns of diversity across spatial scales, yet the focus has been mainly on taxonomic diversity (Willis \& Whittaker 2002; Chase et al., 2018; Chase et al., 2019). As a consequence, our knowledge on the effects of spatial scale and interactions between regional and local diversity for functional diversity is limited (but see Smith et al., 2013; Whittaker et al., 2014; Karadimou et al., 2016). An adequate estimation of functional diversity should consider both components of scale to understand patterns that emerge from local and regional processes (Levin 2000). Species accumulation curves (Scheiner et al., 2011) help detecting diversity changes from regional to local scale and can reveal the factors that determine processes occurring at different scales, e.g., environmental filters (regional processes) or species coexistence (local processes) (Chase \& Knight 2013). Additionally, partitioning of diversity into local (alpha diversity), among local (beta diversity) and regional scale (gamma diversity) (Whittaker 1972; Jost 2007), it is possible to estimate functional diversity variation across space. In doing so, we can analyze the effects of spatial scale on functional diversity and 
identify the factors shaping regional and local patterns of functional diversity. Here, we use the definition of regional scale as a scale shaped by a regional species pool composed of a set of species that grow under similar environmental conditions (Pärtel et al., 1996).

Functional diversity is affected by different extrinsic factors that act differently across space (Díaz \& Cabido 2001; Qiu \& Cardinale 2020). Environmental conditions that cause abiotic stress, such as drought or cold temperatures, filter the number of viable traits and thereby tend to homogenize the functional trait combinations in a community (Spasojevic \& Suding 2012). For instance, species tend to converge upon similar trait combinations, such as high leaf thickness and stem density to tolerate hydric stress (van Huysduynen et al., 2020). Biotic interactions and interspecific competition may increase viable trait combinations, as interacting species are forced to use resources differently, for which different trait combinations are required (Spasojevic \& Suding 2012). Thus, environmental filters should reduce functional diversity whereas species interactions should increase it (Cavender-Bares et al., 2004), whereby the effect of each factor is expected to affect functional diversity differently depending on the spatial scale. At regional scales, environmental conditions, such as temperature, precipitation, and elevation may prevail in affecting functional diversity more strongly by limiting traits of a regional species pool. At local scale, species interactions, such as competition, may shape more strongly functional diversity, leading to divergent trait combinations and hence higher functional diversity (Kraft et al., 2008; kraft et al., 2015). Thus, examining functional diversity at different spatial scales, from regional to local scale can reveal which processes are influencing local communities and regional species pools (Ackerly \& Cornwell 2007).

Here, we investigate the effect of spatial grain and extent on the plant functional diversity of an oceanic island, Tenerife. We quantified functional diversity using eight plant traits that we collected for nearly all Tenerife native seed plants (80\%). We defined the regional scale as the Tenerife vegetation types, which are six climatically distinct areas corresponding to the altitudinal vegetation belts of the island (Humboldt \& Bonplandt in 1814). The vegetation types range from arid to semi-arid areas in the lowlands, humid at mid-elevations, to cold and arid in the highlands (Figure III-1 and Supplementary Figure 1) (Fernández-Palacios \& de Nicolás 1995). We assessed functional diversity at the local and regional scales integrating vegetation relevés, gridded floristic data and regional species inventories with detailed trait measurements of 434 seed native plant species. We then assessed how climatic and topographic conditions impact Tenerife's functional 
diversity at two local grains $\left(100 \mathrm{~m}^{2}\right.$ vs $\left.1 \mathrm{~km}^{2}\right)$. We addressed two main questions: (1) Are functional diversity patterns scale dependent and do the functional diversity patterns percolate down from regional to local scales, i.e., from vegetation types down to the two local spatial grains? (2) How do climate and topography impact local scale functional diversity, and are these impacts consistent across spatial grains? We expect functional diversity to be scale dependent and have a nonlinear relation with space. At regional spatial scale we expect environmental filters to determine functional diversity and at local scale species interactions should shape functional diversity. Further, we expect functional diversity to differ across Tenerife vegetation types due to differences in the environmental conditions (Cavender-Bares et al., 2004; Spasojevic \& Suding 2012). Where resource-rich areas (i.e., vegetation types with high water supply, such as laurel forest) have higher functional diversity than resource-limited areas (e.g., arid or alpine such as summit scrub) because unfavourable conditions restrict the amount of functionally distinct species that can exist (Smith et al., 2013). Lastly, as vegetation types are broadly defined by the island elevational gradient, we expect elevation to have a clear imprint on local-scale functional diversity (Sanders \& Rahbek 2012).

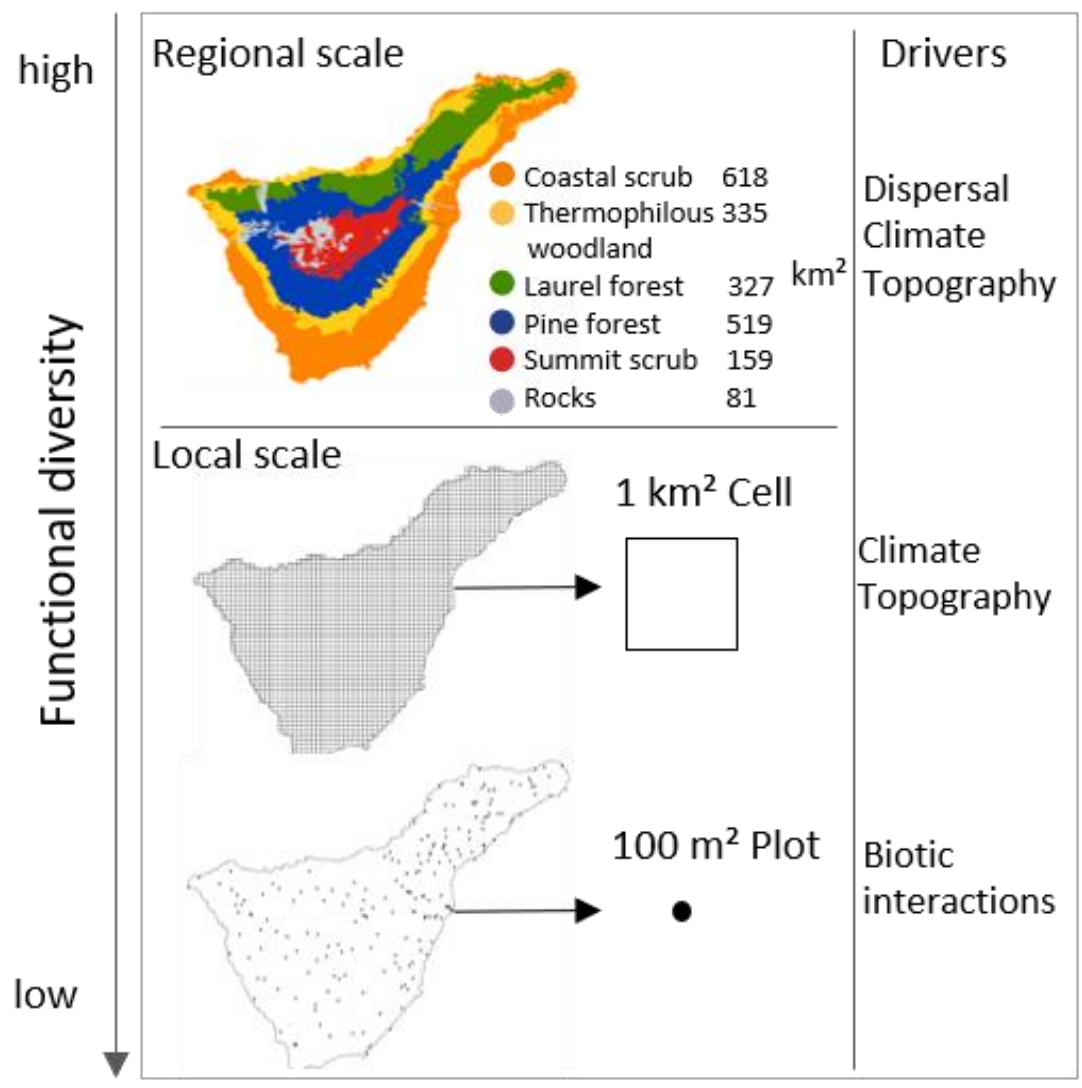

Figure III-1 Conceptual diagram of study, illustrating the spatial scales and grains at which we examine patterns and drivers of plant functional diversity on Tenerife. At the regional (gamma) scale, we compare functional diversity across vegetation types, while at the local (alpha) scale we compare functional diversity across two spatial grains, plot (100 $\left.\mathrm{m}^{2}\right)$ and cell $\left(1 \mathrm{~km}^{2}\right)$ and vegetation types. Within vegetation types, we also evaluate spatial heterogeneity in functional diversity, i.e.,beta diversity, across spatial grains and vegetation types. 


\section{MATERIALS AND METHODS}

\section{Tenerife and its main vegetation types}

Our study was conducted on Tenerife, a volcanic island with an area size of $2058 \mathrm{~km}^{2}$ and a maximum elevation of $3700 \mathrm{~m}$ a.s.l. that belongs to the Canary Islands archipelago. Tenerife has a highly heterogeneous environment marked by a Mediterranean climate and (Sperling et al., 2004; Whittaker \& Fernández-Palacios, 2007) and steep topography and climatic conditions. Usually, six major vegetation types are considered (del Arco Aguilar et al., 2006 http://www.idecanarias.es/resources/Vegetacion/Memoria MapaVegetacion.pdf) (Figure III-1): coastal scrub $\left(618 \mathrm{~km}^{2},>19^{\circ} \mathrm{C}, 50-300 \mathrm{~mm}\right.$ annual rainfall), thermophilous woodland $\left(335 \mathrm{~km}^{2}\right.$, $\left.15-19^{\circ} \mathrm{C},<250-300 \mathrm{~mm} / \mathrm{a}\right)$, laurel forest $\left(327 \mathrm{~km}^{2}, 13-16^{\circ} \mathrm{C}, \mathrm{c} .1000 \mathrm{~mm} / \mathrm{a}\right)$, pine forest $\left(519 \mathrm{~km}^{2}\right.$, $\left.10-15^{\circ} \mathrm{C}, 400-1000 \mathrm{~mm} / \mathrm{a}\right)$, summit scrub $\left(159 \mathrm{~km}^{2}, 5-10^{\circ} \mathrm{C}, \mathrm{c} .400 \mathrm{~mm} / \mathrm{a}\right)$, and plant assemblages associated with rocky outcrops $\left(81 \mathrm{~km}^{2}\right)$ (here after 'rocks') (Fernández-Palacios, 1992; Fernández-Palacios \& de Nicolás 1995).

\section{Plant traits}

We measured eight plant traits of native seed plant species of Tenerife (Acebes Ginovés et al., 2010), for 361 of the 436 native species (approximately 83\%): leaf area (LA $\mathrm{mm}^{2}$ ) as the one-side surface area of individual lamina, leaf dry matter content (LDMC $\mathrm{mg} \mathrm{g}^{-1}$ ) as the leaf dry mass per unit of water-saturated fresh mass, leaf mass per area $\left(\mathrm{LMA} \mathrm{g} \mathrm{m}^{-2}\right)$ as the leaf dry mass per unit of lamina surface area, leaf nitrogen content $\left(\mathrm{N}_{\text {mass }} \mathrm{mg} \mathrm{g}^{-1}\right)$ as the nitrogen content per unit of lamina dry mass, leaf thickness ( $\mathrm{L}_{\mathrm{th}} \mathrm{mm}$ ), stem specific density (SSD $\mathrm{mg} \mathrm{mm}^{-3}$ ) as dry mass per unit of fresh stem volume. These eight traits relate to species resource acquisition for growth along the fastslow continuum (Wright et al., 2004; Reich 2014), and to the size-recruitment trade-off that differentiates between plants that live long from plants that live short times (Grime 1979). We collected samples across the entire island at more than 500 different sites (Figure III-1 and Supplementary Figure 1), covering the full elevational gradient of Tenerife from sea level to 2700 $\mathrm{m}$ a.s.l. We sampled species with large distributions on multiple sites to capture intraspecific variability. We sampled rare species at only one site and 10 species in botanical gardens (Jardín de aclimatación de La Orotava in Tenerife and Jardín Botánico Canario Viera y Clavijo in Gran Canaria). We collected three individuals for $60 \%$ of all 361 sampled species, one to two replicates for $16 \%$, and four to five replicates for $6 \%$ of all sampled species. 
We measured leaf, stem, and seed trait following standardized protocols (Pérez-Harguindeguy et al., 2013). We collected healthy, adult and fully expanded sun leaves from individual plants. Depending on leaf size, we collected between 10 (for $>1 \mathrm{~cm}^{2}$ leaves) to 100 (for $<1 \mathrm{~cm}^{2}$ leaves) leaves per individual. To ensure that plants were not damaged, we measured stem traits for the first adjacent branch of the main plant stem. We stored the fresh plant material in coolers to prevent dehydration and measured fresh leaf mass using an analytical balance $(0.01 \mathrm{mg}$ precision from PCB 2500-2 Kern \& Sohn) within 24 hours after collection. Leaf thickness and leaf area were also measured within the 24 hours after collection. Leaves smaller than $1 \mathrm{~cm}^{2}$ were scanned at 300 and larger than $1 \mathrm{~cm}^{2}$ leaves at $600 \mathrm{dpi}$. We calculated leaf area using the WinFOLIA ${ }^{\mathrm{TM}}$ software (Regent Instruments Canada Inc). To measure the volume of fresh stems, we first measured its length and diameter with a digital caliper. Because stems are not perfect cylinders, we measured the diameter at three different locations and used the mean value per single stem. We computed fresh stem volume using the following formula for cylinders: $V=\Pi r^{2} h$, where $\Pi$ is $\mathrm{Pi}, r$ is radius, and $\mathrm{h}$ is height. We oven-dried leaves and stems at $80^{\circ} \mathrm{C}$ for 48 hours, or until a stable weight was reached and then measured leaf and stem dry mass using the same analytical balance. Nitrogen content of the dry leaves was determined with a C/N elemental analyser (Vario EL III, elementar, Hanau, Germany) (Hertel 2011). We sampled and measured seed mass (in mg, i.e., mass of individual seeds) for $75 \%$ of all native seed plants of Tenerife at the seed bank from the Jardín Botánico Canario "Viera y Clavijo" in Gran Canaria. We measured between 5 to 200 seeds per species and weighed the oven dried seeds (following the leaf drying procedure) using an analytical balance $(0.001 \mathrm{mg}$ precision). We obtained individual seed mass by dividing the total mass of the weighted seeds by the number of seeds. For very small seeds $(<0.1 \mathrm{~mm})$, we calculated seed mass using a test tube containing a volume of seeds for which the seed count was known. Lastly, we obtained maximum plant height $(\mathrm{H}$ in meters, i.e., the upper boundary of the main photosynthetic tissue at maturity) for $90 \%$ of all native species of Tenerife from the literature (Muer et al., 2016).

As our dataset contains missing trait values, we used phylogenetic imputation by Penone et al., (2014) and imputed $20 \%$ of leaf trait values, $24 \%$ of stem density, $26 \%$ of seed mass and $3 \%$ of maximum plant height. To this end, we first constructed a phylogeny using the mega-phylogeny of Smith and Brown (2018) and conservatively bound species onto the backbone using dating information from congeners in the tree with the 'congeneric.merge' function in the R package 'pez' (Pearse 2013). We then used the 'missForest' function from the R package (Stekhoven \& Buehlmann 2012) to predict the missing trait values (see density distribution of original and imputed trait values in Supplementary Figure 2). We tested the prediction performance of the random forest algorithm that included phylogenetic relationship among species against a naïve 
prediction (i.e., with no phylogenetic information). We found that phylogenetically informed imputation was superior to that of the non-phylogenetically informed imputation, as measured by out-of-bag error rates (Supplementary Table 1).

\section{Plant distributions}

We obtained species occurrence information of native seed plants at two local spatial grains, 100 $\mathrm{m}^{2}$ and $1 \mathrm{~km}^{2}$. (1) Data from the smaller spatial grain are from a network of $19910 \times 10$ meters plots (hereafter 'plots') placed across Tenerife (Figure III-1) (Fernández-Palacios 1992). We compiled species composition for each plot; a total of 146 species, or $33 \%$ of the plant species of Tenerife, were found across all plots. (2) Data for the larger spatial grain are 'Banco de Datos de Biodiversidad' (Atlantis 3.1 at www.biodiversidadcanarias.es), in which species composition for $500 \times 500 \mathrm{~m}$ cells was obtained and includes $99 \%$ of native seed plant species of Tenerife (434 species). Species composition is based on all known distribution records of species on the Canary Islands. We used cells with the highest occurrence precision, i.e., levels 1 and 2, in which species were identified and recorded within the cell. We aggregated cells at $1 \mathrm{~km}^{2}$ and removed 535 cells (out of a total of 2043 island cells) located in urban areas (Supplementary Figure 3). We note that the Banco de Datos de Biodiversidad data may have sampling issues related to sampling effort, as certain cells may be oversampled due to accessibility or the presence of endemic species (Steinbauer et al., 2016). To overcome these reasons, we aggregated cells at a larger grain $\left(1 \mathrm{~km}^{2}\right)$. We assigned each plot and cell to the vegetation type where they were located based on the vegetation map for the Canary Islands (Del Arco Aguilar 2006) (http://www.idecanarias.es/resources/Vegetacion/Memoria MapaVegetacion.pdf), and we checked the mount of shared species across vegetation types (Figure III-3 f and Supplementary Figure 6).

\section{Estimating functional diversity}

To investigate patterns of functional diversity across and within local and regional scales, we used the distance-based approach by Chao et al., (2019) to measure functional diversity and dissimilarity. Conventional distance-based approaches, such as functional richness, evenness, and dispersion (Laliberté \& Legendre 2010), are not very sensitive to species pairwise distances (Villéger et al., 2008) potentially leading to similar functional diversity values for assemblages with 
high functionally distinct species (Chao et al., 2019). Here, we used an approach that is more sensitive to species-pairwise distances (Chao et al., 2019), which implements the parameter tau. Tau specifies the level of threshold distinctiveness between any two species and is interpreted as: at a given threshold level of tau, when the distance of two species is less than tau, we assume that species are functionally equally distinct from the other species. We used the suggested tau $=D_{\text {mean }}$ (Chao et al., 2019), which is the mean distance of any two randomly chosen individuals based on the distance matrix (in contrast to the conventional approach which uses the maximum value of the distance matrix). To produce a distance matrix that reflects functional dissimilarity between species, we assessed the number of dimensions that maximizes the quality of the matrix (Maire et al., 2015); based on the eight plant functional traits, we determined that five dimensions maximized the quality of the resulting functional space (Supplementary Figure 4).

\section{Effect of spatial scale on functional diversity}

To assess the effect of spatial scale on functional diversity we constructed functional diversity accumulation curves for the whole island and for the six vegetation types using sample-based rarefaction (Gotelli \& Colwell 2001; Chiarucci et al., 2008) for both local spatial grains. The rarefaction curves resemble the species-area relationship (Rosenzweig 1995) and are built by successively selecting sample units and calculating the average functional diversity when $1,2, \ldots, \mathrm{N}$ ( $N$ = all sample units) are combined together (Gotelli \& Colwell 2001). For each number of selected sample units, we repeated this process 999 times. We calculated functional diversity using the

'FunD' function implemented (Chao et al., 2019; https://github.com/AnneChao/FunD/blob/master/FunD Rcode.txt). To evaluate if functional diversity patterns at the regional scale percolate down to the local scale, we calculated functional diversity within plot and cells (alpha functional diversity), as well as among plots and cells (beta functional diversity) per vegetation type. To have comparable values of alpha and beta functional diversity across vegetation types, as each vegetation type covers a different area on the island (Figure III-1), we standardized alpha and beta functional diversity to a common number of sampling units (Gotelli \& Colwell 2001). To this end, we standardized functional diversity to eight sampling units (the vegetation type with the minimum number of plots comprised 10 , thus 8 plots were selected for the rarefaction) for each spatial grain, which were randomly selected 999 times for each vegetation type and then calculated functional diversity based on the sub-sample. Standardized alpha and beta produced unbiased values of the differences among vegetation types within spatial grains. We used the 'FunD' and 'Multi.Beta' functions (Chao et al., 2019) to compute 
alpha and beta functional diversity respectively. Beta functional diversity calculated here is based on functional dissimilarity, i.e., Sørensen functional non-overlap measure (Chao et al., 2019), which quantifies the effective average proportion of non-shared species across sample units. We defined gamma diversity as the total functional diversity of a vegetation type at both spatial grains. We calculated gamma functional diversity by selecting all species occurring within a vegetation type and then computing functional diversity with 'FunD' function. As our analysis was based on incidence data, we used Hill number $q=0$ that counts species equally without accounting for their relative abundances. Finally, for comparison purposes, we built species richness accumulation curves and calculated alpha, beta, and gamma taxonomic diversity, for both spatial grains per vegetation type. For this, we used the 'FunD' function and set the tau value to minimum, i.e., where the minimum distance (based on the traits-based distance matrix) between any two species defined them as functionally distinct, which reduces the metric to taxonomic diversity (Chao et al., 2019).

\section{Climate and topography}

We investigated the effect of climate on functional diversity using mean annual precipitation (PREC; mm/year) and mean annual temperature (TEMP; ${ }^{\circ} \mathrm{C}$ ) using the Climatologies at High resolution for the Earth's Land Surface Areas (CHELSA) dataset at a spatial grain of c. $1 \mathrm{~km}^{2}$ (Karger et al., 2017). In terms of topography, we used elevation (ELEV; $m$ a.s.I.) and roughness (derived from elevation) from the Shuttle Radar Topography Mission at spatial grain 250 m (SRTM) dataset. We computed terrain roughness (i.e., the largest inter-cell difference of a focal cell and its surrounding cells) (Amatulli et al., 2018) within a $9 \mathrm{~km}^{2}$ area on the elevation data, which comprised $12 \times 12$ pixels for the SRTM data.

\section{Assessing drivers of plant functional diversity at the local scale}

To assess the effects of climate and topography on functional diversity, and if their effects vary across local grains, we assessed functional diversity at the two spatial grains with two main abiotic drivers of diversity, climate and topography. Because species richness was highly correlated with functional diversity (Spearman's correlation coefficient $>0.7$, see Supplementary Figure 5), we controlled for species richness by standardizing functional diversity to a common minimum number of species, i.e., five species. We tested the effect of standardizing functional diversity for two additional minimum numbers of species, three and eight species. We note that standardizing 
functional diversity using larger species (e.g., $\geq 8$ ) led to critical low numbers of plots available, which could complicate the linear regression analysis. Thus, we found the optimal trade-off to standardizing to five species (see Supplementary Figure 5). We then calculated the mean functional diversity value per sample unit for both spatial grains by randomly selecting five species per sample unit and calculating functional diversity with the 'FunD' function with tau = Dmean (Chao et al., 2019) 999 times, after which we calculated mean functional diversity for each sample unit. Lastly, we used a generalized linear model (GLMs) with the gamma family and log link function, as functional diversity (the response variable) was skewed and always positive, to examine variation in functional diversity in response to mean annual precipitation, mean annual temperature, elevation, and roughness. To compare predictor variables with disparate distributions, we standardized them by z-transforming them, i.e., first log transforming variables that were not normally distributed (Supplementary Figure 9). We then fitted two separate models for each spatial grain (Supplementary Figure 10). We assessed GLMs quality by checking residual diagnostics for GLM regression models using DHARMa package R (Hartig 2019) (Supplementary Figure 11).

\section{RESULTS}

We found that functional diversity increased with the number of sampling units for each spatial grain and was higher at the larger spatial grain $\left(1 \mathrm{~km}^{2}\right)$ than at the smaller spatial grain $\left(100 \mathrm{~m}^{2}\right.$; Figure III 2a). Functional diversity for all vegetation types at both spatial grains increased with area sampled (Figure III-2b and c). We found differences in the functional diversity accumulation curves for both spatial grains. At the smaller spatial grain, functional diversity continued to increase, whereas at the larger spatial grain functional diversity saturated rapidly, with the exception of pine forest (Figure III-2 c). 

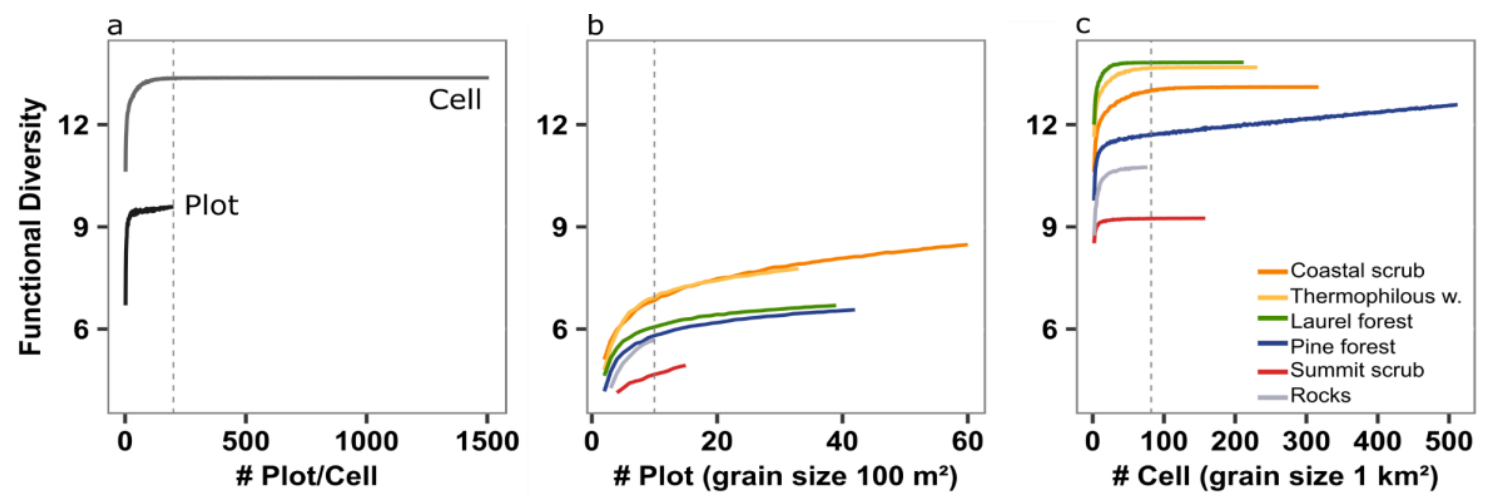

Figure III-2 Functional diversity accumulation curves of native plant communities on Tenerife at two spatial grains, plots $\left(100 \mathrm{~m}^{2}\right)$ and cells $\left(1 \mathrm{~km}^{2}\right)$, across the entire island (a) and per vegetation type at each grain $(\mathrm{b}$ and $\mathrm{c})$. Dotted vertical lines illustrate the largest amount of accumulated sampled plots or cells defined given the smallest number of plots and cells contained in the rocks vegetation types.

Functional diversity varied across the six vegetation types and spatial grains (Figure III-2 b and c). At the smaller spatial grain, coastal scrub and thermophilous woodland had the highest functional diversity, laurel and pine forest had intermediate functional diversity, and the summit scrub had the lowest functional diversity. We also observed differences in the shape of the relationships for some vegetation types, particularly among the slopes near the base of the accumulation curves. For example, summit scrub had a shallow slope relative to all other vegetation types (Figure III-2 b), indicating the prevalence of a few common, functionally equivalent species. In contrast, rock vegetation had the steepest slope at its base (Figure III-2 b), which indicates the presence of a large number of functionally distinct species. At the larger spatial grain, laurel forest and thermophilous woodland had functional diversity, while summit scrub had the lowest functional diversity (Figure III-2 c). At larger spatial grain, the slopes near the base of the accumulation curves across vegetation types well similarly steep, yet initial values of functional diversity differed (Figure III-2 c).

We found that functional diversity patterns across vegetation types at the regional (i.e., gamma) scale percolated down to local scale (see functional diversity hierarchy and trend across vegetation types from alpha to gamma scale Figure III-3 a-b and e-f). Consistently across scales, when using the finest local grain functional diversity was highest in the coastal scrub while using the coarse local grain functional diversity was highest in the laurel forest. In general, beta functional diversity trends mirrored alpha functional diversity patterns for both local grains, i.e., both $100 \mathrm{~m}^{2}$ and $1 \mathrm{~km}^{2}$ (Figure III-3 c, d). But, we found that the beta functional diversity ranking for rocks vegetation type was higher than summit scrub in comparison to alpha functional 
diversity, where rock vegetation types had the lowest values. Lastly, we found similar patterns across vegetation types for beta functional diversity with respect to alpha patterns.

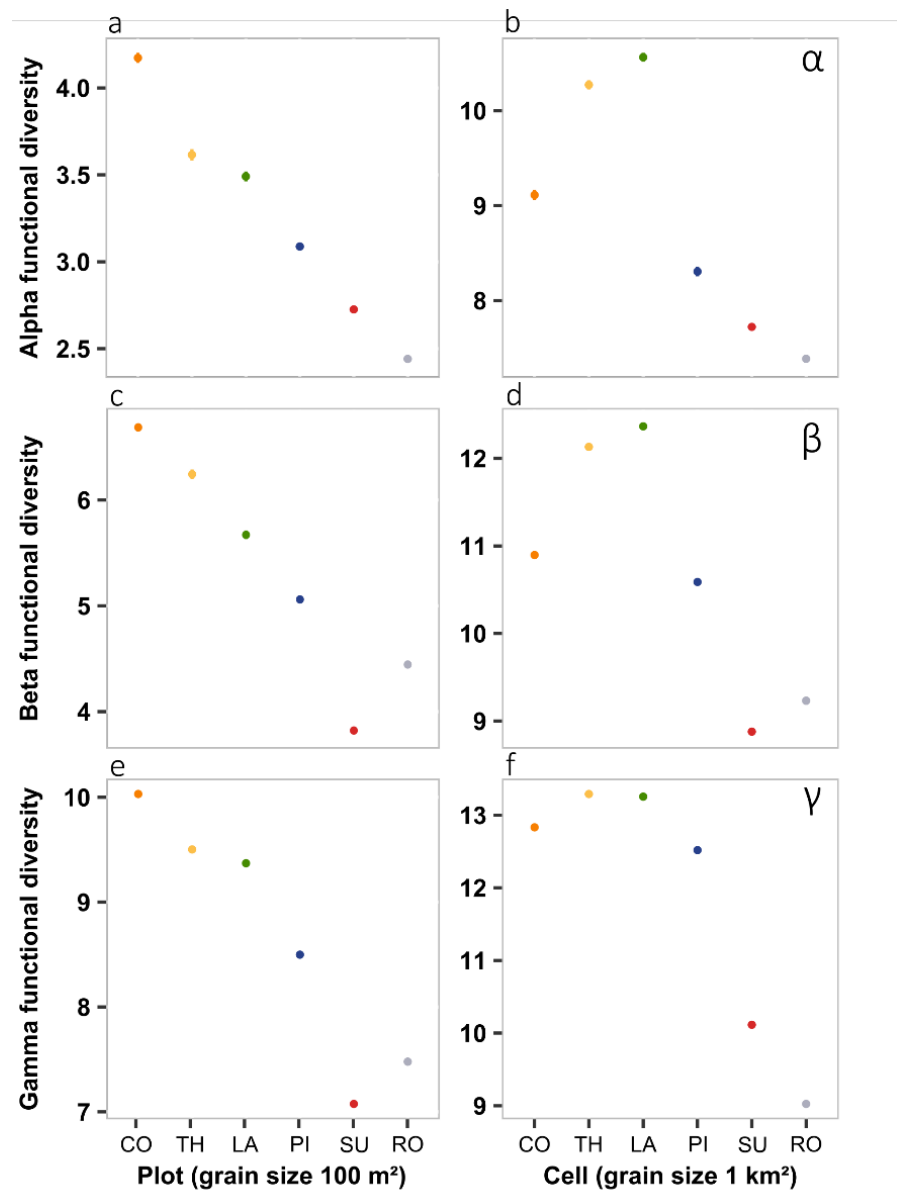

Figure III-3 Functional diversity patterns of Tenerife vegetation types from within local (alpha) and regional (gamma) spatial scales (a, b, c, e) and across local spatial scales (beta) (c, d) for two spatial grains, $100 \mathrm{~m}^{2}$ and $1 \mathrm{~km}^{2}$. Vegetation types are arranged by Tenerife elevational gradient, from coastal scrub in the lowlands to the summit scrub at the high elevations. Note, rock vegetation type covers (as patches) from low to mid elevation of the island. Abbreviations stand for: CO coastal scrub, TH thermophilous woodland, LA and PI laurel and pine forest, SU summit scrub and RO rocks vegetation type.

\section{Drivers of plant functional diversity at the local scale}

We found that climate and topography differentially affected alpha functional diversity across spatial grains (Figure III-4). At the smaller spatial grain, neither climate or topography had detectable effects on functional diversity. At the larger spatial grain, however, functional diversity decreased with increasing elevation and temperature and increased with increasing precipitation. From the GLMs residual diagnostics we found regression residuals deviation for models where functional diversity was estimated at $1 \mathrm{~km}^{2}$ (Supplementary Figure 11). Finally, we found that 
functional diversity accumulated faster with increasing area than species diversity, a pattern that was consistent across vegetation types (Supplementary Figure 7 and 8).

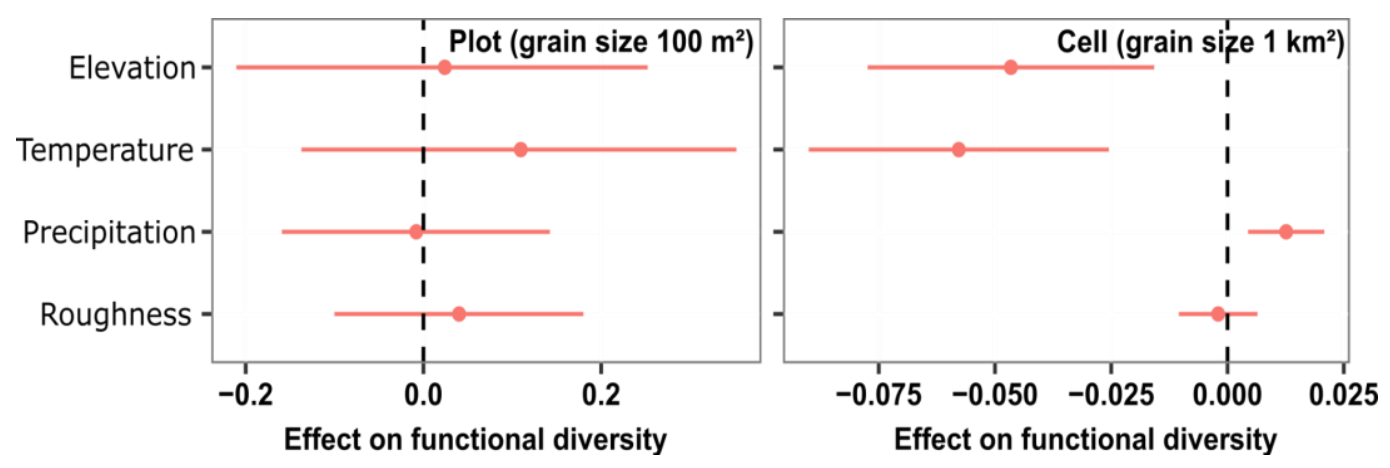

Figure III-4 Scale-dependent environmental effects on functional diversity computed at plot grain (a) and at cell grain (b). We fitted a generalized linear model with the gamma family and log link function after standardizing covariates using z- and log transformation.

\section{DISCUSSION}

In our study we found that functional diversity is scale dependent, it increased nonlinearly with spatial grain and patterns of functional diversity differ depending on spatial grain used to calculate it. We further found that regional patterns of functional diversity percolated to local scales and the processes driving functional diversity act differently depending on the spatial grain. At small grains $\left(100 \mathrm{~m}^{2}\right)$ species interaction may be affecting functional diversity whereas at larger local grains $\left(1 \mathrm{~km}^{2}\right)$ the environment has a significant effect on functional diversity. Lastly, we found that the functional diversity trend across space differs from the taxonomic diversity trend. While functional diversity stagnated with increasing spatial grain, taxonomic diversity continued increasing.

\section{Functional diversity is scale dependent}

As expected, our results provide evidence for the scale dependency of functional diversity, increasing with spatial grain and extent (Figure III-2). Generally, the increase of functional diversity with increasing area relates first to the higher probability of species adding distinct combinations of functional traits, as larger areas contain more species (Rosenzweig 1995). Also, larger areas usually have higher levels of environmental heterogeneity and diversity of habitats (Kallimanis et 
al., 2008; Hortal et al., 2013), which allow species to occupy different niches and enhance the cooccurrence of distinct functional groups (Scheiner 2003; Loreau et al., 2003). Differences in the shape of the accumulation curves among the two spatial grains captures differences in the number of functional types sampled per area, which is expected as one plot is 10,000 times smaller than a grid cell.

\section{Functional diversity at regional scales}

The climatic and elevational gradients on Tenerife have shaped the functional diversity of the island at the regional scales (Figure III-1 and Supplementary Figure 1). In the arid to semi-arid zones of the island, i.e., coastal scrub, thermophilous woodland and summit scrub, hydric and thermal stress as well as poor soils (Fernández-Palacios \& de Nicolás 1995; Otto et al., 2006) constrain trait combinations that are viable under such harsh conditions. For instance, high leaf thickness and intermediate stature of stem succulent plants (e.g., Euphorbia canariensis and Euphorbia balsamifera) allow plants to cope with the prolonged dry season in the lowlands (Otto et al., 2001). In the thermophilous woodland tough leaves and high values of leaf dry matter content prevent water loss for plants (Otto et al., 2001). In the arid and high elevation zones, i.e., summit scrub, plants have reduced stature and relatively high stem densities that allow them to survive the lack of water, low temperatures, high solar radiation and poor soil conditions. In the humid zones at the island mid-elevations laurel forest (located $600-1200 \mathrm{~m}$ a.s.l., at the sea of clouds level) is dominated by trees (e.g., Laurus novocanariensis and Persea indica) (De Nascimento et al., 2009) with tall stature and large seeds. The canopy of the pine forest is dominated by a single tree species the Canarian pine (Pinus canariensis), a tall and large seeded plant with adaptations to a more arid environment (De Nascimento et al., 2009). In both Laurel and Pine forest shrub and herbs species are present in the understory. Such plants have different trait combinations that increase the functional diversity.

The differences of functional diversity across regional scales, relate to the difference in their environmental conditions. The abiotic stress caused by lack of water of the summit scrub tends to homogenize trait combinations among species (Spasojevic \& Suding 2012). Further, the high isolation level of summit scrub, which is climatically isolated from its surrounding similar ecosystems, may also be driving the lower functional diversity (Fernández-Palacios et al., 2014; Ah-Peng et al., 2014). Such conditions constrain plant growth and the distribution of trait 
combinations, resulting in co-occurring species that share similar trait combinations to cope with the harshness of the environmental conditions (Spasojevic \& Suding 2012). In contrast, resourcerich areas such as the laurel forest have higher functional diversity (Spasojevic \& Suding 2012). The high functional diversity of coastal scrub and thermophilous woodland is driven by the presence of various functionally distinct species, i.e., herbaceous, shrubs and tall woody plants. The high functional diversity of laurel forest, at the large local grain $\left(1 \mathrm{~km}^{2}\right)$ is linked to the high resource availability of this vegetation type driven by the high humidity. Precipitation supports high plant productivity as well as species diversity (Kreft et al., 2007; Knapp et al., 2017). The intermediate functional diversity of pine forest compared to other vegetation types relate to the strong prevalence of one species, i.e., the Canarian pine. Lastly, the low functional diversity of rocks vegetation type relates to its small fragmented area and to the reduced number of species that belong to it. Lastly, generally the low functional diversity of both summit scrub and rocks suggests that certain trait combinations are absent, such as tall plants like trees.

\section{Functional diversity from regional to local scales}

Our results showed that functional diversity patterns percolate down from regional to local scale, as functional diversity patterns of alpha, beta and gamma functional diversity were similar. This indicates that the community composition at the local scale and the smaller spatial grain has been shaped by similar abiotic and biotic filters as at the regional scale (Zobel 2016). Further, the similar patterns we found across vegetation types for alpha and beta functional diversity indicate that within each vegetation type, spatial variation in functional diversity is low, which also suggests that ranges and trait syndromes of each vegetation type are limited and similar.

\section{Functional diversity across the elevational gradient of an oceanic island}

Our results provide evidence that functional diversity changes across the elevational gradient (Figure III-3). Functional diversity decreases with increasing elevation, which relates to multiple factors (Rahbek et al., 2019). At high elevations, climatic conditions constrain plant growth and distribution, i.e., low temperature and precipitation filters for species with traits adapted to such conditions, as well as species that can tolerate high solar radiation and poor soil conditions (Girma et al., 2018). With increasing elevation vegetation becomes more isolated, this may also impose a dispersal barrier for plants (Fernández-Palacios et al., 2014). The peak of functional diversity of laurel forest is also related to the species accumulation at the mid-elevations, because it is possible 
for species to immigrate from low to high areas of the islands (Steinbauer et al., 2018). Identifying functional diversity patterns along elevational gradients is key to understanding potential biodiversity changes, such as shifts of functional groups across geographic ranges (upwards) as a response to increasing temperatures (Colwell et al., 2008). With imminent global warming lowland extinctions and, thus, functional diversity of arid vegetation types, such as coastal scrub and thermophilous woodland, may face a big threat (Steinbauer et al., 2018; Nowak et al., 2019).

Our results provide evidence that environmental conditions, i.e., temperature, elevation and precipitation affect functional diversity at the larger $\left(1 \mathrm{~km}^{2}\right)$, but not at the smaller spatial grain $\left(100 \mathrm{~m}^{2}\right)$. The negative effect of both elevation and temperature on functional diversity (see models for $1 \mathrm{~km}^{2}$ spatial grain in Figure III-4) is consistent with the low functional diversity values we found at the regional scale for summit scrub. The positive effect of precipitation on functional diversity we found (see cell models in Figure III-4) relates to the high functional diversity of the humid zones of the island, i.e., laurel forest. Our results are also consistent with several plant diversity studies, where precipitation is generally positively related to functional group and species richness (Otto et al., 2001; Kreft \& Jetz 2007). At the smaller spatial grain however, environmental and topographic conditions did not impact variation in functional diversity, suggesting that biotic interactions, for instance competition, may be shaping functional diversity (de Bello et al., 2012).

\section{Functional diversity complements taxonomy diversity}

In our study, we show that taxonomic measures of biodiversity, such as species richness (Supplementary Figure 7 and 8), are not a surrogate of functional diversity (Díaz \& Cabido 2001). Although high species richness leads to higher functional richness, our results showed that both diversity estimations accumulate differently on space. While functional diversity reached an asymptote with increasing grain size (Figure III-2), taxonomic diversity did not (Supplementary Figure 7 and 8). This suggests that species richness overestimates functional richness and that changes in species identities impoverishment may lead to drastic changes in functional diversity (Díaz \& Cabido 2001). Studying how species traits affect functional aspects of biodiversity is a step forward to understand diversity emerge at local and regional scales (Bender et al., 2019). Lastly, we are aware that in our study we considered species being functionally uniform, yet species traits 
greatly vary among individuals. Such variation may be systematic (e.g. life stage, environment) and it can also affect the functional diversity.

\section{CONCLUSIONS}

Functional diversity is influenced by two components of spatial scale, extent and grain. We found abiotic conditions playing a major role defining the functional diversity of the island, where large and habitat diverse areas, such as the arid and semiarid vegetation types showed high functional diversity. In mesic suitable conditions areas of the island, such as laurel forest functional diversity is positively affected. The steep elevational gradient of Tenerife shaped the island's temperature and humidity gradient and with it the functional diversity. The trend of functional diversity along Tenerife elevational gradient was however different depending on the local grain. Further, we show that taxonomic diversity is not a direct surrogate of functional diversity. Thus, studying both biodiversity facets is key to understanding plant diversity patterns and dynamics. Our study broadens our understanding on the relationship between local estimations of functional diversity and their relation to regional diversity dynamics, which is relevant to identify the processes maintaining biodiversity.

\section{Authors contributions}

HK conceived the initial idea and MPBB and DC further developed the conceptual idea. MPBB collected and measured plant trait data, prepared species distribution data and performed the analysis. PW and AT supported statistical analysis. RO supported plant trait data collection. DH supported preparation of species distribution data. All authors contribute to the results interpretation and writing of the paper.

\section{Acknowledgements}

MPBB and HK acknowledge funding by the German Research Foundation (DFG) Research Training Group 1644 'Scaling Problems in Statistics', grant no. 152112243. MPBB and HK thank the Jardín Botánico Canario "Viera y Clavijo" in Gran Canaria for allowing measurements in the seed bank as well as for the samples taken of rare species that were not possible to find in the field. MPBB thanks the field assistants in Tenerife, who made possible the successful collection and the 
laboratory work of almost all Tenerife native plants, Nora Strassburger, Mercedez Vidal Rodriguez and Arnau Andreu Diez, as well as Rubén Barone Tosco for helping identify plant species. 


\section{CHAPTER IV ENVIRONMENTAL HETEROGENIETY DYNAMICS DRIVE PLANT DIVERSITY ON OCEANIC ISLANDS}

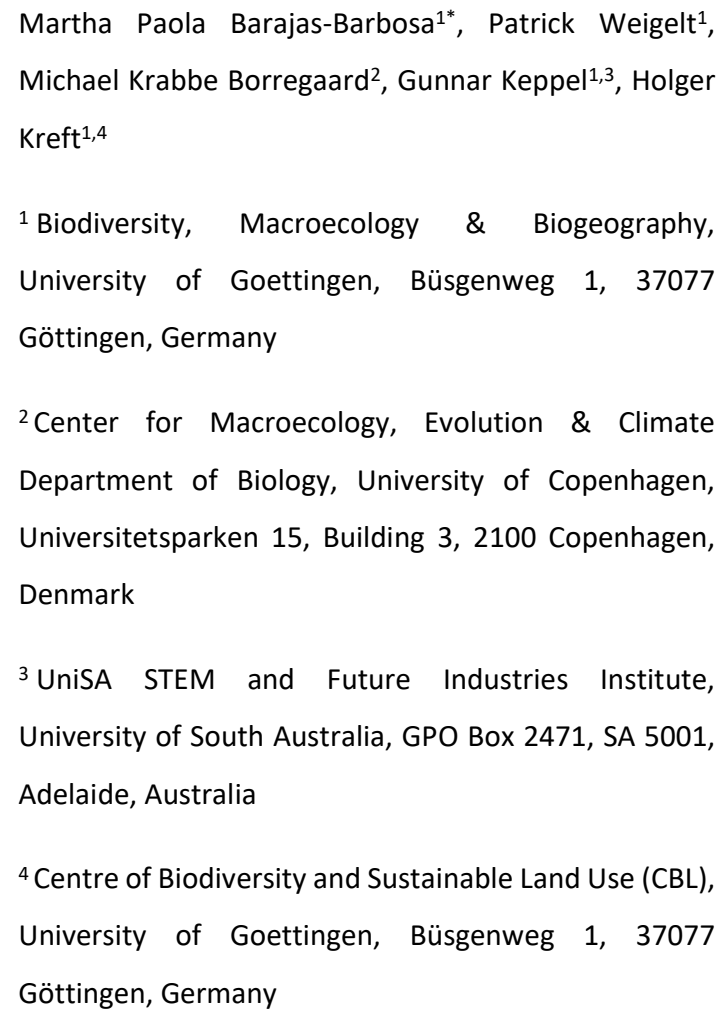

Adelaide, Australia

${ }^{4}$ Centre of Biodiversity and Sustainable Land Use (CBL), University of Goettingen, Büsgenweg 1, 37077

Göttingen, Germany

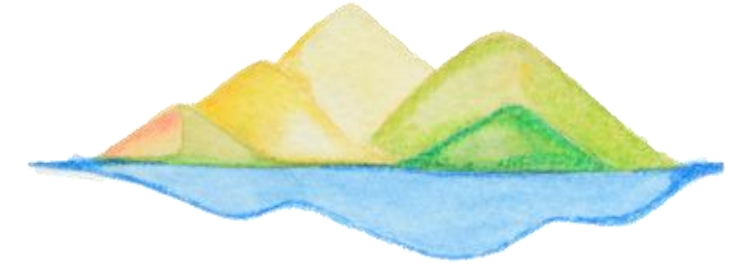

This chapter is published in the Journal of Biogeography. https://doi.org/10.1111/jbi.13925

\section{ABSTRACT}

Aim: The General Dynamic Model (GDM) links island biogeographical processes to island geological history. A key premise of the GDM implies that environmental factors shaping the ecology and evolution of biota on oceanic islands follow a hump-shaped trend over the island's life span and drive dynamics in carrying capacity, species diversity and endemism. An important component of the GDM is environmental heterogeneity $(\mathrm{EH})$, but its effects on insular diversity remain poorly understood. Here, we first quantified $\mathrm{EH}$, tested whether EH follows the expected hump-shaped trend along island ontogeny and evaluated how EH relates to plant diversity.

Location: 135 oceanic islands of volcanic origin.

Taxon: Vascular plants. 
Methods: We calculated $20 \mathrm{EH}$ metrics focusing on topographic and climatic components of EH, and comparing whole-island metrics (e.g., range) and moving-window metrics (e.g., roughness). Using linear mixed-effects models, we evaluated the trends of $\mathrm{EH}$ with island age and the EH-plant diversity relationship expected based on the GDM.

Results: Our analysis revealed some EH components to be collinear, e.g., elevation and temperature heterogeneity, but also that $\mathrm{EH}$ metrics capture different aspects of $\mathrm{EH}$, e.g., climatic gradients vs. climatic complexity. EH generally followed a hump-shaped trend with island age, peaking early during island ontogeny. Among the EH components, climatic heterogeneity had the strongest effect on plant species richness and elevation heterogeneity on endemism. Lastly, including EH metrics in GDMs (traditionally, only island age and area were included) improved their predictive power.

Main conclusions: The EH metrics compared here captured various attributes of the environment that influence insular plant diversity. In line with the GDM, our results strongly support a humpshaped relationship between $\mathrm{EH}$ and island age, suggesting that islands become highly heterogeneous early in their ontogeny. Finally, the contribution of EH to GDM-based models of species richness and endemism suggests that $\mathrm{EH}$ is a main driver of the diversity of oceanic island biotas. 


\section{INTRODUCTION}

Environmental heterogeneity $(\mathrm{EH})$ encompasses the spatial variation of key components of the abiotic and biotic environment, such as climate, topography, land cover and vegetation (hereafter 'EH components'), and is a main driver of species richness (Stein et al., 2014; Keppel et al., 2016). Environments with high levels of heterogeneity, such as mountain ranges, usually host larger numbers of species (Barthlott et al., 2005; Dufour et al., 2006) than homogeneous ones. EH affects species richness via three mechanisms (Stein \& Kreft, 2015). First, greater EH allows more species to coexist by increasing the length of environmental gradients and habitat diversity, which also facilitates the chance of establishment for immigrant species (MacArthur \& MacArthur, 1961; Hoorn et al., 2013; Antonelli et al., 2018). Second, EH enhances species diversification resulting from isolation and adaptation of species to spatially variable conditions (Hortal et al., 2013; Molina-Venegas et al., 2017). Third, EH facilitates species persistence by providing shelter and refugia from adverse environmental conditions, e.g., during glacial cycles or periods of prolonged drought (Svenning \& Skov, 2007; Keppel et al., 2015).

Oceanic islands are highly dynamic systems with heterogeneous environments, unique biota and outstanding levels of endemism (Kier et al., 2009; Weigelt et al., 2013). Oceanic islands are typically characterized by a rapid volcanic growth and a relatively short life span, which can range from days (Sabrina, Azores in 1811) to tens of millions of years (Fuerteventura $20 \mathrm{Ma}$ ) (FernándezPalacios et al., 2014). Some oceanic islands reach remarkable elevations, such as the Mauna Kea (4207 m a.s.l.) on the Island of Hawai'i or Mount Teide (3718 m a.s.l.) on Tenerife, and these impressive elevational gradients cause marked differences in temperature, orographic precipitation regimes and rain shadow effects over short geographical distances. Over geological time scales, island surfaces change from high and smooth volcanos, through highly rugged terrain when erosion shapes mountain ridges, to flat island remnants (Paulay, 1994; Price \& Clague, 2002). Such changes are caused by the interplay between volcanic activity, erosion, landslides and subsidence (Carracedo et al., 2011; Badgley et al., 2017). Certain oceanic islands have a complex geological history with repeated episodes of volcanism and mega-landslides (Neall \& Trewick, 2008; Gillespie \& Roderick, 2014). Hence, oceanic islands may exhibit high $\mathrm{EH}$ in terms of topography, climate (e.g., orographic precipitation regimes) and soil conditions (Whittaker et al., 2007; Seijmonsbergen et al., 2018). However, little is known about how ecologically relevant 
components of EH change over the life span of oceanic islands and how these changes affect the biogeographical processes generating and maintaining insular diversity.

Investigating how the dynamic nature of $\mathrm{EH}$ through the ontogeny of islands (i.e., island development through its geological life span from island emergence, island building, advanced island age to island submergence) affects colonization, speciation and extinction rates and emergent patterns of insular species diversity is at the forefront of modern island biogeography (Borregaard et al., 2017; Whittaker et al., 2017). The General Dynamic Model (GDM) links the geological dynamics of oceanic islands to biogeographical rates and diversity patterns (Whittaker et al., 2008). One of the three premises of the GDM states that island elevational range, topographic complexity (both belonging to the topographic component of $\mathrm{EH}$ ) and island area change in a predictable manner over time and peak at intermediate island age, causing a humpshaped pattern in island carrying capacity and species richness (Whittaker et al., 2008; Valente et al., 2014; Lim \& Marshall, 2017). The peaks in carrying capacity and species richness are assumed to occur between the time when an island first reaches its maximum elevation with steep climatic gradients, and the times when it reaches maximum topographic complexity after having experienced erosion, i.e., a rugged and dissected landscape with a large number of different habitats. The hump-shaped relationship between species diversity, island area and age has been summarised in the GDM and was originally mathematically expressed as: Biodiversity $\ln ($ Area $)+$ Time + Time ${ }^{2}$, called the 'ATT² model' (Whittaker et al., 2008).

Despite these clear theoretical underpinnings, the complex geological histories and often idiosyncratic trajectories of individual oceanic islands (Ali, 2017) may limit the applicability of the GDM (Keppel et al., 2016; Borregaard et al., 2017). Most empirical tests of the GDM have focused on the relationship of island area and age with species richness (Steinbauer et al., 2013; Borregaard et al., 2017; Lenzner et al., 2017). The few studies that included EH found species diversity best explained when both area and EH were included in the models (Keppel et al., 2016). However, the validity of the assumption of a hump-shaped relationship between $\mathrm{EH}$ and island age - to the best of our knowledge - has never been tested before. Also, the effect of EH on insular plant diversity (i.e., inclusion of $\mathrm{EH}$ in the $\mathrm{ATT}^{2}$ model) and species diversity remains poorly understood (but see e.g. Triantis et al., 2003; Hortal et al., 2009). The apparent research gap on $\mathrm{EH}$ research on islands is partly due to $\mathrm{EH}$ being a multifaceted concept and difficult to quantify in 
an ecological meaningful way, i.e., to capture all attributes of heterogeneity in an environment that may drive species diversity.

The quantification of EH is complicated by at least two main challenges. First, EH comprises a potentially large number of different components (e.g., related to precipitation, topography and soil types). Second, different quantification methods may capture different aspects of EH (Stein \& Kreft, 2015). In addition, the spatial scale at which EH is calculated may affect the results of EH quantification (Jackson \& Fahrig, 2015) and interactions with island area can potentially modify the effect of EH on diversity (Allouche et al., 2012; Hortal et al., 2013). For instance, the areaheterogeneity trade-off hypothesis predicts species diversity to decrease at high levels of EH, because the effective area of individual habitats is reduced (Allouche et al., 2012). While theoretical arguments opposing the area-heterogeneity trade-off hypothesis have been raised (Hortal et al., 2013), it remains largely unknown if there is an interactive (positive or negative) effect of island area and EH on diversity on islands (but see Hortal et al., 2009) and how this relates to the GDM.

Therefore, we set three aims for the present study. First, we aim to calculate and compare various alternative, ecologically meaningful EH metrics across a large number of oceanic islands worldwide by focusing on two main abiotic EH components, namely climatic and topographic heterogeneity. Second, we test the GDM premise that EH exhibits a hump-shaped relationship with island age. Finally, we evaluate the effect of EH on plant diversity of oceanic islands and examine the $\mathrm{EH}$ effect on predictor variables of the GDM (island area and time) and the potential interaction between $\mathrm{EH}$ and island area on diversity, by including different variants of $\mathrm{EH}$ in the $\mathrm{ATT}^{2}$ model.

\section{MATERIALS AND METHODS}

We studied the spatial environmental heterogeneity $(\mathrm{EH})$, its relationship with island age and its effect on species diversity of vascular plants for 135 oceanic islands of volcanic origin (Figure IV1), which belong to 41 archipelagos worldwide (Figure S2.1). We restricted the analysis to islands $>2 \mathrm{~km}^{2}$, as EH could not be calculated in a meaningful way for smaller islands, given the spatial grain of the climatic variables $(1 \mathrm{~km})$. We worked with two aspects of plant diversity, (i) species 
richness of native species and (ii) single-island endemics. The latter reflects evolutionary processes on islands, such as in situ speciation (Weigelt et al., 2016). We obtained the information about plant diversity, as well as island characteristics (island age and area), from the Global Inventory of Floras and Traits (GIFT). The GIFT database provides information on distributions and floristic status (native, endemic, alien) of plant species based on a wide range of regional floristic databases, floras and checklists (Weigelt et al., 2020). The full list of original literature resources used to obtain species diversity information is available in Supplementary S1.

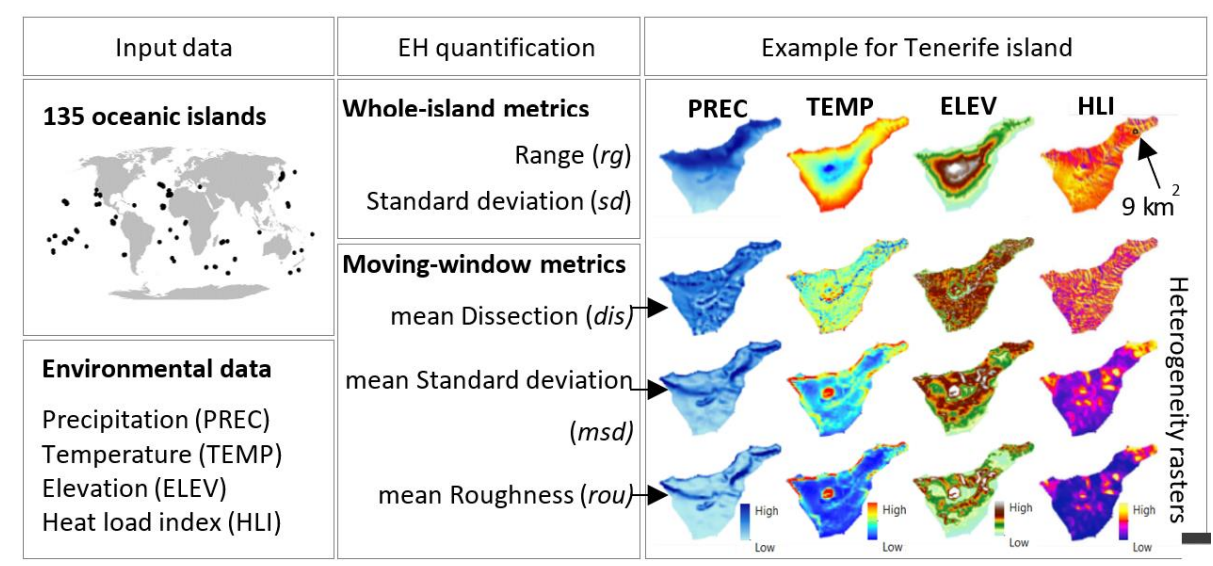

Figure IV-1 Workflow of quantifying environmental heterogeneity (EH) for 135 oceanic islands worldwide, displayed as black dots in the world map. A total of $20 \mathrm{EH}$ metrics were calculated for each island to capture four EH components: elevation (ELEV; $\mathrm{m}$ a.s.I.), mean annual precipitation (PREC; $\mathrm{mm} /$ year) and mean annual temperature (TEMP; ${ }^{\circ} \mathrm{C}$ ), and one derived variable from ELEV, heat load index (HLI). Two types of metrics were investigated (i) whole-island metrics that summarized EH per island by its range (rg) or standard deviation (sd) on the four EH components and (ii) movingwindow metrics that first calculated statistics for a focal cell within the specified window size $\left(9 \mathrm{~km}^{2}\right)$, resulting into heterogeneity rasters for each $\mathrm{EH}$ component, and then summarized $\mathrm{EH}$ for each island using the mean value of the heterogeneity rasters, i.e., mean of dissection (dis), standard deviation (msd) and roughness (rou). Tenerife island (2034 $\mathrm{km}^{2}$ ) is shown as an example displaying the different $\mathrm{EH}$ components, heterogeneity rasters and the $9 \mathrm{~km}^{2}$ window size.

\section{Environmental heterogeneity components}

To assess the climatic component of EH, we used mean annual precipitation (PREC; mm/year) and mean annual temperature (TEMP; $\left.{ }^{\circ} \mathrm{C}\right)$. Both variables influence the water and energy available to plants and are strong determinants of plant diversity (Kreft \& Jetz, 2007). The information of PREC and TEMP were derived from the Climatologies at High resolution for the Earth's Land Surface Areas (CHELSA) dataset at a spatial grain of c. $1 \mathrm{~km}$ (Karger et al., 2017). To evaluate the topographic component of EH, we used elevation (ELEV; $m$ a.s.I.) from the Shuttle Radar Topography Mission (SRTM) dataset, at a spatial grain of $250 \mathrm{~m}$ (Jarvis et al., 2008). From the ELEV data, we derived the heat load index $(H L I)$, using the formula: $H L I=-1.467+1.582 * \cos (L) * \cos (S)$ $-1.5 * \cos (F a) * \sin (S) * \sin (L)-0.262 * \sin (L) * \sin (S)+0.607 * \sin (F a) * \sin (S)$, where $L=$ latitude, 
$S=$ slope and $F a=$ folded aspect (see Equation 1 in McCune \& Keon, 2002 and McCune, 2007). HLI assesses topography-associated thermal gradients by including the slope aspect. Slope aspect strongly influences local temperature, i.e., equatorial facing slopes are warmer than polar facing slopes. Thus, slope aspect influences the thermal condition in a habitat (McCune, 2007). HLI has already been related to distribution patterns of plant diversity (He et al., 2017).

\section{Quantification of EH across oceanic islands}

To quantify the two main EH components, climatic and topographic heterogeneity, we calculated two types of metrics (Figure IV-1). First, we used whole-island metrics describing the range and the spatial variability of the EH components over the whole island. These metrics can describe island carrying capacity of an entire oceanic island (Stein et al., 2015). To this end, we summarized $\mathrm{EH}$ per island by the range $(r g)$ and the standard deviation $(s d)$ of the environmental variables ELEV, HLI, PREC and TEMP. Second, we used moving-window metrics to calculate the local environmental turnover of either climate or topography within a defined area (Amatulli et al., 2018). This group of EH metrics can provide information about climatic and topographic complexity, and potential topography-associated dispersal barriers within islands.

We applied a moving window approach (Hagen-Zanker, 2016) that calculates statistics for a focal cell within a specified window size (here $9 \mathrm{~km}^{2}$ comprised $3 \times 3$ and $12 \times 12$ pixels for CHELSA and SRTM data, respectively). Within the $9 \mathrm{~km}^{2}$ window, we calculated three statistics (1) dissection = $\left(z-z_{\min }\right) /\left(z_{\max }-z_{\min }\right)$, where $z_{\max }=$ maximum, $z_{\min }=$ minimum and $z=$ focal cell value within the window, (2) standard deviation and (3) roughness (i.e., the largest inter-cell difference of a focal cell and its surrounding cells) (Riley et al., 1999; Amatulli et al., 2018). This produced three new raster layers for each EH component (hereafter 'heterogeneity rasters') with identical spatial extent and grain as the input and each new cell describing the heterogeneity within the window. We then summarized $\mathrm{EH}$ for each island by calculating the mean value of the heterogeneity rasters and termed them 'dis', 'msd' and 'rou', respectively (Figure IV-1). We named the EH metrics by referring first to the environmental variable abbreviation in uppercase, followed by the calculation metric abbreviation in lower case, e.g., ELEVrou for the mean roughness in elevation per island and PRECrg for the range in precipitation per island. 
Window size and spatial grain can influence $\mathrm{EH}$ quantification. We therefore tested three alternative window sizes $\left(3,25\right.$ and $\left.49 \mathrm{~km}^{2}\right)$ on three different spatial grains $(250 \mathrm{~m}, 500 \mathrm{~m}$ and 1 $\mathrm{km}$, the last two grains were aggregated from initial ELEV at $250 \mathrm{~m}$ ) using the ELEV data only (Supplementary Figure S3.6). Following the same procedure as described above for movingwindow metrics, we obtained EH values per island and compared values across islands using correlation analysis. We calculated the EH metrics using R version 3.5.2 (R Development Core Team, 2018) using the extract function from the package raster (Hijmans et al., 2018). For computing the $\mathrm{HLI}$ and the heterogeneity rasters dissection, roughness and standard deviation, we used the Spatial Analyst extension and the Geomorphometry \& Gradient Metrics toolbox (Evans et al., 2014) in ESRI ArcGIS version 10.4.

\section{Statistical analysis}

We used Pearson's correlation coefficients to relate EH metrics to each other, and to assess similarities among EH components and the two types of metrics. To test the GDM premise of a hump-shaped trend in $\mathrm{EH}$ over island age (see relationships between island age and individual $\mathrm{EH}$ metrics in Supplementary Figure S4.7), we replaced 'Biodiversity' with a respective EH metric as a response variable in a modified GDM formula that uses a log-transformation of Time (Steinbauer et al., . 2013): $\ln \left(\right.$ EH metric) $\sim \ln ($ Area $)+\ln ($ Time $)+\ln \left(\right.$ Time $\left.^{2}\right)+(1 \mid$ Archipelago $)$, where 'In' is the natural logarithm (hereafter ' $\mathrm{EH} \sim \mathrm{ATT}{ }^{2 \prime}$ model). We fitted the $\mathrm{EH} \sim \mathrm{ATT}{ }^{2}$ formula using linear mixed effect models (LMM) that account for the variation across archipelagos as random intercept, because $\mathrm{EH}$ and species diversity of individual islands depend on archipelago characteristics (Bunnefeld \& Phillimore, 2012; Borregaard et al., 2016). All EH metrics were scaled to zero mean and unit variance to facilitate comparisons among different $\mathrm{EH}$ measures. We then produced model predictions to assess the trend of $\mathrm{EH}$ with island age, by keeping island area and archipelago constant (median island area and one selected archipelago, Hawaii). We verified if the log-transformation of island age produced statistically more robust models by fitting the EH $\sim \mathrm{ATT}^{2}$ formula without log-transforming island age and using Akaike's Information Criterion (AIC), and how island area influenced the EH metrics, as area may interfere with the identification of EH per se (Stein et al., 2014), by plotting coefficient estimates for the $\mathrm{EH} \sim \mathrm{ATT}{ }^{2}$ models.

We evaluated the effect of EH on the diversity of vascular plants, by including each EH metric separately as a predictor variable in the modified GDM formula (Steinbauer et al., 2013): Biodiversity $\sim \ln ($ EH metric $)+\ln ($ Area $)+\ln ($ Time $)+\ln \left(\right.$ Time $\left.^{2}\right)+(1 \mid$ Archipelago $)+(1 \mid$ Observation $)$ 
(hereafter 'EHATT ${ }^{2 \prime}$ model), where we replaced Biodiversity by (i) number of native species and (ii) number of single-island endemic species of vascular plants. We fitted the EHATT ${ }^{2}$ models and for comparison also the $\mathrm{ATT}^{2}$, which did not include $\mathrm{EH}$, using generalized linear mixed-effect models (GLMM, with Poisson distribution error). To identify the differential effect of the investigated predictor variables, i.e., Area, Time, and each EH metric (we verified the effect of logtransforming the metrics, see Table 4.2, Supplementary Figure S3.2 and Figure S4.9), we compared the model coefficient estimates (Supplementary Figure S4.8). To determine if EH in addition to Area and Time improved model support, we used AIC values. Additionally, to test if island area affected the effect of $\mathrm{EH}$ on plant diversity, we ran the $\mathrm{ATT}^{2}$ and $\mathrm{EHATT}^{2}$ models including the interaction term $\ln (\mathrm{EH}$ metric) * $\ln$ (Area). Lastly, based on model predictions, we evaluated the trend of plant diversity over island age, and tested the effect of excluding the quadratic term of age (Time ${ }^{2}$ ) from all EHATT ${ }^{2}$ and $\mathrm{ATT}^{2}$ models to identify the importance of this term, based on AIC values. For a complete model assessment, we first evaluated absolute model fit by computing marginal (fixed effects) and conditional (random effects) $R^{2}$ values (Nakagawa \& Schielzeth, 2013) for EH ATT ${ }^{2}$, as well as for EHATT ${ }^{2}$ and $\mathrm{ATT}^{2}$ models (Table S4.1 and Table S4.3). Second, using model diagnostics (QQ plot and residual vs. predicted values), we determined whether there were significant degrees of overdispersion for GLMM (i.e., EHATT' ${ }^{2}$ and $\mathrm{ATT}^{2}$ ). Overdispersion is common in models for count data and can be caused by aggregation among observations (Harrison et al., 2018), i.e., islands. It may cause Type I errors (false positives), as standard errors are underestimated. To fix this, we used the observation-level random effect approach (i.e., the identity of islands was set as random intercept), which gives more accurate estimates of standard errors (Harrison, 2014, 2015). $R^{2}$ values and overdispersion tests were computed in MuMIn (Bartoń, 2018) and DHARMa (Hartig, 2019), respectively. All statistical analysis were done using R 3.5.2 (R Development Core Team, 2018). The LMM and GLMM were fitted using the package Ime4, and model coefficient estimates plots were produced using the package dotwhisker (Solt \& Hu, 2015).

\section{RESULTS}

\section{Assessment of EH metrics}

Our comparison of different $\mathrm{EH}$ metrics revealed strong similarities among topographic and climatic heterogeneity, namely between ELEV and TEMP heterogeneity (Pearson's correlation coefficients between $0.5-1$ and average 0.72 , see Supplementary Figure S3.3). PREC 
heterogeneity, on the other hand, was only relatively weakly correlated with the other $\mathrm{EH}$ components (Pearson's correlation coefficients between $0.1-0.7$ and average 0.29 ). Within the whole-island metrics, i.e., range ( $\mathrm{rg}$ ) and standard deviation (sd), we found a strong and positive correlation (Pearson's correlation coefficients between $0.5-0.9$ and average 0.61 ) and within two moving-window metrics roughness (rou) and standard deviation (msd) the correlation was also positive (Pearson's correlation coefficients between $0.6-0.8$ and average 0.57 ). Across wholeisland metrics and moving-window metrics the correlation was somewhat weaker (Pearson's correlation coefficients between $0.1-0.9$ and average 0.49 ). In contrast, the moving-window metric using dissection weakly to negatively correlated with the other EH metrics (Pearson's correlation coefficients commonly $<0.4$ and average 0.08 ). Our test using different window sizes and spatial grains showed high correlations across small and intermediate windows $\left(3,9,25 \mathrm{~km}^{2}\right.$ calculated with $250 \mathrm{~m}, 500 \mathrm{~m}$ and $1 \mathrm{~km}$ spatial grain), yielding almost identical EH values per island (correlation coefficients $>0.88$, Supplementary Figure S3.6), whereas the larger window $49 \mathrm{~km}^{2}$ showed a slight difference in EH values (Supplementary Figure S3.6). In addition, we found that the heterogeneity rasters based on $9 \mathrm{~km}^{2}$ window size clearly identified landscape features, such as ravines and mountainous areas, while the $49 \mathrm{~km}^{2}$ window generally led to more diffuse patterns (see example in Supplementary Figure S3.4).

\section{Trends of EH over island age}

We found hump-shaped relationships between $\mathrm{EH}$ and island age for 16 out of the $20 \mathrm{EH}$ metrics (Figure IV-2). Those $16 \mathrm{EH}$ metrics showed a similar pattern over time, i.e., EH rapidly increased and peaked early, followed by a slow decrease over time. The remaining four EH metrics (movingwindow metrics using dissection, see yellow lines in Figure IV-2) showed an asymptotically or exponentially decreasing trend over time. The model comparison revealed that the logtransformation of island age in the $\mathrm{EH} \sim A \mathrm{AT}^{2}$ formula was always stronger supported than models with untransformed data (Table S4.1). 
(a)

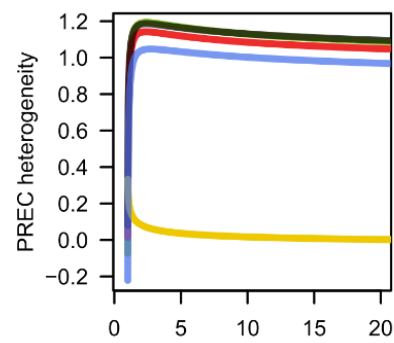

(c)

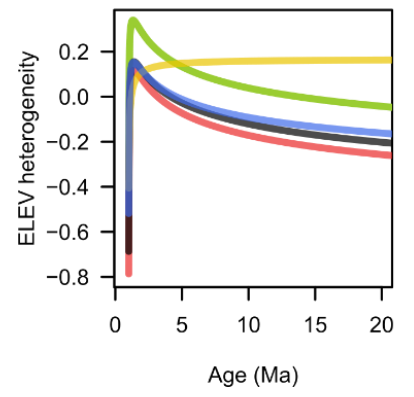

(b)

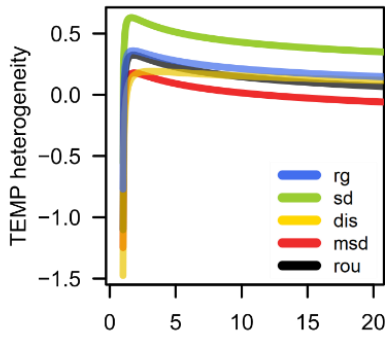

(d)

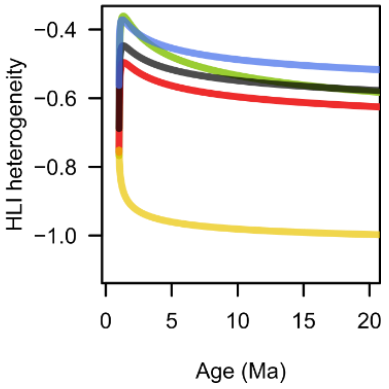

Figure IV-2 Temporal trends of environmental heterogeneity (EH) over island age (in millions of years i.e., Ma) based on data for 135 oceanic islands. Predictions from EH ATT ${ }^{2}$ models where island area and archipelago were kept constant (median island area and one selected archipelago, i.e., Hawaii). The EH components are displayed separately, (a) mean annual precipitation (PREC), (b) mean annual temperature (TEMP), (c) elevation (ELEV) and (d) heat load index (HLI). Colored lines correspond to the type of metrics used, whole-island metrics are displayed in blue $=\mathrm{range}(\mathrm{rg})$ and green = standard deviation (sd), and moving-window metrics in yellow = dissection (dis), red = standard deviation (msd) and black = roughness (rou). EH metrics were scaled (zero mean, unit variance) to facilitate comparisons among different EH measures.

\section{$\mathrm{EH}$ as a predictor of plant diversity in the $A \mathrm{AT}^{2}$ model}

The majority of EH metrics had a positive effect on insular plant diversity (Figure IV-3), and they had an even stronger effect on single-island endemic species (compare $\mathrm{x}$-axis in Figure IV-3). For the number of native species, PREC and TEMP heterogeneity had the strongest effect (Figure IV3a), particularly precipitation and temperature range (i.e., whole-island metrics PRECrg and TEMPrg). It was followed by the positive effect of climatic complexity in terms of precipitation (i.e., moving-window metrics PRECmsd and PRECrou) (Figure IV-3a). The number of single-island endemics species was most strongly affected by TEMP and ELEV heterogeneity (Figure IV-3b), specifically the range in temperature and elevation (TEMPrg and ELEVrg). Climatic (in terms of temperature) and topographic complexity (i.e., moving-window metrics TEMProu, ELEVmsd, HLImsd) also had a positive effect on single-island endemic species but PREC heterogeneity did not affect single-island endemics (Figure IV-3b). Moving-window metrics that used dissection neither affected native nor single-island endemic species (Figure IV-3). 
(a)

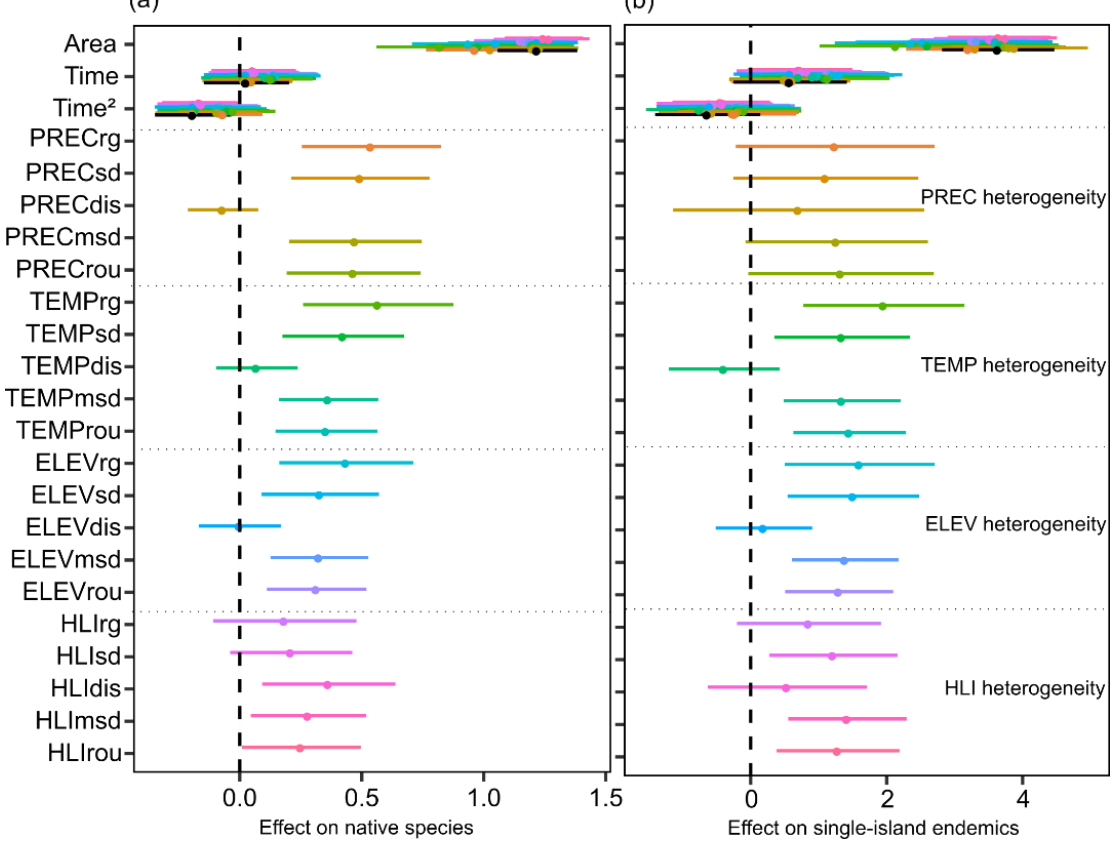

Figure IV-3 Effects of environmental heterogeneity (EH) components and metrics, island area and age on species richness and endemism of vascular plants, in the framework of the general dynamic model (GDM). Coefficient estimates (dots) and 95\% confidence intervals (bars) for (a) number of native species and (b) number of single-island endemic species, from models fitted with $\mathrm{EHATT}^{2}$ and $\mathrm{ATT}^{2}$ to compare the effect of including EH. The colored dots and bars correspond to a particular model depending on the EH metric included. Coefficients and error bars of the ATT ${ }^{2}$ models are highlighted in black. Vertical dashed lines mark zero effects and covariates are not considered significant if the error bar intersects with the zero. Coefficient estimates were automatically scaled for direct comparison by 2 times their standard deviation.

In all EHATT ${ }^{2}$ and $A T^{2}$ models, island area had the strongest effect (Figure IV-3), but its effect particularly decreased when whole-island metrics that measured ranges (TEMPrg, ELEVrg and PRECrg) were included in the models (see models coefficients and error bars of the ATT' model highlighted in black in Figure IV-3). Island age had a weak effect in all EHATT ${ }^{2}$ and $\mathrm{ATT}^{2}$ models (see Time and Time ${ }^{2}$ coefficients estimates and error bars in Figure IV-3). However, the effect of both terms for age changed after including whole-island metrics measuring ranges (again TEMPrg, ELEVrg, PRECrg), i.e., the effect of the linear term (Time) increased and the quadratic term $\left(\mathrm{Time}^{2}\right)$ decreased. The decrease of the effect of the quadratic term caused an asymptotic relationship of species richness and endemism with time (Supplementary Figure S5.10). Furthermore, models without the quadratic term of age (i.e., EHAT models) had lower AIC values than the EHATT ${ }^{2}$ models (Table S5.4) and therefore a stronger support. Also, the majority of the EHATT${ }^{2}$ models received stronger statistical support than the $\mathrm{ATT}^{2}$ model (Table S4.3), namely 15 out of $20 \mathrm{EHATT}^{2}$ models for predicting number of native species and 11 out of $20 \mathrm{EHATT}^{2}$ models for predicting number of single-island endemics (Table S4.3). 
Finally, there was only limited support for an interaction between island area and EH (Supplementary Figure S5.11). For models predicting the number of native species, the positive interactions for one whole-island metric (PRECrg) and two moving-window metrics (PRECmsd and PRECrou) with island area (Supplementary Figure S5.11a) received statistical support. For models predicting the number single-island endemic species, nearly all moving-window metrics capturing precipitation and temperature heterogeneity (PRECdis, PRECmsd, PRECrou, TEMPmsd, TEMProu) had a significant and positive interaction with island area (Supplementary Figure S5.11b). None of the EH metrics for elevation and HLI significantly interacted with island area.

\section{DISCUSSION}

Our study aimed to identify ecologically meaningful measures of environmental heterogeneity (EH) on oceanic islands by assessing climatic and topographic components of heterogeneity related to precipitation (PREC), temperature (TEMP), elevation (ELEV) and heat load (HLI), and to evaluate the performance of whole-island as well as of moving-window metrics (Figure IV-1). We then tested a key premise of the general dynamic model of island biogeography (GDM; Whittaker et al., 2008) and showed that EH indeed follows the expected hump-shaped relationship with island age (Figure IV-2). We found strong evidence for an important role of EH as a driver of plant species richness and endemism of oceanic islands (Table S4.3). Metrics reflecting climatic heterogeneity (i.e., PREC and TEMP heterogeneity) are particularly relevant for species richness and temperature and topographic complexity (i.e., ELEV and TEMP and HLI heterogeneity) are particularly relevant for endemic species (Figure IV-3). Together, our results contribute to a better understanding of the role of $\mathrm{EH}$ for insular diversity patterns.

\section{Capturing the heterogeneity of insular environments}

Our assessment of different alternative ways to quantify EH of oceanic islands revealed that certain environmental components strongly co-vary, as seen in the strong positive correlation of elevation and temperature related heterogeneity metrics. This is due to the strong dependency of temperature gradients on the topography (Dobrowski et al., 2009). In contrast, precipitation heterogeneity was less strongly associated with metrics of other EH components (Supplementary Figure S3.3), indicating that EH metrics capture different aspects of the spatial variability in island 
environments. This is further supported by the low to intermediate correlations among different types of metrics (whole-island metrics vs. moving-window metrics).

The Island of Hawai'i nicely illustrates the contrast between whole-island and moving-window metrics (see Hawaiian archipelago EH-map in Supplementary Figure S3.5), as it had the largest observed values for climatic and topographic ranges (PRECrg, TEMPrg, ELEVrg metrics), but comparatively low climatic and topographic complexity (PRECrou, TEMProu, ELEVrou metrics). The large values for range metrics are explained by the fact that the Island of Hawai'i is the highest oceanic island worldwide. This produces steep and long gradients in temperature, as well as dramatic precipitation gradients created by the high elevation of the island and the trade winds (Giambelluca et al., 2013). Likewise, the Island of Hawai'i is characterized by a comparatively low climatic and topographic complexity, because the surface of this young island is relatively smooth compared to older, more eroded islands. These results indicate that whole-island metrics successfully describe total energy (TEMPrg, HLIrg), water supply (PRECrg) and available space for species (ELEVrg), all major elements of island carrying capacity (Hui, 2006). Moving window metrics, in contrast, are more suitable for describing the climatic and topographic complexity of islands (Cramer \& Verboom, 2017), when using roughness or standard deviation, because they capture local changes in temperature and precipitation regimes and the terrain complexity, e.g., ridges and valleys (Bonetti et al., 2020), found in landscapes such as the Anaga mountains on Tenerife (Figure IV-1), Moka in Mauritius and Koke'e in Kauai (see island maps in Supplementary Figure S3.4).

Moving-window metrics of dissection computed here as the mean value of the heterogeneity rasters of dissection per island, did not always reliably inform about how dissected an island landscape is. Our results showed that (mean) dissection values varied independently of island age (Supplementary Figure S4.7). For instance, Christmas Island (20 Ma) and Genovesa Island (0.3 Ma) had the highest (mean) dissection values for elevation among all islands studied. The first is an old, highly eroded island with steep escarpments around its boundaries, the second is a young volcano. Both island landscapes are mostly smooth with little topographic complexity (i.e., no valleys and ridges), but rather have a continuously descending landform (e.g., cone-shape). In both cases, the dissection formula led to high values for landscape incisions (i.e., descending areas within the $9 \mathrm{~km}^{2}$ window size) or its analogue for climate (see Tenerife heterogeneity rasters in Figure IV-1). Thus, islands with a relatively flat or cone-shaped landscapes can have high average 
dissection values despite having limited EH. The spatial grains used here (250 m for ELEV and HLI and $1 \mathrm{~km}$ for TEMP and PREC) produced comparable estimates of EH. Our test using different window sizes confirmed that within-island $\mathrm{EH}$, caused by island ravines, ridges and valleys, is captured well at an intermediate scale (i.e., $9 \mathrm{~km}^{2}$ ) (Supplementary Figure S3.4.). At a larger scale (i.e., $49 \mathrm{~km}^{2}$ ) such landscape features were averaged out and disappeared, potentially leading to an underestimation of EH (see $9 \mathrm{~km}^{2}$ vs. $49 \mathrm{~km}^{2}$ window sizes in Supplementary Figure S3.6.). This is relevant for plant diversity because at intermediate scales geology and soil conditions, in addition to topography and climate, create a matrix of habitats that can host distinct plant communities (Crawley, 2001; Miguet et al., 2016).

\section{The trajectory of environmental heterogeneity (EH) over oceanic island ontogeny}

With few exceptions, the EH metrics investigated here showed a hump-shaped relationship with island age (Figure IV-2), with peaks early in the island ontogeny (higher model support with logtransformed island age see Table S4.1). This result lends strong support to one of the fundamental premises of the GDM (Whittaker et al., 2008), i.e., island elevational range and topographic complexity have a hump-shaped pattern over time. In contrast to the graphical model representation in Whittaker et al., . (2008), we found that EH peaks before the 'middle-age' of an island, because most of the volume and elevation of volcanic hotspot islands usually forms within the first million years (Troll \& Carracedo, 2016). Shortly after island emergence, the onset of erosion, occurrence of mega-landslides and collapses of calderas contribute to a complex island topography (Carracedo, 1994). With the peak in elevation, maximum climatic ranges are also reached and within-island climatic complexity increases. Two young islands from our analysis exemplify this: La Palma (2380 m a.s.l. and ca. 1.7 Ma) and Tahiti (1670 m a.s.l. and ca. 1.3 Ma) have large climatic and elevation gradients and a complex climate and topography (e.g., both received high values for moving-window metrics of roughness), as they had already undergone geomorphological processes that considerably modified their surface configuration (Ferrier et al., 2013).

The slow decline of EH over time (Figure IV-2) indicates that it may take several million years for an island to be eroded. For instance, the island of Lanzarote is $16 \mathrm{Ma}$ old, its highest point is 650 $\mathrm{m}$ a.s.I., and it still holds considerable EH. The main factors responsible for the decline of island's EH are long-term erosion through rainfall (Ferrier et al., 2011), subsidence in certain archipelagos, 
e.g., Galapagos Islands (Ali \& Aitchison, 2014) and coastal erosion (Ramalho et al., 2013). Also, the trade-off between losing elevational range (Price \& Clague, 2002) and increasing topographic complexity slows the decline of island $\mathrm{EH}$. The slow decline in $\mathrm{EH}$ has relevant biogeographical implications. Extinction rates should rise only slowly while speciation rates might be maintained at higher levels, which would lead to a slower decline in species richness than previously thought (Whittaker et al., 2008). This has been shown for birds, insects and plants in the Hawaiian islands, where evolutionary decline is much slower compared to evolutionary radiation at the beginning of island building (Lim \& Marshall, 2017). The few exceptional cases where EH metrics (i.e., dissection metrics in Figure IV-2) did not show a humped-shaped trend over time, were caused by the unclear relationship between the metrics and island age (i.e., both young and old islands had intermediate to high dissection values, see Supplementary Figure S4.7). Lastly, we note that although island $\mathrm{EH}$ is generally related to island area and certain $\mathrm{EH}$ metrics are more affected by area per se (Supplementary Figure S4.8), the EH trends we find here are not due to the variation of island area, as area entered the analysis as a covariate.

\section{Environmental heterogeneity (EH) as a determinant of insular species richness and endemism}

Insular vascular plant diversity was strongly affected by EH, and most notably, native and endemic species richness were differentially affected by EH. Specifically, we found that climatic heterogeneity (PREC and TEMP heterogeneity) was the most important predictor of native species richness (Figure IV-3a), whereas temperature and elevation heterogeneity were most important for the number of single-island endemic species (Figure IV-3b). Climatic heterogeneity influences species richness on oceanic islands by increasing the number of climatic niches, where plant colonizers can establish and a large number of species can coexist (Stein et al., 2014) and persist if climatic fluctuations occur (Keppel et al., 2018). Elevation heterogeneity, on the other hand, is known for its key role in promoting species diversification (Rahbek et al., 2019). Steep elevation gradients, which directly relate to changes in temperature, create selection pressures that can lead to new species adaptations (Badgley et al., 2017). Furthermore, a complex topography implies geographic barriers that isolate species populations (Irl et al., 2015), disrupt their gene flow and eventually lead to within-island diversification (Kisel \& Barraclough, 2010). Overall, this result is consistent with previous (meta-)studies (e.g., Kreft et al., 2008; Stein et al., 2014) and emphasizes how EH, which is characteristically high on oceanic islands (Fernández-Palacios, 1992; Mueller-Dombois \& Fosberg, 1998), is a key determinant of insular plant diversity. 


\section{Effect of including EH in the $A T^{2}$ model}

Including $\mathrm{EH}$ in the $\mathrm{AT}^{2}$ model improved the statistical power and also modified the effect of island area and age on species richness and endemism of vascular plants. The decreased effect of island area after including EH, particularly with whole-island metrics (i.e., PRECrg, TEMPrg and ELEVsd), provides evidence that both, island area per se and EH, need to be considered in models of species richness and endemism (Triantis et al., 2012). Including EH had opposite effects on the two terms for island age. It increased effect of the linear term (Time in Figure IV-3) and decreased the effect of the quadratic term (Time ${ }^{2}$ in Figure IV-3), leading to an overall asymptotically increasing relationship between species richness and endemism with time (Supplementary Figure S5.10) and not to the hump-shaped relationship predicted by the GDM (Whittaker et al., 2008). This change highlights three key phenomena occurring during island ontogeny. Firstly, more and more species colonize and eventually diversify with time (Heaney, 2000). Secondly, colonization and speciation slow down when many species are already present (Borregaard et al., 2017). Thirdly, and importantly, the negative effect of time on island carrying capacity, and hence island diversity, can be captured directly by the effects of decreasing island area and EH.

The lack of significant interactions for most models suggests that overall island area and EH affect species richness and endemism largely additively. However, the positive and significant interactions (Supplementary Figure S5.11) we found between island area and EH (only for climatic heterogeneity) indicate that the effect of EH depends on island size and lend limited support to the area-heterogeneity trade-off hypothesis (Allouche et al., 2012). Our finding shows that on large islands climatic heterogeneity has a positive and strong effect on species diversity, while on small islands climatic heterogeneity has a weaker to even negative effect on species diversity. Therefore, small islands even if exhibiting high levels of climatic heterogeneity, will not have large numbers of species, particularly not endemic ones (compare x-axis Supplementary Figure S5.11), because the effective area per habitat required for species to persist or even speciate is limited.

There are several limitations of our study. First, using a space-for-time substitution for understanding biodiversity patterns that change over time only allows for limited inference (Pickett, 1989). Second, the challenges imposed by the complexity and often idiosyncratic development of volcanic island ontogenies hamper the search for generality (Ali, 2017; Borregaard 
et al., 2017). Finally, there are further potential EH components crucial for plant diversity, such as heterogeneity in soil conditions (Crews et al., 1995) or heterogeneity in biological interactions, which currently are not possible to evaluate at the geographical extent of our study.

We conclude that our EH quantification across a large number of oceanic islands worldwide underlines that investigating a suite of alternative environmental heterogeneity metrics, calculated with different methods (i.e., whole-island and moving-window metrics) and using an intermediate spatial scale $\left(9 \mathrm{~km}^{2}\right)$ contributes to an improved understanding of the importance of island environmental heterogeneity as a driver of diversity patterns. Our results lend strong support to one of the central premises of the GDM, namely that EH follows a hump-shaped relationship with island age. One important finding in this context was that EH peaked early in island ontogeny and declined more slowly over time than reflected in most models. This suggests that island maximum carrying capacity can be reached relatively fast and that it is maintained for a comparatively long time during island geological progression. This has strong implications for understanding insular species richness and endemism, as ecological opportunities and vacant niche space may remain available for several millions of years. Hence, EH plays an important role in determining the diversity of vascular plants on oceanic islands and including $\mathrm{EH}$ in the $\mathrm{ATT}^{2}$ model strongly affects its characteristics. Together, these results increase our understanding of how area, EH and time shape plant diversity and endemism on oceanic islands.

\section{Authors contributions}

MPBB, HK and PW conceived the idea. MPBB performed the analysis and PW supported the analysis. All co-authors contributed to the interpretation of the results and writing of the manuscript.

\section{Data availability}

Data analysed and produced in this study, i.e.,number of native and single-island endemic species, island age, area, archipelago information and EH metrics, as well as environmental components (elevation, precipitation, temperature and heat load index), heterogeneity rasters and the code for analyses in $R$ can be download from Dryad repository URL: https://datadryad.org/stash/share/xoxOp2qIVOub-qHcQaGK5R fgylOISKId55lalprQsA. Dataset doi:10.5061/dryad.6hdr7sqx4.

\section{Acknowledgements}


MPBB and HK acknowledge funding by the German Research Foundation (DFG) Research Training Group 1644 'Scaling Problems in Statistics', grant no. 152112243. MKB acknowledges grant DNRF96 for support of the Center for Macroecology, Evolution and Climate and Carlsberg Foundation: CF19-0695. GK was partially supported by an Alexander von Humboldt Foundation Fellowship for Experienced Researchers. 


\title{
CHAPTER V COLLABORATIVE PUBLICATIONS
}

In my PhD I collaborated with two PhD Students, who's works also focused on using a trait-based approach for investigating the diversity of Canary Island's plants. The first collaboration focused on evaluating the source of traits information, e.g., from scientific floras versus trait collected in the field. The second collaboration focused on understanding functional diversity patterns of different plant species groups of the Canary Islands (e.g., exotics and endemics) and relate the pattern to the climatic conditions of the islands.

\section{Scientific floras can be reliable sources for some trait data in a system with poor coverage in global trait databases}

Vanessa Cutts ${ }^{1}$, Dagmar M. Hanz ${ }^{2}$, Martha Paola Barajas-Barbosa ${ }^{3}$, Adam C. Algar ${ }^{1,4}$, Manuel J. Steinbauer ${ }^{5,6}$, Severin D. H. $\mid \mathbf{r l}^{2}$, Holger Kreft ${ }^{3}$, Patrick Weigelt ${ }^{3}$, Jose María Fernandez Palacios ${ }^{7}$, Richard Field ${ }^{1}$

My contribution: I provided the leaf trait data I collected in the field for 360 plant species. I supported the defining the trait data comparison from the field versus trait data from the literature. I supported the review and editing of different versions of the document.

Status: the paper has been accepted in the Journal of Vegetation Science and is going through the last proofreading process.

\begin{abstract}
Trait-based approaches are increasingly important in ecology and biogeography, but progress is often hampered by the availability of high-quality quantitative trait data collected in the field. Alternative sources of trait information include scientific floras and taxonomic monographs. Here we test the reliability and usefulness of trait data acquired from scientific floras against trait values measured in the field, and those in TRY, the most comprehensive global plant trait database. Study location was in Tenerife and La Palma, Canary Islands, Spain. We measured leaf area and specific leaf area (SLA) in the field for 451 native vascular plant species and compared them with equivalent trait data digitized from the most recent and comprehensive guide of the Canarian
\end{abstract}


flora, and data sourced from TRY. We regressed the field-measured traits against their equivalents estimated from the literature and used the regression models from one island to predict the trait values on the other island. For leaf area, linear models showed good agreement between values from the scientific flora and those measured in the field $\left(r^{2}=0.86\right)$. These models were spatially transferable across islands. In contrast, for specific leaf area we found a weak relationship between field-measured values and the best estimates from the scientific flora $\left(r^{2}=0.11\right)$. Insufficient data were available in the TRY database for our study area to calculate trait correlations with other data sources. Scientific floras can act as useful data sources for quantitative plant trait data for some traits but not others, whilst the TRY database contains many traits, but is incomplete in species coverage for our study region, and oceanic islands in general. 


\title{
Climatic and biogeographic drivers of functional diversity in the flora of the Canary Islands
}

Dagmar M. Hanz ${ }^{1}$, Vanessa Cutts², Martha Paola Barajas-Barbosa ${ }^{3}$, Adam C. Algar², Carl Beierkuhnlein ${ }^{4,5,6}$, José-María Fernández-Palacios ${ }^{7}$, Richard Field ${ }^{2}$, Holger Kreft ${ }^{3}$, Manuel J. Steinbauer ${ }^{8,9}$, Patrick Weigelt ${ }^{3}$ \& Severin D. H. $|r|^{1,5}$

My contribution: I supported the methodological part of the paper, i.e., implementation and interpretation of the functional diversity metrics used for the analysis. With the first and second Authors we conducted several discussions about the interpretation of the results. I supported the review and editing of different version of the document.

Status: the paper is in preparation. Target journal Global Ecology and Biogeography.

\begin{abstract}
Functional traits can help elucidate biogeographical and ecological processes driving community and assemblage structure. We analyzed the functional diversity of plant species of different evolutionary origins across an entire archipelago comparing them to each other along environmental gradients and across different phases of island ontogeny. The study area of this study is Canary Islands, Spain. We collected data for four traits (plant height, leaf length, flower length and fruit length) associated with resource allocation, reproduction and dispersal ability of 893 endemic, non-endemic native and alien plant species ( $43 \%$ of the Canary Island flora) from the literature. Linking these traits to species' occurrences across a $500 \mathrm{~m} \times 500 \mathrm{~m}$ grid, we calculated functional diversity for endemic, non-endemic native and alien assemblages using multi-dimensional functional hypervolumes, and related the resulting patterns to climatic (humidity) and island biogeographic (geographical isolation, topographic complexity, geological age) gradients. Trait space of endemic and non-endemic native species overlapped considerably, while alien species added novel trait combinations, expanding the overall hypervolume of the Canary Islands. On a grid cell scale, we found that functional diversity of endemic plant assemblages was highest in humid ecosystems at intermediate elevation, while functional diversity of non-endemic native assemblages was highest under humid conditions at mid- to high elevation sites. In contrast, functional diversity of alien assemblages was highest in arid coastal ecosystems. Topographic complexity and geological age only had a subordinate effect on
\end{abstract}


functional diversity across all floristic groups. We found that endemic and non-endemic native island species possess similar traits, while alien species tend to fill open niches in ecosystems where they have been introduced. The spatial distribution of the floristic groups' functional diversity is very distinct across environmental gradients, indicating that species assemblages of different evolutionary origins functionally thrive in dissimilar habitats. 


\section{CHAPTER VI SYNTHESIS}

The results of my PhD work evidence the relevance of oceanic islands as model systems to study patterns and drivers of functional diversity, as well as to study the complexity and heterogeneity of the environment shaping plant diversity. Concretely, the results of my PhD work (Chapter II) evidence how biogeography and evolution, and the environment determine the functional trait space and diversity of oceanic island plants. I found (Chapter II) that plants of an oceanic island experience the same ecological constraints as other plants on Earth. In particular, my results strongly suggest that Tenerife's arid and semi-arid environment causes functional convergence towards a trait syndrome, where plants coincide in the shrubby growth form. This convergence of traits placed Tenerife plants in between the two global functional hotspots (Díaz et al., 2016), that is, between small herbaceous and tall woody plants. Second, I evidence (Chapter III) that functional diversity is scale dependent and the trend across space between taxonomic diversity and functional diversity differ. The results from Chapter III further suggest that patterns of regional functional diversity scale-down to local scale and the processes driving functional diversity act differently depending on the spatial grain at which functional diversity is quantified. At small local grains $\left(100 \mathrm{~m}^{2}\right)$ species interactions may be affecting functional diversity, whereas at larger local grains $\left(1 \mathrm{~km}^{2}\right)$ the environment affects functional diversity. Third, I reveal (Chapter IV) how the environmental heterogeneity of oceanic islands, in terms of climate and topography vary along island ontogeny, where it follows a humped shape over time. This result indicates that island environments are highly dynamic and also that their environments rapidly become highly heterogeneous over time. This temporal dynamic of insular environmental heterogeneity affects plant diversity and endemism levels. To this end, I discuss and synthesize the contribution of my PhD work and how it improves the understanding of insular plant diversity in the following part of this synthesis.

\section{The assembly of an oceanic island flora from a functional diversity perspective}

Influential theories and concepts explaining how insular plant diversity assemble in space and time, i.e., Theory of Island Biogeography (MacArthur \& Wilson 1967) and the General Dynamic Model of Oceanic Island Biogeography (Whittaker et al., 2008) have assumed that species have the same probabilities to arrive and establish on an island. Yet, ecologists and island 
biogeographers have started thinking about species not only in terms of their identities but also in their functional traits (Díaz \& Cabido 2001; Westoby \& Wright 2006; Whittaker et al., 2017). This is relevant because the processes defining diversity are likely acting on species traits rather than one species per se (Weiher \& Keddy 1995; Kraft \& Ackerly 2014), thus, applying trait-based approaches are key to understanding insular diversity (Whittaker et al., 2017; Ottaviani et al., 2019). The results of Chapter II, where I describe for the first time (to my knowledge based on English and Spanish literature research) the plant functional trait space of a complete native flora, evidence how useful a trait-based approach is in island biogeography research. Namely to understand how biogeography, evolution and ecology determine species ecological strategies of insular environments.

The high convergence of a trait syndrome I found on Tenerife is responsible for the overrepresentation of shrubby plants on the island (Chapter II) and further evidences that ecological processes are the main drivers of the island's functional diversity, as shrubs adapt well to Mediterranean conditions. This result is consistent with seminal functional ecology studies that found habitat filtering and abiotic conditions limiting trait ranges and syndromes on mainland (kraft et al., 2007; Spasojevic \& Suding 2012; Kraft \& Ackerly 2014) and island systems (CarvajalEndara et al., 2017). Furthermore, I found both biogeography (via dispersal) and evolution (via speciation) differently shaping island plant functional diversity (Chapter II). On one hand, I found that both long-distance dispersal, i.e., the mechanism that populates island biota (Carlquist 1966; Carlquist 1981) and inter-island dispersal, i.e., species movements within an archipelago (Whittaker \& Fernández-Palacios 2007), are the mechanisms increasing Tenerife functional diversity. Concretely, they increase the overdispersion of trait combinations. On the other hand, I found that evolution via speciation has an opposite effect and drives underdispersion of the insular plant trait syndromes (Chapter II). The result contrasts previous hypotheses and expectations in island biogeography research (Patiño et al., 2017). Speciation, either via cladogenesis or anagenesis, (where an immigrant lineage splits into distinct species or it gradually changes into another species), increases species numbers (MacArthur \& Wilson 1967; Stuessy 1990). Particularly, in adaptive radiation where lineages rapidly multiply as species occupy new island niches (Schluter 2000; Gavrilets \& Losos 2009; Kavanagh \& Burns 2014), functional diversity should increase because species evolve new trait combinations to cope with new island environments (Carlquist, 1966; Givnish et al., 2009). Therefore, it is expected that through speciation, functional diversity increases. However, my results (Chapter II) suggest that on Tenerife speciation is not increasing island functional diversity. To understand this result, Tenerife 
environmental conditions have to be considered. The island's predominant Mediterranean climate is marked by drought seasons in the lowlands and aridity at high elevations (FernandezPalacios 1992). Such conditions favour speciation of shrubs, but also colonization, establishment of this type of plants (Carlquist 1974; Lens et al., 2013). Recent research on the Canary Islands found that the increase of woodiness (typical of shrubs) have allowed plants to cope better with the lack of water common of the canary ecosystems (Dória et al., 2018; Van Huysduynen et al., 2020). Traits converge as a water economy response of plants, where wood density (in this case relatively high for shrubs) positively relates to water transport efficiency, regulation of leaf water balance, and avoidance of turgor loss (Meinzer 2003). Lastly, these results are also in line with long-standing concepts of island research, stating that shrubs are better competitors in terms of resources than their herbaceous counterparts on islands (Darwin 1859).

The results of Chapter II suggest that oceanic island plants experience the same ecological, evolutionary and environmental constraints as other plants, as shown in the comparison of Tenerife with the global trait space of plant form and function (Díaz et al., 2016). Yet, the strong convergence of island plants towards shrubs is responsible for the clear mismatch I found between island and the global spectrum of plant forms and function. Tenerife flora is highly packed in between the two globally most dominant trait syndromes, i.e., plants with large seed and stature that grow slowly and live long, and plants that are short-statured with small seeds and do not live long (Díaz et al., 2016). This mismatch caused by the shrubby growth form is the response of plants adaptation to arid conditions. Therefore, the shrub growth form is advantageous on an oceanic island where an arid environment dominates.

\section{Functional diversity of an oceanic island across different spatial scales}

Biodiversity is scale dependent (Chase et al., 2018) and ecological and evolutionary processes determining it act differently across space (Leibold et al., 2004). Ecology studies have predominantly focused on the scale-dependency of taxonomic diversity (Crawley \& Harral 2001; Adler and Lauenroth 2003; Scheiner 2003; Chase \& Knight 2013; Chase et al., 2018) but few have focused on functional diversity (De Bello et al 2009; Whittaker et al., 2014; White et al., 2018), which limits the understanding about spatial patterns of functional diversity. The results of Chapter III expand the understanding about the variation of functional diversity across space and 
the factors governing functional diversity from regional to local scale on an oceanic island. As previously reported for taxonomic, phylogenetic and functional diversity (Morlon et al., 2011; Whittaker et al., 2014; Chase et al., 2018), the results of Chapter III also show that functional diversity is scale-dependent, whereby it increases with spatial grain. The results in Chapter III additionally show that functional diversity patterns across Tenerife vegetation types (areas defined by their climatic and altitudinal conditions) mirrored from local, within local and regional scale (alpha, beta and gamma functional diversity). This result demonstrates how regional ecological processes, such as the environmental filter imposed by each vegetation type, percolate down to determine local functional diversity. Furthermore, in Chapter III I found a large variation of functional diversity across Tenerife's vegetation types, which evidences how resource availability and climatic conditions of each type (Otto et al., 2007; Fernández-Palacios et al., 2014; Fernández-Palacios et al., 2017) drive the functional diversity of the island. The contrasting functional diversity values I found for laurel forest and summit scrub exemplify this (see details in the results Chapter III). While laurel forest, a resource rich area due to its large amount of rainfall and mild temperatures, has high functional diversity (Fernández-Palacios et al., 2017), summit scrub, a dry area with low temperatures, has low functional diversity.

The results of Chapter III, further revealed that the environment has a different effect on functional diversity across local grains. At a coarse local grain $\left(1 \mathrm{~km}^{2}\right)$ the environment (mainly temperature) significantly influenced functional diversity, whereas at a fine local grain $\left(100 \mathrm{~m}^{2}\right)$ the environment does not significantly affect functional diversity. This result suggests that while at coarse local grain ecological factors, such as environmental filtering shape functional diversity, at finer local grain species interactions, such as competition, may be playing a more important role (Cornwell \& Ackerly 2009). In addition, the variation of functional diversity across Tenerife's vegetation types evidence that high resource availability, in terms of energy and water availability, increases functional diversity (Spasojevic \& Suding 2012). Chapter III findings are also consistent with the hypothesis that habitat filter drives functional diversity (Cornwell et al., 2006; Mason et al., 2007; De Bello et al 2009); as well as with recently studies that found a strong coupling between climate, plant functional traits and life forms in the Canary Islands, where shrub (i.e., chamaephytes) showed a positive relationship with island temperature and trees a positive relationship with precipitation (Irl et al., 2020). Overall, the results I present in Chapter II and III are tightly related, as the environmental conditions of Tenerife drive the convergence of plant trait syndromes of Tenerife and the functional diversity differences across Tenerife vegetation types. 
Lastly, the work I performed for Chapter III where I transferred classical ecological analysis, i.e., species accumulation curve (Scheiner et al., 2011) to a functional diversity framework together with functional diversity partitioning, i.e., alpha, beta and gamma diversity (Whittaker 1972), prove that taxonomic diversity is not a surrogate for functional diversity. Both diversity facets are scale dependent but their trends across space differ. Functional diversity accumulates faster with increasing area than species diversity (Chapter III). Such a difference means that changes in species richness, for instance species impoverishment, can lead to drastic changes in functional diversity, i.e., loss of key functional groups and ecosystems functioning (Díaz \& Cabido 2001; Gonzalez et al., 2020).

\section{Temporal dynamic of environmental heterogeneity on oceanic islands and its effect on plant diversity}

In Chapter IV, I studied the dynamics of environmental heterogeneity during the ontogeny of oceanic islands (i.e., island development through its geological life span from emergence, building, advanced age to island submergence) and how these dynamics affect insular plant diversity. I used the General Dynamic Model (Whittaker et al., 2008), which links island geological ontogeny to ecological processes driving insular diversity. Both area and environmental heterogeneity are expected to have a hump-shaped relationship with time, where mid-aged islands reach the highest environmental heterogeneity level (Whittaker et al., 2008). The dynamic of island area over island life-span had been previously assessed (Steinbauer et al., 2013; Borregaard et al., 2017). However, previous to my PhD work, the temporal dynamics and effects of environmental heterogeneity on insular diversity remained unresolved. Correct estimations of environmental heterogeneity are not trivial (Barajas-Barbosa et al., 2020); capturing the variability of the environment that affects plant diversity poses challenges, such as controlling the effect of area on environmental heterogeneity. I tackled these challenges by calculating 20 ecologically meaningful metrics (termed as 'EH-metrics') that estimated environmental heterogeneity, in terms of climate and topography, for 135 oceanic islands distributed across the globe. I identified spatially suitable EH-metrics for oceanic island sizes, as oceanic islands are generally small landmasses, and I considered the dependency of environmental heterogeneity on area (Jackson \& Fahrig 2015). As environmental heterogeneity encompasses different aspects (Stein et al., 2015), I included climate and topography in the assessment. The resulting EH-metrics captured different aspects of environmental heterogeneity, such as climatic and topographic ranges versus climatic and 
topographic complexity. The EH-metrics calculation allowed me to test the dynamic of environmental heterogeneity in the context of the General Dynamic Model (Whittaker et 2008). In the results of Chapter IV, I identified that oceanic island environments rapidly become highly heterogeneous (in their first Million years). In fact, much faster than previously depicted by the General Dynamic Model, which had predicted intermediate age islands (between 4 to 10 Million years) to have the highest environmental heterogeneity values. This temporal dynamic of environmental heterogeneity has direct implications on the levels of plant diversity of oceanic islands, as environmental heterogeneity can be understood as island carrying capacity (Whittaker et al., 2007; Borregaard et al., 2017).

Heterogeneous environments have different climatic niches where new plants can establish, large numbers of species can coexist and persist and species can diversify (Hortal et al., 2013; Stein et al., 2014). The positive effect I found between EH-metrics and plant diversity (after controlling for the effect of island area, see results Chapter IV) also suggest that plant diversity levels of an oceanic island rapidly increase during island ontogeny (Barajas-Barbosa et al., 2020). The results of Chapter IV, are consistent with previous studies that have found plant diversity being high at early stages of island ontogeny (Steinbauer et al., 2013; Lenzner et al., 2017). Further, these results also indicate that island maximum environmental heterogeneity, in other words island carrying capacity, is rapidly reached and maintains high levels for a long period of the island's life-span. This influences the ecological opportunities and vacant niche space, which remain available for several millions of years.

\section{The importance trait-based approaches and future perspectives}

Trait-based approaches are gaining importance and major advances in functional ecology research have been achieved (Wright et al., 2004; Moles et al., 2009; Bjorkman et al., 2018). The globalspectrum of plant form and function (Díaz et al., 2016) and trait-environment relationships (Bruelheide et al., 2018) are great examples of this progress. Such studies have mainly used trait data gathered in databases (e.g., TRY Kattge et al., 2020), which have been collected with different purposes in mind. The trait data has been then used for synthesis analyses, which have mostly focused on mainland systems. Functional island biogeography, on the other hand, is still an emerging research field (Whittaker et al., 2014; Ottaviani et al., 2020) but we still lack empirical 
measurements of functional traits of island biota (although see Schrader et al., 2020; Kühn et al., 2021; Westerband et al., 2021). The scarcity of systematically collected functional traits on oceanic islands was the principal motivation for the unique and nearly complete sampling of plant functional traits I performed on Tenerife. The plant data I collected was not only used for the development of the main objectives of my PhD work (i.e., Chapter II and III) but was also key for the collaborations during my PhD (Chapter V). It allowed us to test the usefulness of alternative sources for plant trait information, such as scientific floras and taxonomic monographs; when insitu trait sampling is not possible to conduct. The Tenerife trait data can continue being used for future collaborations and to address research questions in the fields of functional island biogeography and functional ecology. Potential research questions that can be addressed are: in which direction is evolution (via adaptive radiation) driving plant diversity of oceanic islands? This question can be addressed by reconstructing ancestral traits of the radiated lineages present on Tenerife and comparing them with the traits I collected for these species of the lineages. Can contemporary insular plant communities and ecosystems adapt to arid environments cope with global warming? This can be addressed by focusing on the functional diversity of the coastal scrub and thermophilous woodland vegetation type of Tenerife and relating it to climate change trends. Furthermore, because mountain systems contain very high species diversity (Rahbek et al., 2019) and Tenerife has a steep and large elevation range, research questions in this topic can also be addressed; for instance, how functional diversity relates to an oceanic island elevational gradient and does elevation affect functional and taxonomic diversity equality? This last research question is also an opportunity to investigate functional diversity in relation to island geodiversity.

\section{Conclusion}

I summarized the key take-home messages from my $\mathrm{PhD}$ work hereafter. Biogeography (via dispersal), evolution (via speciation) and ecology (via environmental filtering) are key processes driving the functional diversity of an oceanic island native flora. Yet, these processes differently affect functional diversity, namely functional diversity increases through dispersal events, decreases due to environmental filters and does not necessarily increase with speciation process. Plant trait syndromes of an oceanic island flora are similar to the previously documented syndromes for the globe, but environmental filters can drive a strong convergence of a plant trait syndrome (e.g., overrepresentation of shrubs in Tenerife). Plant functional diversity patterns of oceanic island are scale-dependent and these patterns percolate from regional to local scales. The 
environmental conditions (mainly Tenerife temperature) impact local functional diversity, but the impacts are not always consistent across local grains. Importantly, functional and taxonomic diversity increase differently across space. Therefore, taxonomic diversity is not a complete surrogate for functional diversity. Lastly, environmental heterogeneity, a key factor determining species diversity, exhibits a hump-shaped relationship with island age; however earlier than previous research had hypothesized. Overall, my PhD work demonstrates the relevance of studying different biodiversity facets. Taxonomic and functional diversity are tightly related to ecosystem functioning and services and their spatial dynamics allows us to understand how ecosystems and biodiversity respond to environmental change. My work further reveals that unifying theories of island biogeography and classical concepts and methods of ecology allow us to improve our understanding about the diversity of the insular plants. 


\section{REFERENCES}

Acebes Ginovés JR, León Arencibia MC, Rodríguez Navarro ML, et al. (2010). Spermatophyta. In: Arechavaleta M, Rodríguez S, Zurita N, García A, eds. Lista de especies silvestres de Canarias. Hongos, plantas y animales terrestres 2009. Santa Cruz de Tenerife: Gobierno de Canarias, 122172.

Acevedo-Rodríguez, P., \& Strong, M. T. (2007). Catalogue of the seed plants of the West Indies Website. Retrieved from http://botany. si.edu/antilles/Westlndies/index.htm Accessed $1 / 3 / 2011$.

Ackerly, D. D., \& Cornwell, W. K. (2007). A trait-based approach to community assembly: partitioning of species trait values into within-and among-community components. Ecology letters, 10(2), 135-145.

Adler, P. B., \& Lauenroth, W. K. (2003). The power of time: spatiotemporal scaling of species diversity. Ecology letters, 6(8), 749-756.

Ah-Peng, C., Flores, O., Wilding, N., Bardat, J., Marline, L., Hedderson, T. A., \& Strasberg, D. (2014). Functional diversity of subalpine bryophyte communities in an oceanic island (La Réunion). Arctic, Antarctic, and Alpine Research, 46(4), 841-851.

Albrecht, J., Classen, A., Vollstädt, M. G., Mayr, A., Mollel, N. P., Costa, D. S., ... \& Schleuning, M. (2018). Plant and animal functional diversity drive mutualistic network assembly across an elevational gradient. Nature communications, 9(1), 1-10.

Ali, J.R. (2017) Islands as biological substrates: classification of the biological assemblage components and the physical island types. Journal of Biogeography, 44, 984-994.

Ali, J.R. \& Aitchison, J.C. (2014) Exploring the combined role of eustasy and oceanic island thermal subsidence in shaping biodiversity on the Galápagos. Journal of Biogeography, 41, 12271241.

Allouche, O., Kalyuzhny, M., Moreno-Rueda, G., Pizarro, M., \& Kadmon, R. (2012) Areaheterogeneity tradeoff and the diversity of ecological communities. Proceedings of the National Academy of Sciences of the United States of America, 109, 17495-17500.

Amatulli, G., Domisch, S., Tuanmu, M. N., Parmentier, B., Ranipeta, A., Malczyk, J., \& Jetz, W. (2018). A suite of global, cross-scale topographic variables for environmental and biodiversity modeling. Scientific data, 5(1), 1-15.

Antonelli, A., Kissling, W.D., Flantua, S.G.A., Bermúdez, M.A., Mulch, A., Muellner-Riehl, A.N., Kreft, H., Linder, H.P., Badgley, C., Fjeldså, J., Fritz, S.A., Rahbek, C., Herman, F., Hooghiemstra, H., \& Hoorn, C. (2018) Geological and climatic influences on mountain biodiversity. Nature Geoscience, 11, 718-725.

Arechavaleta, M., M., Zurita, N., Marrero, M. C., \& Martín, J. L. (2005). Lista preliminar de especies silvestres de Cabo Verde (hongos, plantas y animales terrestres). Santa Cruz de Tenerife, Spain: Consejería de Medio Ambiente y Ordenación Territorial, Gobierno de Canarias

Arechavaleta, M., Rodríguez, S., Zurita, N., \& García, A. (2009). Lista de especies silvestres de Canarias. Hongos, plantas y animals terrestres. Santa Cruz de Tenerife, Spain: Consejería de Medio Ambiente y Ordenación Territorial, Gobierno de Canarias.

Arrhenius, O. (1921). Species and area. Journal of Ecology, 9(1), 95-99. 
Ashmole, P., \& Ashmole, M. (2000). St Helena and Ascension Island: A natural history. Oswestry, Shropshire, UK: Anthony Nelson Ltd.

Badgley, C., Smiley, T.M., Terry, R., Davis, E.B., DeSantis, L.R.G., Fox, D.L., Hopkins, S.S.B., Jezkova, T., Matocq, M.D., Matzke, N., McGuire, J.L., Mulch, A., Riddle, B.R., Roth, V.L., Samuels, J.X., Strömberg, C.A.E., \& Yanites, B.J. (2017) Biodiversity and Topographic Complexity: Modern and Geohistorical Perspectives. Trends in Ecology and Evolution, 32, 211-226.

Barajas-Barbosa, M. P., Weigelt, P., Borregaard, M. K., Keppel, G., \& Kreft, H. (2020). Environmental heterogeneity dynamics drive plant diversity on oceanic islands. Journal of Biogeography, 47(10), 2248-2260.

Barthlott, W., Mutke, J., Rafiqpoor, M., Kier, G., \& Kreft, H. (2005) Global centers of vascular plant diversity. Nova Acta Leopoldina NF, 92(342), 61-83.

Bartoń, K. (2018) MuMIn: multi-model inference. R package version 1.42.1. URL: https://cran.rproject.org/web/packages/MuMln/index.html.

Bässler, C., Cadotte, M. W., Beudert, B., Heibl, C., Blaschke, M., Bradtka, J. H., ... \& Müller, J. (2016). Contrasting patterns of lichen functional diversity and species richness across an elevation gradient. Ecography, 39(7), 689-698.

Bender, I. M., Kissling, W. D., Böhning-Gaese, K., Hensen, I., Kühn, I., Nowak, L., ... \& Schleuning, M. (2019). Projected impacts of climate change on functional diversity of frugivorous birds along a tropical elevational gradient. Scientific reports, 9(1), 1-12.

Benjamin Blonder. (2019). R Pakcage: Hypervolume: High Dimensional Geometry and Set Operations Using Kernel Density Estimation, Support Vector Machines, and Convex Hulls

BGCl (2017). GlobalTreeSearch online database. Retrieved from www.bgci.org/globaltree_search.php Accessed 14/08/2017.

Biddick, M., Hendriks, A., \& Burns, K. C. (2019). Plants obey (and disobey) the island rule. Proceedings of the National Academy of Sciences, 116(36), 17632-17634.

Bjorkman, A. D., Myers-Smith, I. H., Elmendorf, S. C., Normand, S., Rüger, N., Beck, P. S., ... \& Weiher, E. (2018). Plant functional trait change across a warming tundra biome. Nature, 562(7725), 57-62.

Blonder, B. (2016). Do hypervolumes have holes?. The American Naturalist, 187(4), E93-E105.

Blonder, B., Morrow, C. B., Maitner, B., Harris, D. J., Lamanna, C., Violle, C., ... \& Kerkhoff, A. J. (2018). New approaches for delineating $n$-dimensional hypervolumes. Methods in Ecology and Evolution, 9(2), 305-319.

Bohle, U.R., Hilger, H.H., \& Martin, W.F. (1996) Island colonization and evolution of the insular woody habit in Echium L. (Boraginaceae). Proceedings of the National Academy of Sciences, 93, 11740-11745.

Bond, E. M., \& Chase, J. M. (2002). Biodiversity and ecosystem functioning at local and regional spatial scales. Ecology letters, 5(4), 467-470.

Bonetti, S., Hooshyar, M., Camporeale, C., \& Porporato, A. (2020) Channelization cascade in landscape evolution. Proceedings of the National Academy of Sciences of the United States of America, 117, 1375-1382.

Borges, P. A. V., Abreu, C., Aguiar, A. M. F., Carvalho, P., Jardim, R., Melo, I., ... Vieira, P. (2008). Listagem dos fungos, flora e fauna terrestres dos arquipélagos da Madeira e Selvagens. Funchal 
and Angra do Heroísmo, Portugal: Direcção Regional do Ambiente da Madeira and Universidade dos Açores.

Borges, P. A. V., Costa, A., Cunha, R., Gabriel, R., Gonçalves, V., Martins, A. F., ... Vieira, V. (2010). $A$ list of the terrestrial and marine biota from the Azores. Cascais: Princípia

Borregaard, M. K., Amorim, I. R., Borges, P. A., Cabral, J. S., Fernández-Palacios, J. M., Field, R., ... \& Whittaker, R. J. (2017). Oceanic island biogeography through the lens of the general dynamic model: assessment and prospect. Biological Reviews, 92(2), 830-853.

Borregaard, M.K., Matthews, T.J., \& Whittaker, R.J. (2016) The general dynamic model: towards a unified theory of island biogeography? Global Ecology and Biogeography, 25, 805-816.

Brofas, G., Karetsos, G., Panitsa, M., \& Theocharopoulos, M. (2001). The flora and vegetation of Gyali Island, SE Aegean, Greece. Willdenowia, 31, 51-70.

Bruelheide, H., Dengler, J., Purschke, O., Lenoir, J., Jiménez-Alfaro, B., Hennekens, S. M., ... \& Jandt, U. (2018). Global trait-environment relationships of plant communities. Nature ecology \& evolution, 2(12), 1906-1917.

Bunnefeld, N. \& Phillimore, A.B. (2012) Island, archipelago and taxon effects: mixed models as a means of dealing with the imperfect design of nature's experiments. Ecography, 35, 15-22.

Burns, K. C. (2019). Evolution in isolation: the search for an island syndrome in plants. Cambridge University Press.

Burton, R. M. (1991). A check-list and evaluation of the flora of Nisyros (Dodecanese, Greece). Willdenowia, 20, 15-38.

Byrd, G. V. (1984). Vascular vegetation of Buldir Island, Aleutian Islands, Alaska, compared to another Aleutian Island. Arctic, 37, 37-48.

Cadotte, M. W., Carscadden, K., \& Mirotchnick, N. (2011). Beyond species: functional diversity and the maintenance of ecological processes and services. Journal of applied ecology, 48(5), 1079-1087.

Cadotte, M., Albert, C. H., \& Walker, S. C. (2013). The ecology of differences: assessing community assembly with trait and evolutionary distances. Ecology letters, 16(10), 1234-1244.

Carlquist, S. (1966). The biota of long-distance dispersal. II. Loss of dispersibility in Pacific Compositae. Evolution, 20(1), 30-48.

Carlquist, S. (1974). Island biology-Columbia University Press. New York, USA.

Carlquist, S. (1981). Chance dispersal: long-distance dispersal of organisms, widely accepted as a major cause of distribution patterns, poses challenging problems of analysis. American Scientist, 69(5), 509-516.

Carlquist, S. J. (1974). Island biology. Columbia University Press.

CARMABI (2009). Dutch Caribbean Biodiversity Explorer. Retrieved from http://www.dcbiodata.net/explorer/home Accessed 24/06/2011.

Carracedo, J.C. (1994) The Canary Islands: an example of structural control on the growth of large oceanic-island volcanoes J.C. Journal of Volcanology and Geothermal Research, 60, 225241.

Carracedo, J.C., Guillou, H., Nomade, S., Rodríguez-Badiola, E., Pérez-Torrado, F.J., RodríguezGonzález, A., Paris, R., Troll, V.R., Wiesmaier, S., Delcamp, A., \& Fernández-Turiel, J.L. (2011) 
Evolution of Ocean-Island rifts: The northeast rift zone of Tenerife, Canary Islands. Bulletin of the Geological Society of America, 123, 562-584.

Carvajal-Endara, S., Hendry, A. P., Emery, N. C., \& Davies, T. J. (2017). Habitat filtering not dispersal limitation shapes oceanic island floras: species assembly of the Galápagos archipelago. Ecology Letters, 20(4), 495-504.

Case, T. J., Cody, M. L., \& Ezcurra, E. (2002). A new island biogeography of the Sea of Cortés. New York, NY: Oxford University Press.

Cavender-Bares, J., Ackerly, D. D., Baum, D. A., \& Bazzaz, F. A. (2004). Phylogenetic overdispersion in Floridian oak communities. The American Naturalist, 163(6), 823-843. Species occurring in similar environmental conditions are likely to share functional traits because of the effect of process of environmental filtering.

Chao, A., Chiu, C. H., Villéger, S., Sun, I. F., Thorn, S., Lin, Y. C., ... \& Sherwin, W. B. (2019). An attribute-diversity approach to functional diversity, functional beta diversity, and related (dis) similarity measures. Ecological monographs, 89(2), e01343.

Chase, J. M. (2014). Spatial scale resolves the niche versus neutral theory debate. Journal of vegetation science, 25(2), 319-322.

Chase, J. M., \& Knight, T. M. (2013). Scale-dependent effect sizes of ecological drivers on biodiversity: why standardised sampling is not enough. Ecology letters, 16, 17-26.

Chase, J. M., \& Leibold, M. A. (2002). Spatial scale dictates the productivity-biodiversity relationship. Nature, 416(6879), 427-430.

Chase, J. M., \& Leibold, M. A. (2009). Ecological niches. University of Chicago Press.

Chase, J. M., McGill, B. J., McGlinn, D. J., May, F., Blowes, S. A., Xiao, X., ... \& Gotelli, N. J. (2018). Embracing scale-dependence to achieve a deeper understanding of biodiversity and its change across communities. Ecology letters, 21(11), 1737-1751.

Chase, J. M., McGill, B. J., Thompson, P. L., Antão, L. H., Bates, A. E., Blowes, S. A., ... \& O'Connor, M. (2019). Species richness change across spatial scales. Oikos, 128(8), 1079-1091.

Chernyaeva, A. M. (1973). Flora of Onekotan Island. Bulletin of Main Botanical Garden, 87, 2129.

Chiarucci, A., Bacaro, G., Rocchini, D., \& Fattorini, L. (2008). Discovering and rediscovering the sample-based rarefaction formula in the ecological literature. Community Ecology, 9(1), 121123.

Christmas Island National Park. (2002). Third Christmas Island national park management plan. Christmas Island, Australia: Parks Australia North.

Clarke, A., \& Gaston, K. J. (2006). Climate, energy and diversity. Proceedings of the Royal Society B: Biological Sciences, 273(1599), 2257-2266.

Colwell, R. K., Brehm, G., Cardelús, C. L., Gilman, A. C., \& Longino, J. T. (2008). Global warming, elevational range shifts, and lowland biotic attrition in the wet tropics. science, 322(5899), 258261.

Cornwell, W. K., \& Ackerly, D. D. (2009). Community assembly and shifts in plant trait distributions across an environmental gradient in coastal California. Ecological Monographs, 79(1), 109-126. 
Cornwell, W. K., Pearse, W. D., Dalrymple, R. L., \& Zanne, A. E. (2019). What we (don't) know about global plant diversity. Ecography, 42(11), 1819-1831

Cornwell, W. K., Schwilk, D. W., \& Ackerly, D. D. (2006). A trait-based test for habitat filtering: convex hull volume. Ecology, 87(6), 1465-1471.

Cramer, M.D. \& Verboom, G.A. (2017) Measures of biologically relevant environmental heterogeneity improve prediction of regional plant species richness. Journal of Biogeography, 44, 579-591.

Craven, D., Knight, T. M., Barton, K. E., Bialic-Murphy, L., \& Chase, J. M. (2019). Dissecting macroecological and macroevolutionary patterns of forest biodiversity across the Hawaiian archipelago. Proceedings of the National Academy of Sciences, 116(33), 16436-16441.

Crawley, M. J., \& Harral, J. E. (2001). Scale dependence in plant biodiversity. Science, 291(5505), 864-868.

Crews, T.E., Kitayama, K., Fownes, J.H., Riley, R.H., Herbert, D.A., Mueller-Dombois, D., \& Vitousek, P.M. (1995) Changes in Soil Phosphorus Fractions and Ecosystem Dynamics across a Long Chronosequence in Hawaii. Ecology, 76, 1407-1424.

Cronk, Q. C. B. (1989). The past and present vegetation of St Helena. Journal of Biogeography, 16, 47-64.

Darwin, C. (2016). On the origin of species, 1859.

de Bello, F., Price, J. N., Münkemüller, T., Liira, J., Zobel, M., Thuiller, W., ... \& Pärtel, M. (2012). Functional species pool framework to test for biotic effects on community assembly. Ecology, 93(10), 2263-2273.

De Nascimento, L., Willis, K. J., Fernández-Palacios, J. M., Criado, C., \& Whittaker, R. J. (2009). The long-term ecology of the lost forests of La Laguna, Tenerife (Canary Islands). Journal of Biogeography, 36(3), 499-514.

Del Arco, M. J., Wildpret De La Torre, W., Perez de Paz, P. L., Rodriguez Delgado, O., Acebes Ginovez, J., R., Garcia gallo, A., Martin Osorio, V. E., Reyes Betancort, J. A., Salas Pacual, M., Diaz, M. A., Bermejo Dominguez, J. A., Gonzales Gonzales, R., Cabrera Lacalzada and Garcia Avila, S., (2006). Mapa de vegetación de Canarias. Grafcan. Santa Cruz de Tenerife.

Díaz, S., Kattge, J., Cornelissen, J. H., Wright, I. J., Lavorel, S., Dray, S., ... \& Gorné, L. D. (2016). The global spectrum of plant form and function. Nature, 529(7585), 167-171.

Díaz, S., Settele, J., Brondízio, E. S., Ngo, H. T., Agard, J., Arneth, A., ... \& Zayas, C. N. (2019). Pervasive human-driven decline of life on Earth points to the need for transformative change. Science, 366(6471).

Díaz, S., \& Cabido, M. (2001). Vive la différence: plant functional diversity matters to ecosystem processes. Trends in ecology \& evolution, 16(11), 646-655.

Dobrowski, S.Z., Abatzoglou, J.T., Greenberg, J.A., \& Schladow, S.G. (2009) How much influence does landscape-scale physiography have on air temperature in a mountain environment? Agricultural and Forest Meteorology, 149, 1751-1758.

Dória, L. C., Podadera, D. S., del Arco, M., Chauvin, T., Smets, E., Delzon, S., \& Lens, F. (2018). Insular woody daisies (Argyranthemum, Asteraceae) are more resistant to drought-induced hydraulic failure than their herbaceous relatives. Functional Ecology, 32(6), 1467-1478. 
Du Puy, D. J. (1993). Christmas Island: species lists. Retrieved from http://www.anbg.gov.au/abrs/online-resources/flora/ Accessed 06/04/2011.

Dufour, A., Gadallah, F., Wagner, H.H., Guisan, A., \& Buttler, A. (2006) Plant species richness and environmental heterogeneity in a mountain landscape: effects of variability and spatial configuration. Ecography, 29, 573-584.

Egorova, E. M. (1964). Flora of Shiashkotan Island. Bulletin of the Main Botanical Garden, 54, 114-120.

Emerson, B. C., \& Gillespie, R. G. (2008). Phylogenetic analysis of community assembly and structure over space and time. Trends in ecology \& evolution, 23(11), 619-630.

Evans, J.S., Oakleaf, J., \& Cushman, S.A. (2014) An ArcGIS Toolbox for Surface Gradient and Geomorphometric Modeling, version 2.0-0. URL:

https://github.com/jeffreyevans/GradientMetrics.

Exell, A. W. (1944). Catalogue of the vascular plants of S. Tome (with Principe and Annobon). London, UK: Trustees of the British Museum.

Fernández-Palacios, J. M., Arévalo, J. R., Balguerías, E., Barone, R., De Nascimento, L., Elias, R. B., ... \& Otto, R. (2017). La Laurisilva. Canarias, Madeira y Azores.

Fernández-Palacios, J. M., Otto, R., Thebaud, C., \& Price, J. (2014). Overview of habitat history in subtropical oceanic island summit ecosystems. Arctic, Antarctic, and Alpine Research, 46(4), 801809.

Fernández-Palacios, J.M. (1992) Climatic responses of plant species on Tenerife, The Canary Islands. Journal of Vegetation Science, 3, 595-603.

Fernández-Palacios, J.M., Otto, R., Thebaud, C., \& Price, J. (2014) Overview of Habitat History in Subtropical Oceanic Island Summit Ecosystems. Arctic, Antarctic, and Alpine Research, 46, 801809.

Fernández-Palacios, J. M. (1992). Climatic responses of plant species on Tenerife, The Canary Islands. Journal of Vegetation Science, 3(5), 595-603.

Fernández-Palacios, J. M., \& de Nicolás, J. P. (1995). Altitudinal pattern of vegetation variation on Tenerife. Journal of Vegetation Science, 6(2), 183-190.

Ferrier, K., Perron, J.T., Mukhopadhyay, S., Rosener, M., Stock, J.D., Huppert, K.L., \& Slosberg, M. (2011) Erosion rates across a steep rainfall gradient on Kauai over 5 year to 5 million year timescales. American Geophysical Union, Fall Meeting 2011 Abstracts.

Ferrier, K.L., Huppert, K.L., \& Perron, J.T. (2013) Climatic control of bedrock river incision. Nature, 496, 206-209.

Florence, J., Chevillotte, H., Ollier, C., \& Meyer, J.-Y. (2007). Base de données botaniques Nadeaud de l'Herbier de la Polynésie française (PAP). Retrieved from http://www.herbiertahiti.pf/ Accessed 01/07/2011.

Foster, B. J. 1964. Evolution of mammals on islands. Nature 202:234-235.

Franco, M., \& Silvertown, J. (1996). Life history variation in plants: an exploration of the fast-slow continuum hypothesis. Philosophical Transactions of the Royal Society of London. Series B:

Biological Sciences, 351(1345), 1341-1348. 
Franklin, J., Keppel, G., \& Whistler, W. A. (2008). The vegetation and flora of Lakeba, Nayau and Aiwa islands, central Lau Group, Fiji. Micronesica, 40, 169-225.

Gavrilets, S., \& Losos, J. B. (2009). Adaptive radiation: contrasting theory with data. Science, 323(5915), 732-737.

Giambelluca, T.W., Chen, Q., Frazier, A.G., Price, J.P., Chen, Y.-L., Chu, P.-S., Eischeid, J.K., \& Delparte, D.M. (2013) Online Rainfall Atlas of Hawai'i. Bulletin of the American Meteorological Society, 94, 313-316.

Gillespie, R. G. (2007). Oceanic islands: models of diversity. Encyclopedia of biodiversity, 1-13.

Gillespie, R. G., \& Baldwin, B. G. (2010). Island biogeography of remote archipelagoes. The theory of island biogeography revisited, 358-387.

Gillespie, R.G. \& Roderick, G.K. (2014) Evolution: Geology and climate drive diversification. Nature, 509, 297-298.

Girma, Z., Chuyong, G., Evangelista, P., \& Mamo, Y. (2018). Vascular plant species composition, relative abundance, distribution, and threats in Arsi Mountains National Park, Ethiopia. Mountain Research and Development, 38(2), 143-152.

Givnish, T. J. (1995). Plant stems: biomechanical adaptation for energy capture and influence on species distributions. In Plant stems (pp. 3-49). Academic Press

Givnish, T. J., Millam, K. C., Mast, A. R., Paterson, T. B., Theim, T. J., Hipp, A. L., ... \& Sytsma, K. J. (2009). Origin, adaptive radiation and diversification of the Hawaiian lobeliads (Asterales: Campanulaceae). Proceedings of the Royal Society B: Biological Sciences, 276(1656), 407-416.

Gonzalez, A., Germain, R. M., Srivastava, D. S., Filotas, E., Dee, L. E., Gravel, D., ... \& Loreau, M. (2020). Scaling-up biodiversity-ecosystem functioning research. Ecology Letters, 23(4), 757-776.

Gotelli, N. J., \& Colwell, R. K. (2001). Quantifying biodiversity: procedures and pitfalls in the measurement and comparison of species richness. Ecology letters, 4(4), 379-391.

Götzenberger, L., de Bello, F., Bråthen, K. A., Davison, J., Dubuis, A., Guisan, A., ... \& Zobel, M. (2012). Ecological assembly rules in plant communities-approaches, patterns and prospects. Biological reviews, 87(1), 111-127.

Graham, N. R., Gruner, D. S., Lim, J. Y., \& Gillespie, R. G. (2017). Island ecology and evolution: challenges in the Anthropocene. Environmental Conservation, 44(4), 323-335.

Gray, A., Pelembe, T., \& Stroud, S. (2005). The conservation of the endemic vascular flora of Ascension Island and threats from alien species. Oryx, 39, 449-453.

Green, P. S. (1994a). Lord Howe Island: species lists. Retrieved from http://www.environment.gov.au/biodiversity/abrs/online-resources/flora/49/index.html Accessed 06/04/2011.

Green, P. S. (1994b). Norfolk Island: Species lists. Retrieved from http://www.environment.gov.au/biodiversity/abrs/online-resources/flora/49/index.html Accessed 06/04/2011.

Greene, S. W., \& Walton, D. W. H. (1975). An annotated check list of the sub-Antarctic and Antarctic vascular flora. Polar Record, 17, 473-484.

Grime, J. P. (1979, November). Primary strategies in plants. In Transactions of the Botanical Society of Edinburgh (Vol. 43, No. 2, pp. 151-160). Taylor \& Francis Group. 
Hagen-Zanker, A. (2016) A computational framework for generalized moving windows and its application to landscape pattern analysis. International Journal of Applied Earth Observation and Geoinformation, 44, 205-216.

Harrison, X.A. (2014) Using observation-level random effects to model overdispersion in count data in ecology and evolution. PeerJ, 2, e616.

Harrison, X.A. (2015) A comparison of observation-level random effect and Beta-Binomial models for modelling overdispersion in Binomial data in ecology \&amp; evolution. PeerJ, 3 , e1114.

Harrison, X.A., Donaldson, L., Correa-Cano, M.E., Evans, J., Fisher, D.N., Goodwin, C.E.D., Robinson, B.S., Hodgson, D.J., \& Inger, R. (2018) A brief introduction to mixed effects modelling and multi-model inference in ecology. PeerJ, 6, e4794.

Hartig, F. (2019) DHARMa: Residual Diagnostics for Hierarchical (Multi-Level / Mixed) Regression Models. R package version 0.2.6. URL: https://CRAN.R-project.org/package=DHARMa.

Hartig, F. (2019). DHARMa: residual diagnostics for hierarchical (multi-level/mixed) regression models. R package version $0.2,4$.

He, S., Zhong, Y., Sun, Y., Su, Z., Jia, X., Hu, Y., \& Zhou, Q. (2017) Topography-associated thermal gradient predicts warming effects on woody plant structural diversity in a subtropical forest. Scientific Reports, 7, 40387.

Heaney, L. R. (2007). Is a new paradigm emerging for oceanic island biogeography?

Heaney, L.R. (2000) Dynamic disequilibrium: a long-term, large-scale perspective on the equilibrium model of island biogeography. Global Ecology and Biogeography, 9, 59-74.

Hertel, D. (2011). Tree roots in canopy soils of old European beech trees-An ecological reassessment of a forgotten phenomenon. Pedobiologia, 54(2), 119-125.

Hertel, D. (2011). Tree roots in canopy soils of old European beech trees-An ecological reassessment of a forgotten phenomenon. Pedobiologia, 54(2), 119-125.

Hijmans, R.J., van Etten, J., Cheng, J., Mattiuzzi, M., Sumner, M., Greenberg, J.A., Lamigueiro, O.P., Bevan, A., Racine, E.B., \& Shortridge, A. (2018) Raster: Geographic Data Analysis and Modeling. R package version 3.0-12. URL: https://CRAN.R-project.org/package=raster. $R$ package.

Hnatiuk, R. J. (1993). Subantarctic Islands: species lists. Retrieved from http://www.environment.gov.au/biodiversity/abrs/online-resources/flora/50/index.html Accessed 07/04/2011.

Hoorn, C., Mosbrugger, V., Mulch, A., \& Antonelli, A. (2013) Biodiversity from mountain building. Nature Geoscience, 6, 154-154.

Hortal, J., Carrascal, L. M., Triantis, K. A., Thébault, E., Meiri, S., \& Sfenthourakis, S. (2013). Species richness can decrease with altitude but not with habitat diversity. Proceedings of the National Academy of Sciences, 110(24), E2149-E2150.

Hortal, J., Triantis, K. A., Meiri, S., Thébault, E., \& Sfenthourakis, S. (2009). Island species richness increases with habitat diversity. The American Naturalist, 174(6), E205-E217.

Hui, C. (2006) Carrying capacity, population equilibrium, and environment's maximal load. Ecological Modelling, 192, 317-320. 
Imada, C. T. (Ed.) (2012). Hawaiian Native and Naturalized Vascular Plants Checklist (December 2012 update). Bishop Musem Technical Report: Vol. 60. Honolulu, Hawai'i: Hawaii Biological Survey, Bishop Museum

Irl, S. D., Harter, D. E., Steinbauer, M. J., Gallego Puyol, D., Fernández-Palacios, J. M., Jentsch, A., \& Beierkuhnlein, C. (2015). Climate vs. topography-spatial patterns of plant species diversity and endemism on a high-elevation island. Journal of Ecology, 103(6), 1621-1633.

Irl, S. D., Obermeier, A., Beierkuhnlein, C., \& Steinbauer, M. J. (2020). Climate controls plant lifeform patterns on a high-elevation oceanic island. Journal of Biogeography, 47(10), 2261-2273.

Jackson, H.B. \& Fahrig, L. (2015) Are ecologists conducting research at the optimal scale? Global Ecology and Biogeography, 24, 52-63.

Jacquet, C., Mouillot, D., Kulbicki, M., \& Gravel, D. (2017). Extensions of Island Biogeography Theory predict the scaling of functional trait composition with habitat area and isolation. Ecology Letters, 20(2), 135-146.

Jaramillo Díaz, P., \& Guézou, A. (2011). CDF checklist of Galapagos vascular plants. Retrieved from http://www.darwinfoundation.org/ datazone/checklists/vascular-plants/ Accessed 02/02/2011.

Jarvis, A., Reuter, H.I., Nelson, A., \& Guevara, E. (2008) Hole-filled SRTM for the globe Version 4. URL: https://cgiarcsi.community/data/srtm-90m-digital-elevation-database-v4-1/.

Johnson, P. N., \& Campbell, D. J. (1975). Vascular plants of the Auckland Islands. New Zealand Journal of Botany, 13, 665-720.

Jost, L. (2007). Partitioning diversity into independent alpha and beta components. Ecology, 88(10), 2427-2439.

Junak, S., Philbrick, R., Chaney, S., \& Clark, R. (1997). A checklist of vascular plants of Channel Islands National Park (2nd ed.). Tucson, Arizona: Southwest Parks and Monuments Association.

Kallimanis, A. S., Mazaris, A. D., Tzanopoulos, J., Halley, J. M., Pantis, J. D., \& Sgardelis, S. P. (2008). How does habitat diversity affect the species-area relationship?. Global Ecology and Biogeography, 17(4), 532-538.

Karadimou, E. K., Kallimanis, A. S., Tsiripidis, I., \& Dimopoulos, P. (2016). Functional diversity exhibits a diverse relationship with area, even a decreasing one. Scientific reports, 6(1), 1-9.

Karger, D.N., Conrad, O., Böhner, J., Kawohl, T., Kreft, H., Soria-Auza, R.W., Zimmermann, N.E., Linder, H.P., \& Kessler, M. (2017) Climatologies at high resolution for the earth's land surface areas. Scientific Data, 4, 1-20.

Kattge, J., Bönisch, G., Díaz, S., Lavorel, S., Prentice, I. C., Leadley, P., ... \& Cuntz, M. (2020). TRY plant trait database-enhanced coverage and open access. Global change biology, 26(1), 119-188.

Kattge, J., Diaz, S., Lavorel, S., Prentice, I. C., Leadley, P., Bönisch, G., ... \& Wirth, C. (2011). TRY-a global database of plant traits. Global change biology, 17(9), 2905-2935.

Kavanagh, P. H., \& Burns, K. C. (2014). The repeated evolution of large seeds on islands. Proceedings of the Royal Society B: Biological Sciences, 281(1786), 20140675.

Keppel, G., Gillespie, T. W., Ormerod, P., \& Fricker, G. A. (2016). Habitat diversity predicts orchid diversity in the tropical south-west Pacific. Journal of Biogeography, 43(12), 2332-2342. 
Keppel, G., Mokany, K., Wardell-Johnson, G. W., Phillips, B. L., Welbergen, J. A., \& Reside, A. E. (2015). The capacity of refugia for conservation planning under climate change. Frontiers in Ecology and the Environment, 13(2), 106-112.

Keppel, G., Ottaviani, G., Harrison, S., Wardell-Johnson, G.W., Marcantonio, M., \& Mucina, L. (2018) Towards an eco-evolutionary understanding of endemism hotspots and refugia. Annals of Botany, 122, 927-934.

Kier, G., Kreft, H., Lee, T.M., Jetz, W., Ibisch, P.L., Nowicki, C., Mutke, J., \& Barthlott, W. (2009) A global assessment of endemism and species richness across island and mainland regions. Proceedings of the National Academy of Sciences, 106, 9322-9327.

Kingston, N., Waldren, S., \& Bradley, U. (2003). The phytogeographical affinities of the Pitcairn Islands - a model for south-eastern Polynesia? Journal of Biogeography, 30, 1311-1328.

Kirchner, F., Picot, F., Merceron, E., \& Gigot, G. (2010). Flore vasculaire de La Réunion. La Liste rouge des espèces menacées en France.

Kisel, Y. \& Barraclough, T.G. (2010) Speciation Has a Spatial Scale That Depends on Levels of Gene Flow. The American Naturalist, 175, 316-334.

Knapp, A. K., Avolio, M. L., Beier, C., Carroll, C. J., Collins, S. L., Dukes, J. S., ... \& Smith, M. D. (2017). Pushing precipitation to the extremes in distributed experiments: recommendations for simulating wet and dry years. Global Change Biology, 23(5), 1774-1782.

König, C., Weigelt, P., Schrader, J., Taylor, A., Kattge, J., \& Kreft, H. (2019). Biodiversity data integration - the significance of data resolution and domain. PLoS biology, 17(3), e3000183

König, C., Weigelt, P., Taylor, A., Stein, A., Dawson, W., Essl, F., ... \& Kreft, H. (2021). Source pools and disharmony of the world's island floras. Ecography, 44(1), 44-55.

Kraft, N. J., \& Ackerly, D. D. (2014). Assembly of plant communities. Ecology and the Environment, 8, 67-88.

Kraft, N. J., Cornwell, W. K., Webb, C. O., \& Ackerly, D. D. (2007). Trait evolution, community assembly, and the phylogenetic structure of ecological communities. The American Naturalist, 170(2), 271-283.

Kraft, N. J., Godoy, O., \& Levine, J. M. (2015). Plant functional traits and the multidimensional nature of species coexistence. Proceedings of the National Academy of Sciences, 112(3), 797802.

Kraft, N. J., Valencia, R., \& Ackerly, D. D. (2008). Functional traits and niche-based tree community assembly in an Amazonian forest. Science, 322(5901), 580-582.

Kreft, H. \& Jetz, W. (2007) Global patterns and determinants of vascular plant diversity. Proceedings of the National Academy of Sciences, 104, 5925-5930.

Kreft, H., Jetz, W., Mutke, J., Kier, G., \& Barthlott, W. (2008). Global diversity of island floras from a macroecological perspective. Ecology letters, 11(2), 116-127.

Kühn, P., Ratier Backes, A., Römermann, C., Bruelheide, H., \& Haider, S. (2021). Contrasting patterns of intraspecific trait variability in native and non-native plant species along an elevational gradient on Tenerife, Canary Islands. Annals of botany, 127(4), 565-576.

Laliberté, E., \& Legendre, P. (2010). A distance-based framework for measuring functional diversity from multiple traits. Ecology, 91(1), 299-305. 
Lande, R. (1982). A quantitative genetic theory of life history evolution. Ecology, 63(3), 607-615.

Landrum, J. V. (2002). Four succulent families and 40 million years of evolution and adaptation to xeric environments: What can stem and leaf anatomical characters tell us about their phylogeny?. Taxon, 51(3), 463-473.

Lavergne, S., Mouquet, N., Thuiller, W., \& Ronce, O. (2010). Biodiversity and climate change: integrating evolutionary and ecological responses of species and communities. Annual review of ecology, evolution, and systematics, 41, 321-350.

Lavorel, S., \& Garnier, E. (2002). Predicting changes in community composition and ecosystem functioning from plant traits: revisiting the Holy Grail. Functional ecology, 16(5), 545-556.

Leibold, M. A., Holyoak, M., Mouquet, N., Amarasekare, P., Chase, J. M., Hoopes, M. F., ... \& Gonzalez, A. (2004). The metacommunity concept: a framework for multi-scale community ecology. Ecology letters, 7(7), 601-613.

Lens, F., Davin, N., Smets, E., \& del Arco, M. (2013). Insular woodiness on the Canary Islands: a remarkable case of convergent evolution. International Journal of Plant Sciences, 174(7), 9921013.

Lens, F., Tixier, A., Cochard, H., Sperry, J. S., Jansen, S., \& Herbette, S. (2013). Embolism resistance as a key mechanism to understand adaptive plant strategies. Current Opinion in Plant Biology, 16(3), 287-292

Lenzner, B., Weigelt, P., Kreft, H., Beierkuhnlein, C., \& Steinbauer, M. J. (2017). The general dynamic model of island biogeography revisited the level of major flowering plant families. Journal of biogeography, 44(5), 1029-1040.

Levin, G. A., \& Moran, R. (1989). The vascular flora of Socorro, Mexico. Memoirs of the San Diego Society of Natural History, 16, 1-71.

Levin, S. A. (2000). Multiple scales and the maintenance of biodiversity. Ecosystems, 3(6), 498506.

Lim, J.Y. \& Marshall, C.R. (2017) The true tempo of evolutionary radiation and decline revealed on the Hawaiian archipelago. Nature, 543, 710-713.

Loiseau, N., Mouquet, N., Casajus, N., Grenié, M., Guéguen, M., Maitner, B., ... \& Velez, L. (2020). Global distribution and conservation status of ecologically rare mammal and bird species. Nature communications, 11(1), 1-11.

Lomolino, M. V. (2000). Ecology's most general, yet protean pattern: the species-area relationship. Journal of Biogeography, 17-26.

Lord, J. M. (2015). Patterns in floral traits and plant breeding systems on Southern Ocean Islands. AoB Plants, 7, plv095.

Loreau, M., Mouquet, N., \& Gonzalez, A. (2003). Biodiversity as spatial insurance in heterogeneous landscapes. Proceedings of the National Academy of Sciences, 100(22), 1276512770.

Losos, J. B., \& Ricklefs, R. E. (2009). Adaptation and diversification on islands. Nature, 457(7231), 830-836.

MacArthur \& Wilson (1967). The theory of island biogeography. Princeton University Press. 
MacArthur, R. H., \& Wilson, E. O. (1963). An equilibrium theory of insular zoogeography. Evolution, 373-387.

MacArthur, R., \& Levins, R. (1967). The limiting similarity, convergence, and divergence of coexisting species. The american naturalist, 101(921), 377-385.

MacArthur, R.H. \& MacArthur, J.W. (1961) On bird species diversity. Ecology, 42, 594-598.

Maire, E., Grenouillet, G., Brosse, S., \& Villéger, S. (2015). How many dimensions are needed to accurately assess functional diversity? A pragmatic approach for assessing the quality of functional spaces. Global Ecology and Biogeography, 24(6), 728-740.

Mammola, S., \& Cardoso, P. (2020). Functional diversity metrics using kernel density ndimensional hypervolumes. Methods in Ecology and Evolution.

Marrugat, J. \& Sala, J. (1997) [Registries of morbimortality in cardiology: methods]. Revista espanola de cardiologia, 50, 48-57.

Marticorena, C., Stuessy, T. F., \& Baeza, C. M. (1998). Catalogue of the vascular flora of the Robinson Crusoe or Juan Fernández islands, Chile. Gayana Botánica, 55, 187-211.

Mason, N. W., Mouillot, D., Lee, W. G., \& Wilson, J. B. (2005). Functional richness, functional evenness and functional divergence: the primary components of functional diversity. Oikos, 111(1), 112-118.

McClatchey, W., Thaman, R., \& Vodonaivalu, S. (2000). A preliminary checklist of the flora of Rotuma with Rotuman names. Pacific Science, 54, 345-363.

McCune, B. (2007) Improved estimates of incident radiation and heat load using non- parametric regression against topographic variables. Journal of Vegetation Science, 18, 751-754.

McCune, B. \& Keon, D. (2002) Equations for potential annual direct incident radiation and heat load and heat load. 13, 603-606.

Meinzer, F. C. (2003). Functional convergence in plant responses to the environment. Oecologia, 134(1), 1-11.

Meiri, S. (2017). Oceanic island biogeography: Nomothetic science of the anecdotal. Frontiers of Biogeography, 9(1).

Miguet, P., Jackson, H.B., Jackson, N.D., Martin, A.E., \& Fahrig, L. (2016) What determines the spatial extent of landscape effects on species? Landscape Ecology, 31, 1177-1194.

Moles, A. T. (2018). Being John Harper: Using evolutionary ideas to improve understanding of global patterns in plant traits. Journal of Ecology, 106(1), 1-18.

Moles, A. T., Warton, D. I., Warman, L., Swenson, N. G., Laffan, S. W., Zanne, A. E., ... \&

Leishman, M. R. (2009). Global patterns in plant height. Journal of Ecology, 97(5), 923-932.

Molina-Venegas, R., Aparicio, A., Lavergne, S., \& Arroyo, J. (2017) Climatic and topographical correlates of plant palaeo- and neoendemism in a Mediterranean biodiversity hotspot. Annals of Botany, 119, 229-238.

Moran, R. (1996). The flora of Guadalupe Island, Mexico. Memoirs of the California Academy of Sciences: Vol. 19. San Francisco, CA: California Academy of Sciences.

Morlon, H., Schwilk, D. W., Bryant, J. A., Marquet, P. A., Rebelo, A. G., Tauss, C., ... \& Green, J. L. (2011). Spatial patterns of phylogenetic diversity. Ecology letters, 14(2), 141-149. 
Mouchet, M. A., Villéger, S., Mason, N. W., \& Mouillot, D. (2010). Functional diversity measures: an overview of their redundancy and their ability to discriminate community assembly rules. Functional Ecology, 24(4), 867-876.

Mueller-Dombois, D. \& Fosberg, R. (1998) Vegetation of the tropical Pacific Islands. Springer Science \& Business Media.

Muer, T., Sauerbier, H., \& Calixto, F. C. (2016). Die Farn-und Blütenpflanzen der Kanarischen Inseln. Weikersheim, Germany: Margraf.

Myers, N., Mittermeier, R. A., Mittermeier, C. G., Da Fonseca, G. A., \& Kent, J. (2000). Biodiversity hotspots for conservation priorities. Nature, 403(6772), 853-858.

Nakagawa, S. \& Schielzeth, H. (2013) A general and simple method for obtaining R2 from generalized linear mixed-effects models. Methods in Ecology and Evolution, 4, 133-142.

Neall, V.E. \& Trewick, S.A. (2008) The age and origin of the Pacific islands: a geological overview. Philosophical transactions of the Royal Society of London. Series B, Biological sciences, 363 , 3293-308.

Nowak, L., Kissling, W. D., Bender, I. M., Dehling, D. M., Töpfer, T., Böhning-Gaese, K., \& Schleuning, M. (2019). Projecting consequences of global warming for the functional diversity of fleshy-fruited plants and frugivorous birds along a tropical elevational gradient. Diversity and Distributions, 25(9), 1362-1374.

Ottaviani, G., Keppel, G., Götzenberger, L., Harrison, S., Opedal, Ø. H., Conti, L., ... \& Negoita, L. (2020). Linking plant functional ecology to island biogeography. Trends in Plant Science, 25(4), 329-339.

Otto, R., Fernández-Palacios, J. M., \& Krüsi, B. O. (2001). Variation in species composition and vegetation structure of succulent scrub on Tenerife in relation to environmental variation. Journal of Vegetation Science, 12(2), 237-248.

Otto, R., Krüsi, B. O., \& Kienast, F. (2007). Degradation of an arid coastal landscape in relation to land use changes in Southern Tenerife (Canary Islands). Journal of Arid Environments, 70(3), 527539.

Otto, R., Krüsi, B. O., Burga, C. A., \& Fernández-Palacios, J. M. (2006). Old-field succession along a precipitation gradient in the semi-arid coastal region of Tenerife. Journal of Arid Environments, 65(1), 156-178.

Pärtel, M., Zobel, M., Zobel, K., \& van der Maarel, E. (1996). The species pool and its relation to species richness: evidence from Estonian plant communities. Oikos, 111-117.

Patiño, J., Whittaker, R. J., Borges, P. A., Fernández-Palacios, J. M., Ah-Peng, C., Araújo, M. B., ... \& de Nascimento, L. (2017). A roadmap for island biology: 50 fundamental questions after 50 years of The Theory of Island Biogeography. Journal of Biogeography, 44(5), 963-983.

Paulay, G. (1994) Biodiversity on Oceanic Islands : Its Origin and Extinction. American Zoologist, 34, 134-144.

Pearse, W. D., Cadotte, M. W., Cavender-Bares, J., Ives, A. R., Tucker, C. M., Walker, S. C., \& Helmus, M. R. (2015). Pez: Phylogenetics for the environmental sciences. Bioinformatics, 31(17), 2888-2890.

Penone, C., Davidson, A. D., Shoemaker, K. T., Di Marco, M., Rondinini, C., Brooks, T. M., ... \& Costa, G. C. (2014). Imputation of missing data in life-history trait datasets: Which approach performs the best?. Methods in Ecology and Evolution, 5(9), 961-970. 
Pérez-Harguindeguy, N., Diaz, S., Gamier, E., Lavorel, S., Poorter, H., Jaureguiberry, P., ... \& Comelissen, J. H. C. (2013). New handbook for stand-ardised measurement of plant functional traits worldwide. Aus-tralian Journal of Botany 61: 167-234.

Pickett, S.T.A. (1989) Space-for-time substitution as an alternative to long-term studies. In Longterm studies in ecology. Long-Term Studies in Ecology Springer: New York.

Price, J. P., \& Wagner, W. L. (2011). A phylogenetic basis for species-area relationships among three Pacific Island floras. American Journal of Botany, 98, 449-459.

Price, J. P., Otto, R., Menezes de Sequeira, M., Kueffer, C., Schaefer, H., Caujapé-Castells, J., \& Fernández-Palacios, J. M. (2018). Colonization and diversification shape species-area relationships in three Macaronesian archipelagos. Journal of Biogeography, 45(9), 2027-2039.

Price, J.P. \& Clague, D.A. (2002) How old is the Hawaiian biota? Geology and phylogeny suggest recent divergence. Proceedings of the Royal Society of London. Series B: Biological Sciences, 269, 2429-2435.

Qiu, J., \& Cardinale, B. J. (2020). Scaling up biodiversity-ecosystem function relationships across space and over time. Ecology, 101(11), e03166.

R Development Core Team (2018) R: A language and environment for statistical computing. Vienna, Austria.

Rahbek, C. (1995). The elevational gradient of species richness: a uniform pattern?. Ecography, 200-205.

Rahbek, C., Borregaard, M.K., Colwell, R.K., Dalsgaard, B., Holt, B.G., Morueta-Holme, N., Nogues-Bravo, D., Whittaker, R.J., \& Fjeldså, J. (2019) Humboldt's enigma: What causes global patterns of mountain biodiversity? Science, 365, 1108-1113.

Ramalho, R.S., Quartau, R., Trenhaile, A.S., Mitchell, N.C., Woodroffe, C.D., \& Ávila, S.P. (2013) Coastal evolution on volcanic oceanic islands: A complex interplay between volcanism, erosion, sedimentation, sea-level change and biogenic production. Earth-Science Reviews, 127, 140-170.

Raulerson, L. (2006). Checklist of plants of the Mariana Islands. University of Guam Herbarium Contribution, 37, 1-69

Reich, P. B. (2014). The world-wide 'fast-slow'plant economics spectrum: a traits manifesto. Journal of Ecology, 102(2), 275-301.

Ricklefs, R. E. (1987). Community diversity: relative roles of local and regional processes. Science, 235(4785), 167-171.

Ricklefs, R. E., \& Jenkins, D. G. (2011). Biogeography and ecology: towards the integration of two disciplines. Philosophical Transactions of the Royal Society B: Biological Sciences, 366(1576), 2438-2448.

Riley, S.J., DeGloria, S.D., \& Elliot, R. (1999) A Terrain Ruggedness Index that Qauntifies Topographic Heterogeneity. Intermountain Journal of Sciences, 5, 23-27.

Rosenzweig, M. L. (1995). Species diversity in space and time. Cambridge University Press.

Roux, J. P. (2009). Synopsis of the Lycopodiophyta and Pteridophyta of Africa, Madagascar and neighbouring islands. Cape Town, South Africa: South African National Biodiversity Institute.

Royal Botanic Gardens and Domain Trust. (2017). PlantNET - The NSW Plant Information Network System. Retrieved from http:// plantnet.rbgsyd.nsw.gov.au Accessed 16/09/2016. 
Rundell, R. J., \& Price, T. D. (2009). Adaptive radiation, nonadaptive radiation, ecological speciation and nonecological speciation. Trends in Ecology \& Evolution, 24(7), 394-399.

Sanders, N. J., \& Rahbek, C. (2012). The patterns and causes of elevational diversity gradients. Ecography, 35(1), 1.

Scheiner, S. M. (2003). Six types of species-area curves. Global ecology and biogeography, 12(6), 441-447.

Scheiner, S. M., Chiarucci, A., Fox, G. A., Helmus, M. R., McGlinn, D. J., \& Willig, M. R. (2011). The underpinnings of the relationship of species richness with space and time. Ecological Monographs, 81(2), 195-213.

Schluter, D. (2000). The ecology of adaptive radiation. OUP Oxford)

Schrader, J., König, C., Triantis, K. A., Trigas, P., Kreft, H., \& Weigelt, P. (2020). Species-area relationships on small islands differ among plant growth forms. Global Ecology and Biogeography, 29(5), 814-829.

Schrader, J., Moeljono, S., Keppel, G., \& Kreft, H. (2019). Plants on small islands revisited: The effects of spatial scale and habitat quality on the species-area relationship. Ecography, 42(8), 1405-1414.

Seijmonsbergen, A.C., Guldenaar, J., \& Rijsdijk, K.F. (2018) Exploring Hawaiian long-term insular geodiversity dynamics. Landform Analysis, 35, 31-43.

Shaw, J. D., Spear, D., Greve, M., \& Chown, S. L. (2010). Taxonomic homogenization and differentiation across Southern Ocean Islands differ among insects and vascular plants. Journal of Biogeography, 37, 217-228.

Shmida, A., \& Werger, M. J. A. (1992). Growth form diversity on the Canary Islands. Vegetatio, 102(2), 183-199.

Smith, A. B., Sandel, B., Kraft, N. J., \& Carey, S. (2013). Characterizing scale-dependent community assembly using the functional-diversity-area relationship. Ecology, 94(11), 23922402.

Smith, A. C. (1979-1996). Flora Vitiensis nova: a new Flora of Fiji (spermatophytes only). Lawaii, Hawaii: Pacific Tropical Botanical Garden

Smith, S. A., \& Brown, J. W. (2018). Constructing a broadly inclusive seed plant phylogeny. American journal of botany, 105(3), 302-314.

Solt, F. \& Hu, Y. (2015) dotwhisker: Dot-and-whisker plots of regression results. Available at the Comprehensive R Archive Network (CRAN).

Spasojevic, M. J., \& Suding, K. N. (2012). Inferring community assembly mechanisms from functional diversity patterns: the importance of multiple assembly processes. Journal of Ecology, 100(3), 652-661.

Sperling, F. N., Washington, R., \& Whittaker, R. J. (2004). Future climate change of the subtropical North Atlantic: implications for the cloud forests of Tenerife. Climatic Change, 65(1), 103-123.

Stein, A. \& Kreft, H. (2015) Terminology and quantification of environmental heterogeneity in species-richness research. Biological Reviews, 90, 815-836. 
Stein, A., Beck, J., Meyer, C., Waldmann, E., Weigelt, P., \& Kreft, H. (2015) Differential effects of environmental heterogeneity on global mammal species richness. Global Ecology and Biogeography, 24, 1072-1083.

Stein, A., Gerstner, K., \& Kreft, H. (2014) Environmental heterogeneity as a universal driver of species richness across taxa, biomes and spatial scales. Ecology Letters, 17, 866-880.

Steinbauer, M. J., Dolos, K., Field, R., Reineking, B., \& Beierkuhnlein, C. (2013). Re-evaluating the general dynamic theory of oceanic island biogeography. Frontiers of Biogeography, 5(3), p-185.

Steinbauer, M. J., Field, R., Grytnes, J. A., Trigas, P., Ah-Peng, C., Attorre, F., ... \& Beierkuhnlein, C. (2016). Topography-driven isolation, speciation and a global increase of endemism with elevation. Global Ecology and Biogeography, 25(9), 1097-1107.

Steinbauer, M. J., Grytnes, J. A., Jurasinski, G., Kulonen, A., Lenoir, J., Pauli, H., ... \& Wipf, S. (2018). Accelerated increase in plant species richness on mountain summits is linked to warming. Nature, 556(7700), 231-234.

Steinbauer, M., Dolos, K., Field, R., Reineking, B., \& Beierkuhnlein, C. (2013) Re-evaluating the general dynamic theory of oceanic island biogeography. Frontiers of Biogeography, 5, 217-220.

Stekhoven, D. J., \& Bühlmann, P. (2012). MissForest-non-parametric missing value imputation for mixed-type data. Bioinformatics, 28(1), 112-118.

Strahm, W. A. The conservation and restoration of the flora of Mauritius and Rodrigues. University of Reading, Reading, UK.

Stuessy, T. F., Crawford, D. J., \& Marticorena, C. (1990). Patterns of phylogeny in the endemic vascular flora of the Juan Fernandez Islands, Chile. Systematic Botany, 338-346.

Stuessy, T. F., Jakubowsky, G., Gómez, R. S., Pfosser, M., Schlüter, P. M., Fer, T., ... \& Kato, H. (2006). Anagenetic evolution in island plants. Journal of Biogeography, 33(7), 1259-1265.

Svenning, J. \& Skov, F. (2007) Ice age legacies in the geographical distribution of tree species richness in Europe. Global Ecology and Biogeography, 16(2), 234-245., 16, 234-245.

Takahashi, H., Barkalov, V. Y., Gage, S., \& Zhuravlev, Y. N. (1997). A preliminary study of the flora of Chirpoi, Kuril Islands. Acta Phytotaxonomica Et Geobotanica, 48, 31-42.

Takahashi, H., Barkalov, V. Y., Gage, S., Joneson, S., Ilushko, M., \& Zhuravlev, Y. N. (2002). A floristic study of the vascular plants of Raikoke, Kuril Islands. Acta Phytotaxonomica Et Geobotanica, 53, 17-33.

Takahashi, H., Barkalov, V. Y., Gage, S., Semsrott, B., Ilushko, M., \& Zhuravlev, Y. N. (1999). A preliminary checklist of the vascular plants of Chirinkotan, Kuril Islands. Journal of Phytogeography and Taxonomy, 47, 131-137.

Takahashi, H., Barkalov, V. Y., Gage, S., Semsrott, B., Ilushko, M., \& Zhuravlev, Y. N. (2006). A floristic study of the vascular plants of Kharimkotan, Kuril Islands. Bulletin of the Hokkaido University Museum, 3, 41-66.

Tatewaki, M. (1957). Geobotanical studies on the Kurile Islands. Acta Horti Gotoburgensis, 21, 43-123.

Taylor, A., Keppel, G., Weigelt, P., Zotz, G., \& Kreft, H. (2021). Functional traits are key to understanding orchid diversity on islands. Ecography. 
Taylor, A., Weigelt, P., König, C., Zotz, G., \& Kreft, H. (2019). Island disharmony revisited using orchids as a model group. New Phytologist, 223(2), 597-606.

Taylor, R. (2006). Straight through from London: the Antipodes and Bounty Islands, New Zealand. Christchurch, New Zealand: Heritage Expeditions New Zealand.

Tilman, D. (2001). Functional diversity. Encyclopedia of biodiversity, 3(1), 109-120.

Triantis, K. A., Guilhaumon, F., \& Whittaker, R. J. (2012). The island species-area relationship: biology and statistics. Journal of Biogeography, 39(2), 215-231.

Triantis, K. A., Mylonas, M., Lika, K., \& Vardinoyannis, K. (2003). A model for the species-areahabitat relationship. Journal of Biogeography, 30(1), 19-27.

Triantis, K. A., Rigal, F., Parent, C. E., Cameron, R. A., Lenzner, B., Parmakelis, A., ... \& Cowie, R. H. (2016). Discordance between morphological and taxonomic diversity: land snails of oceanic archipelagos. Journal of Biogeography, 43(10), 2050-2061.

Triantis, K.A., Guilhaumon, F., \& Whittaker, R.J. (2012) The island species-area relationship: biology and statistics. Journal of Biogeography, 39, 215-231.

Triantis, K.A., Mylonas, M., Lika, K., Natural, K.V., \& Museum, H. (2003) A model for the species area - habitat relationship. Journal of Biogeography, 30, 19-27.

Troll, V.R. \& Carracedo, J.C. (2016) The Canary Islands: An Introduction. The Geology of the Canary Islands pp. 1-41. Elsevier,

Trusty, J. L., Kesler, H. C., \& Delgado, G. H. (2006). Vascular flora of Isla del Coco, Costa Rica. Proceedings of the California Academy of Sciences, 57, 247-355.

University of Kent. (2012). Cook Islands Biodiversity and Ethnobiology Database. Retrieved from http://cookislands.pacif icbiodiversity.net/cibed/dbs/search.html Accessed 12/04/2012.

Valente, L.M., Etienne, R.S., \& Phillimore, A.B. (2014) The effects of island ontogeny on species diversity and phylogeny. Proceedings of the Royal Society B: Biological Sciences, 281, 20133227.

van Huysduynen, A. H., Janssens, S., Merckx, V., Vos, R., Valente, L., Zizka, A., ... \& FernándezPalacios, J. M. (2020). Multiple origins of insular woodiness on the Canary Islands are consistent with palaeoclimatic aridification. bioRxiv.

Velayos, M., Barberá, P., Cabezas, F. J., La Estrella, M. d., Fero, M., \& Aedo, C. (2014). Checklist of the Vascular Plants of Annobón (Equatorial Guinea). Phytotaxa, 171, 1-78.

Viana, D. S., \& Chase, J. M. (2019). Spatial scale modulates the inference of metacommunity assembly processes. Ecology, 100(2), e02576.

Villéger, S., Mason, N. W., \& Mouillot, D. (2008). New multidimensional functional diversity indices for a multifaceted framework in functional ecology. Ecology, 89(8), 2290-2301.

Violle, C., Navas, M. L., Vile, D., Kazakou, E., Fortunel, C., Hummel, I., \& Garnier, E. (2007). Let the concept of trait be functional!. Oikos, 116(5), 882-892.

Vitousek, P. M., \& Benning, T. L. (1995). Ecosystem and landscape diversity: islands as model systems. In Islands (pp. 73-84). Springer, Berlin, Heidelberg.

Wace, N. M. (1961). The vegetation of Gough Island. Ecological Monographs, 31, 337-367.

Wace, N. M., \& Dickson, J. H. (1965). The terrestrial botany of the Tristan da Cunha Islands. Philosophical Transactions of the Royal Society of London B Biological Sciences, 249, 273-360. 
Wagner, W. L., \& Lorence, D. H. (2002). Flora of the Marquesas Islands website. Retrieved from http://botany.si.edu/pacificisl andbiodiversity/marquesasflora/index.htm Accessed 28/11/2014.

Wagner, W. L., Herbst, D. R., \& Lorence, D. H. (2005). Flora of the Hawaiian Islands website. Retrieved from http://botany.si.edu/pacif icislandbiodiversity/hawaiianflora/ Accessed 16/10/2010.

Wardle, D. A. (2002). Islands as model systems for understanding how species affect ecosystem properties. Journal of Biogeography, 29(5-6), 583-591.

WCSP. (2014). World Checklist of Selected Plant Families. Retrieved from http://apps.kew.org/wcsp/home.do Accessed 01/12/2014.

Weigelt, P. (2015). The macroecology of island floras. Frontiers of Biogeography, 7(3).

Weigelt, P., \& Kreft, H. (2013). Quantifying island isolation-insights from global patterns of insular plant species richness. Ecography, 36(4), 417-429.

Weigelt, P., Jetz, W., \& Kreft, H. (2013) Bioclimatic and physical characterization of the world's islands. Proceedings of the National Academy of Sciences, 110, 15307-15312.

Weigelt, P., Kissling, W. D., Kisel, Y., Fritz, S. A., Karger, D. N., Kessler, M., ... \& Kreft, H. (2015). Global patterns and drivers of phylogenetic structure in island floras. Scientific reports, 5(1), 113.

Weigelt, P., König, C., \& Kreft, H. (2020). GIFT-A global inventory of floras and traits for macroecology and biogeography. Journal of Biogeography, 47(1), 16-43.

Weigelt, P., Steinbauer, M.J., Cabral, J.S., \& Kreft, H. (2016) Late Quaternary climate change shapes island biodiversity. Nature, 532, 99-102.

Weiher, E., \& Keddy, P. A. (1995). The assembly of experimental wetland plant communities. Oikos, 323-335.

Westerband, A. C., Knight, T. M., \& Barton, K. E. (2021). Intraspecific trait variation and reversals of trait strategies across key climate gradients in native Hawaiian plants and non-native invaders. Annals of botany, 127(4), 553-564.

Westoby, M., \& Wright, I. J. (2006). Land-plant ecology on the basis of functional traits. Trends in ecology \& evolution, 21(5), 261-268.

Westoby, M., Falster, D. S., Moles, A. T., Vesk, P. A., \& Wright, I. J. (2002). Plant ecological strategies: some leading dimensions of variation between species. Annual review of ecology and systematics, 33(1), 125-159.

Whistler, W. A. (2012). Botanical survey of the Ringgold Islands, Fiji. Allertonia, 11, 1-28.

White, H. J., Montgomery, W. I., Pakeman, R. J., \& Lennon, J. J. (2018). Spatiotemporal scaling of plant species richness and functional diversity in a temperate semi-natural grassland. Ecography, 41(5), 845-856.

Whittaker, R. H. (1972). Evolution and measurement of species diversity. Taxon, 21(2-3), 213251.

Whittaker, R. J., \& Fernández-Palacios, J.M. (2007) Island biogeography: ecology, evolution, and conservation. Oxford University Press,

Whittaker, R. J., Fernández-Palacios, J. M., Matthews, T. J., Borregaard, M. K., \& Triantis, K. A. (2017). Island biogeography: Taking the long view of nature's laboratories. Science, 357(6354). 
Whittaker, R. J., Ladle, R. J., Araújo, M. B., María Fernández-Palacios, J., Domingo Delgado, J., \& Ramón Arévalo, J. (2007). The island immaturity-speciation pulse model of island evolution: an alternative to the "diversity begets diversity" model. Ecography, 30(3), 321-327.

Whittaker, R. J., Rigal, F., Borges, P. A., Cardoso, P., Terzopoulou, S., Casanoves, F., ... \& Triantis, K. A. (2014). Functional biogeography of oceanic islands and the scaling of functional diversity in the Azores. Proceedings of the National Academy of Sciences, 111(38), 13709-13714.

Whittaker, R. J., Triantis, K. A., \& Ladle, R. J. (2008). A general dynamic theory of oceanic island biogeography. Journal of Biogeography, 35(6), 977-994.

Whittaker, R.J., Fernández-Palacios, J.M., Matthews, T.J., Borregaard, M.K., \& Triantis, K.A. (2017) Island biogeography: Taking the long view of nature's laboratories. Science, 357, eaam8326.

Whittaker, R.J., Ladle, R.J., Araújo, M.B., Fernández-Palacios, J., Domingo Delgado, J., \& Ramón Arévalo, J. (2007) The island immaturity speciation pulse model of island evolution: an alternative to the "'diversity begets diversity"' model. Ecography, 30, 321-327.

Whittaker, R.J., Triantis, K.A., \& Ladle, R.J. (2008) A general dynamic theory of oceanic island biogeography. Journal of Biogeography, 35, 977-994.

Wieczynski, D.J., Boyle, B., Buzzard, V., Duran, S.M., Henderson, A.N., Hulshof, C.M., Kerkhoff, A.J., McCarthy, M.C., Michaletz, S.T., Swenson, N.G., Asner, G.P., Bentley, L.P., Enquist, B.J. \& Savage, V.M. (2018) Climate shapes and shifts functional biodiversity in forests worldwide. Proceedings of the National Academy of Sciences, 201813723.

Willis, K. J., \& Whittaker, R. J. (2002). Species diversity--scale matters. Science, 295(5558), 12451248.

Wright, I. J., Reich, P. B., Westoby, M., Ackerly, D. D., Baruch, Z., Bongers, F., ... \& Villar, R. (2004). The worldwide leaf economics spectrum. Nature, 428(6985), 821-827.

Wright, I.J., Reich, P.B., Westoby, M., Ackerly, D.D., Baruch, Z., Bongers, F. et al. (2004)

Zobel, M. (1997). The relative of species pools in determining plant species richness: an alternative explanation of species coexistence?. Trends in ecology \& evolution, 12(7), 266-269.

Zobel, M. (2016). The species pool concept as a framework for studying patterns of plant diversity. Journal of Vegetation Science, 27(1), 8-18. 


\section{APPENDIX}

\section{Supplementary material Chapter II}

\section{Extended figures: Assembly of functional diversity of an oceanic island flora}

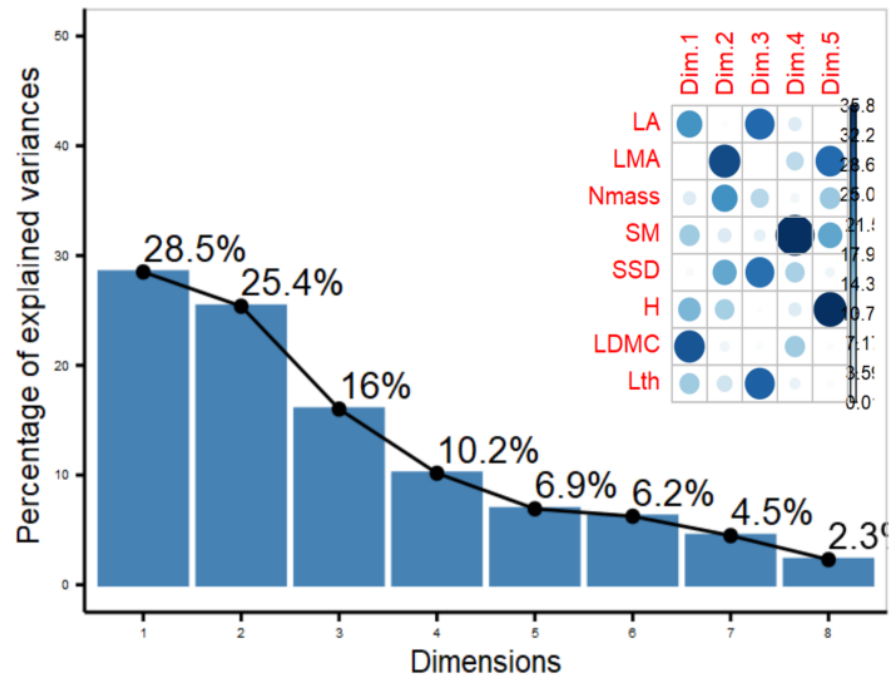

Extended Figure 2. Principal component analysis (PCA) for Tenerife native seed plants based on eight plant functional traits. Left-hand side plot shows the degree contribution per trait to the PCA. Right-hand side shows explained variances and percentage of contributions of each trait to the PCA. Traits values were $z$ - and log-transformed.

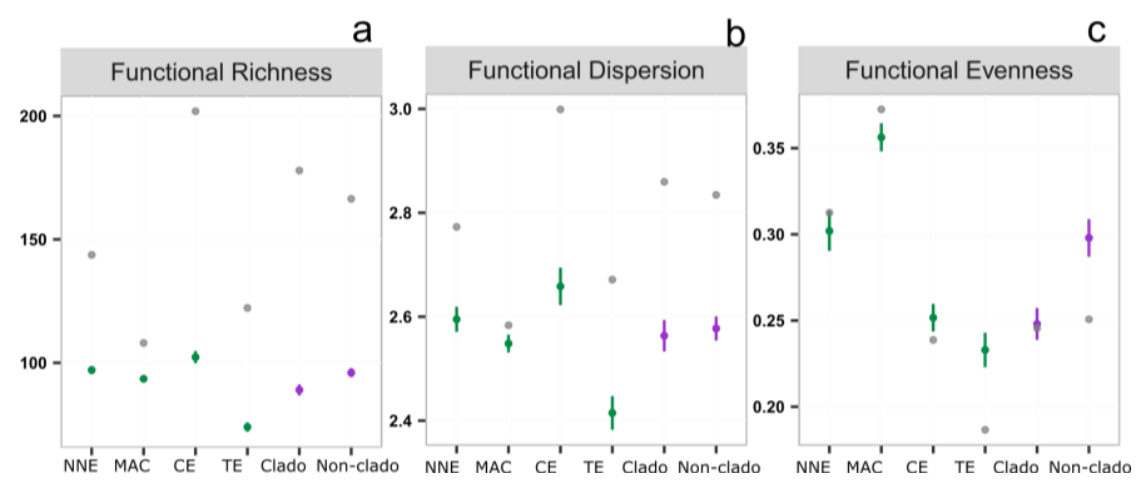

Extended Figure 3. Contribution of different biogeographical groups to the functional diversity of Tenerife. Functional richness (a), functional dispersion (b) and functional evenness (c) were calculated based on $n$-dimensional hypervolumes estimations (see Methods). Observed values are displayed in grey color and sampled-based rarefied values in green (biogeographical groups) and purple (evolutionary groups). Dots and error bars correspond to the mean values and $95 \%$ confidence intervals after standardization. Biogeographical groups are., native non-endemics 
(NNE), Macaronesian-endemics (MAC), Canary-endemics (CE) and Tenerife-endemics (TE). Evolutionary groups are in purple, cladogenetic species (Clado) and non-cladogenetic endemics.

\section{Supplementary: Assembly of functional diversity of an oceanic island flora}

The following analysis is performed for the native plants of Tenerife, i.e., 436 species. We used eight plant functional traits collected for $80 \%$ of Tenerife native plants: Leaf area (LA $\mathrm{mm}^{2}$ ), leaf dry matter content (LDMC $\mathrm{mg} \mathrm{g}^{-1}$ ), leaf mass per area $\left(\mathrm{LMA} \mathrm{g} \mathrm{m}^{-2}\right)$, leaf Nitrogen content $\left(\mathrm{N}_{\text {mass }} \mathrm{mg}\right.$ $\mathrm{g}^{-1}$ ), leaf thickness $\left(L_{\text {th }} \mathrm{mm}\right.$ ), stem specific density (SSD $\mathrm{mg} \mathrm{mm}^{-3}$ ), seed mass (SM $\mathrm{mg}$ ) and maximum plant height $(\mathrm{H} \mathrm{m})$.

\section{Section I: Trait data}

1. Univariate analysis of Tenerife plant traits.
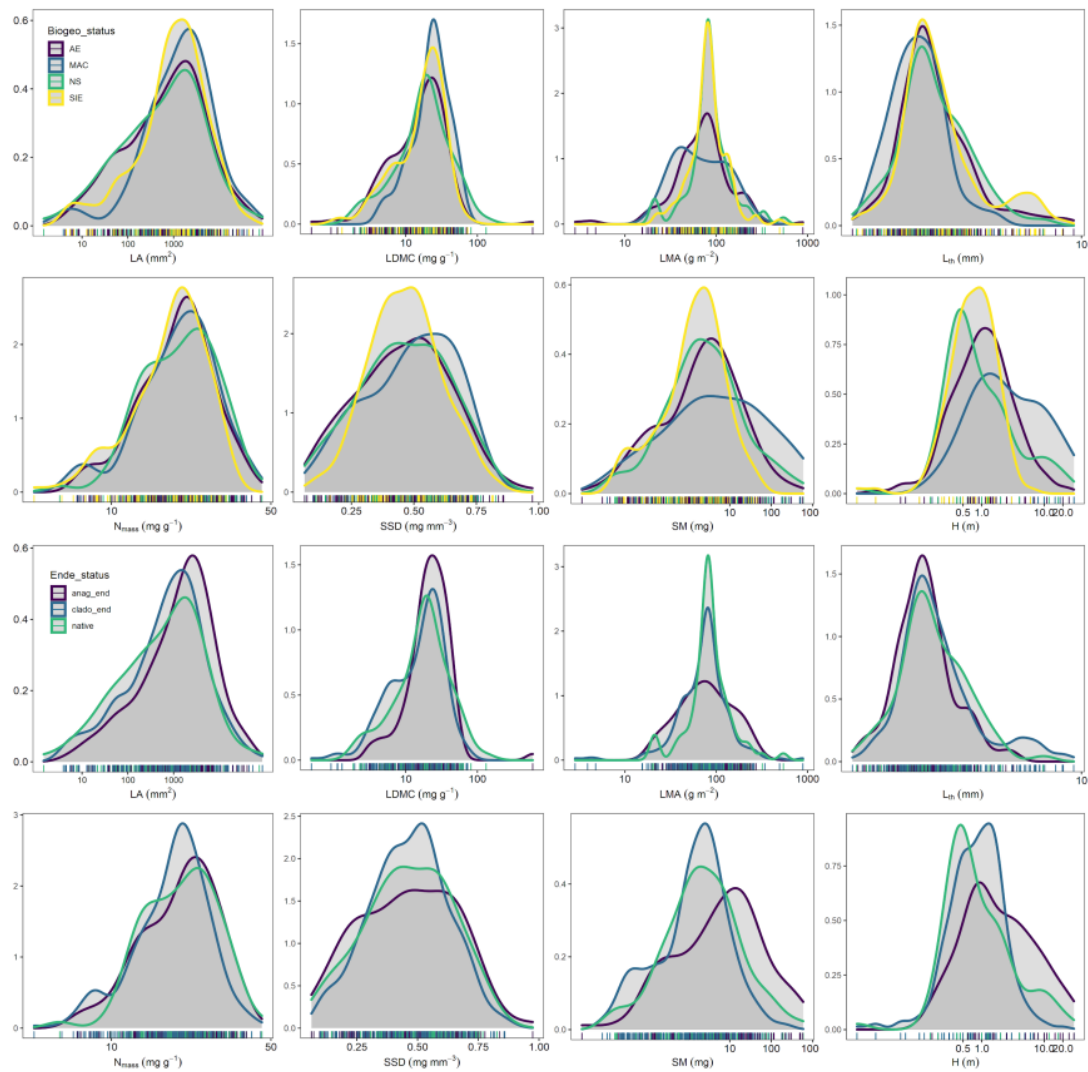

Figure 1. Density distribution per trait and defined group in colors. In the background in grey color, total density distribution of all island species (436 species) Left-hand side plots: density distribution per biogeographical endemism status: AE (canary endemics), MAC (Macaronesian endemics), NS (native non-endemics), SIE (Tenerife single-island endemics). Right-hand side plots: density distribution per Speciation-process status. The $x$ axes are log10 scaled. Here, we included the all ten plant traits measured in Tenerife.

2. Bivariate analysis among Tenerife plant traits. 


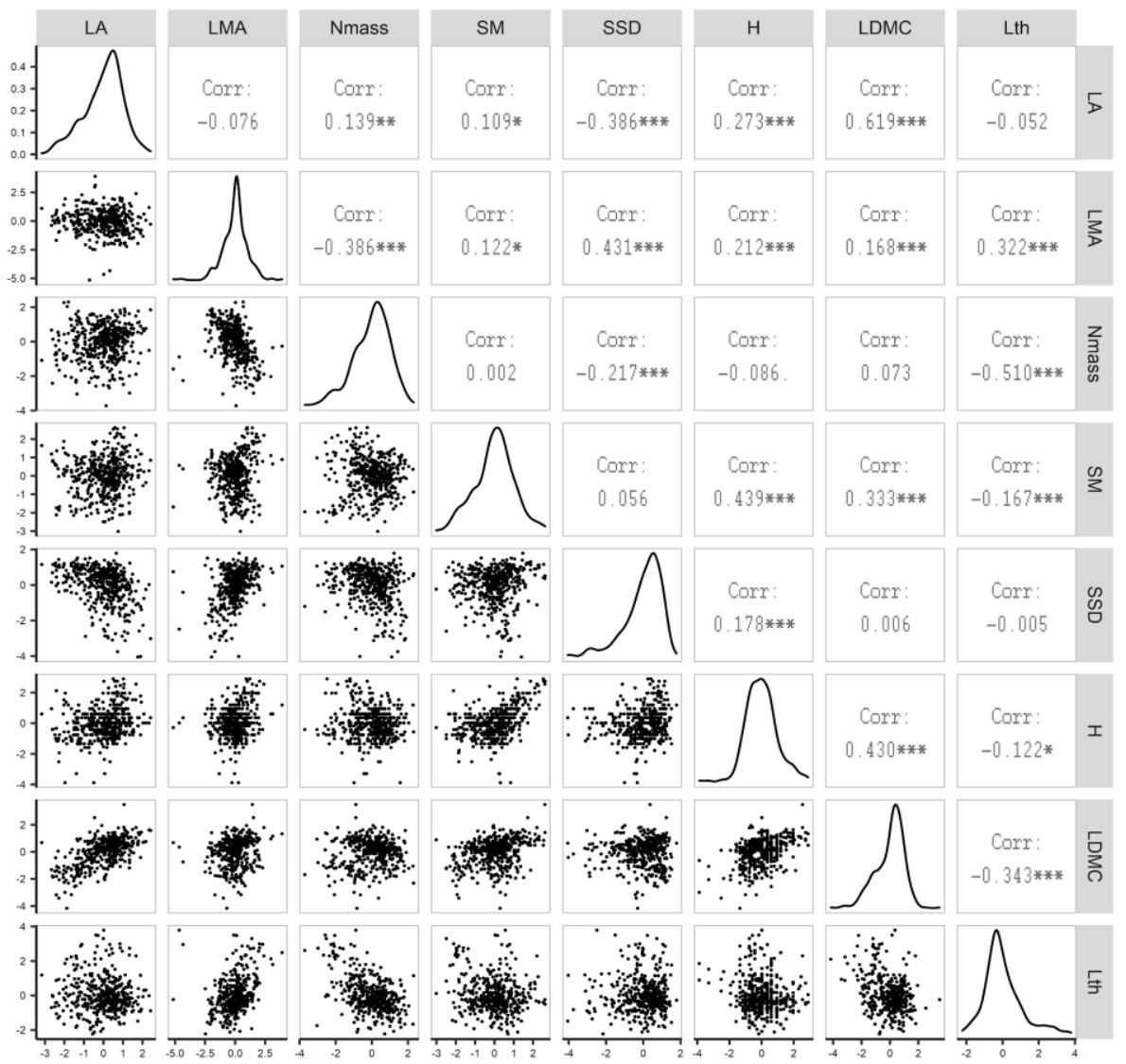

Figure 2. Pearson correlation coefficients among eight plant traits and density distribution for all native species Tenerife seed plants. Trait values are $z$ - and log-transformed.

3. We used Random Forest method/algorithm to deal with missing trait values. The initial data set that includes 436 species and three subspecies missed $20 \%$ of the trait values.

Table 1. Validation of trait value imputation. Out of Bag (OOB) scores indicated, the lower the value the better the random forest algorithm performed. Note: phylogenetically informed trait values had always lower OOB scores, except for SLA predicted values.

\begin{tabular}{|c|r|r|r|}
\hline Imputed trait & $\begin{array}{c}\text { OOB error from } \\
\text { phylogenetically informed } \\
\text { traits }\end{array}$ & $\begin{array}{c}\text { OOB error from non- } \\
\text { phylogenetically informed } \\
\text { (naive) traits }\end{array}$ & Difference \\
\hline LA & 58692693.97 & 62477812.18 & -3785118.2 \\
\hline LDMC & 977.16 & 1135.34 & -158.18 \\
\hline SLA & 242.65 & 171.52 & 71.13 \\
\hline LMA & 1107.54 & 1164.09 & -56.55 \\
\hline Lth & 0.48 & 0.58 & -0.1 \\
\hline N & 31.61 & 40.68 & -9.08 \\
\hline SM & 2334.71 & 2443.22 & -108.51 \\
\hline SSD & 0.02 & 0.02 & 0 \\
\hline H & 4.84 & 6.93 & -2.09 \\
\hline
\end{tabular}



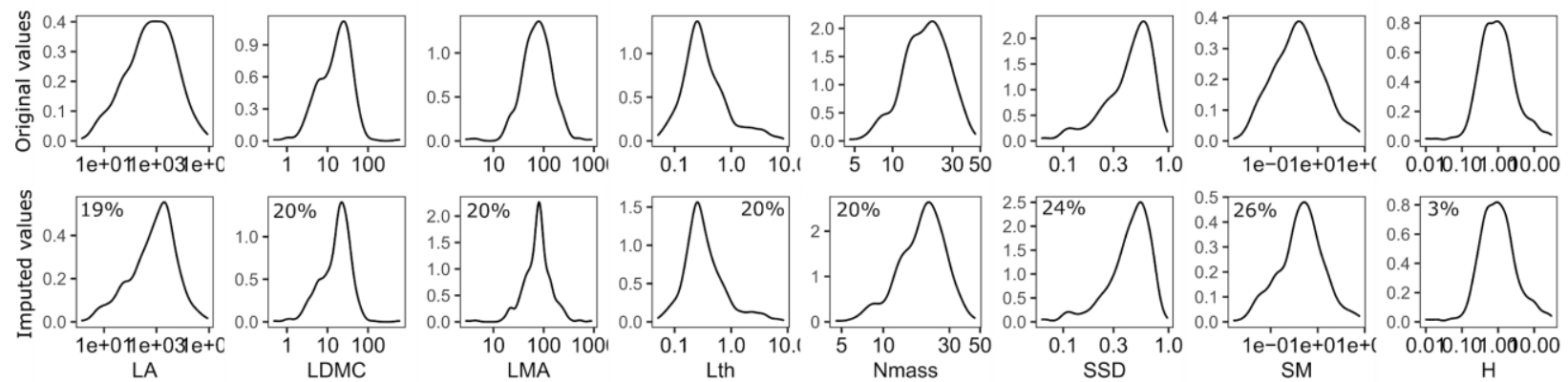

Figure 3. Density distribution of the original true and imputed trait values for each trait. The percentages values correspond to the amount of trait imputed of the total of 436 native plant species.

Section II: Quantification of functional diversity.

Table 2. Calculated overlap metrics for the island and global hypervolumes.

\begin{tabular}{|c|c|c|}
\hline metric & value & description \\
\hline Jaccard & 0.5197 & $\begin{array}{l}\text { Jaccard similarity (volume of intersection of island trait space and global trait } \\
\text { space divided by volume of union of island trait space and global trait space) }\end{array}$ \\
\hline Soerensen & 0.6839 & $\begin{array}{l}\text { Sorensen similarity (twice the volume of intersection of island trait space and } \\
\text { global trait space divided by volume of island trait space plus volume of global } \\
\text { trait space) }\end{array}$ \\
\hline
\end{tabular}

Section III: Radiated lineages

Table 3. Contribution of each lineage to the total island trait space evaluated using Kruskal-Wallis test. Significant codes, marked by the different letters " $a$ " and " $b$ ", indicate from the pairwise comparisons that both groups had significantly different functional contribution or originality values, alpha level 0.05 . Identical letters, e.g., "a" and "a" indicate no significant difference.

\begin{tabular}{|r|r|r|r|r|}
\hline Lineage & Contribution & Kruskal W & Originality & Kruskal W \\
test & & & test \\
\hline non-Aeonium & 250.71 & a & 392.65 & a \\
\hline Aeonium & 216.03 & a & 205.17 & b \\
\hline non-Argyranthemum & 218.54 & a & 220.95 & a \\
\hline Argyranthemum & 216.67 & a & 102.33 & b \\
\hline non-Aspagus1 & 271.75 & a & 286.00 & a \\
\hline Aspagus1 & 218.01 & a & 217.88 & a \\
\hline
\end{tabular}




\begin{tabular}{|c|c|c|c|c|}
\hline non-Bystropogon & 218.67 & a & 219.65 & a \\
\hline Bystropogon & 200.00 & $a$ & 94.50 & $b$ \\
\hline non-Cheirolophus & 229.50 & $a$ & 220.05 & a \\
\hline Cheirolophus & 218.35 & a & 107.17 & $b$ \\
\hline non-Convolvulus1 & 246.25 & a & 219.41 & $a$ \\
\hline Convolvulus1 & 218.24 & $a$ & 120.75 & a \\
\hline non-Crambe & 235.75 & $a$ & 219.37 & a \\
\hline Crambe & 218.34 & a & 124.25 & $a$ \\
\hline non-Descurainia & 218.64 & a & 218.79 & a \\
\hline Descurainia & 203.25 & a & 187.50 & $a$ \\
\hline non-Echium & 219.86 & a & 219.97 & $\mathrm{a}$ \\
\hline Echium & 165.91 & a & 161.64 & $\mathrm{a}$ \\
\hline non-Euphorbia1 & 294.75 & a & 219.00 & a \\
\hline Euphorbia1 & 217.79 & a & 164.75 & a \\
\hline non-Helianthemum 1 & 218.67 & a & 219.69 & a \\
\hline Helianthemum1 & 200.50 & a & 89.50 & $b$ \\
\hline non-Lolium1 & 249.33 & a & 219.41 & $a$ \\
\hline Lolium1 & 218.29 & a & 87.67 & a \\
\hline non-Lotus1 & 219.07 & a & 219.82 & a \\
\hline Lotus1 & 188.25 & a & 147.75 & a \\
\hline non-Micromeria & 219.09 & a & 242.38 & a \\
\hline Micromeria & 186.88 & a & 218.05 & a \\
\hline non-Pericallis & 220.17 & a & 244.00 & a \\
\hline Pericallis & 218.48 & a & 218.14 & a \\
\hline non-Pimpinella & 218.80 & a & 218.89 & a \\
\hline Pimpinella & 186.50 & a & 176.50 & $\mathrm{a}$ \\
\hline non-Polycarpaea1 & 307.29 & a & 340.43 & a \\
\hline Polycarpaea1 & 217.05 & a & 216.51 & $\mathrm{~b}$ \\
\hline non-Sideritis & 220.79 & a & 223.10 & a \\
\hline Sideritis & 154.20 & $b$ & 89.47 & $b$ \\
\hline non-Sonchus & 219.68 & a & 220.15 & a \\
\hline Sonchus & 180.23 & a & 164.77 & a \\
\hline non-Teline 1 & 218.51 & a & 258.75 & a \\
\hline Teline1 & 217.50 & a & 218.13 & a \\
\hline non-Tolpis & 225.20 & a & 219.32 & a \\
\hline Tolpis & 218.42 & a & 147.40 & a \\
\hline
\end{tabular}



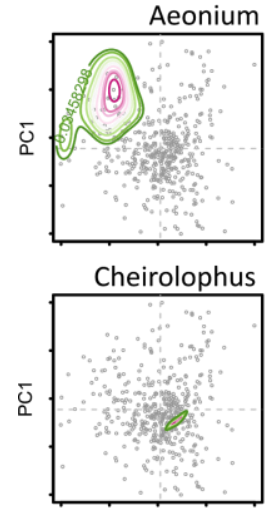

Helianthemum

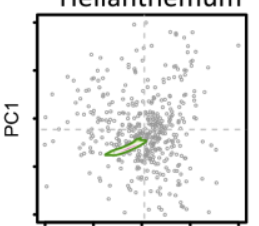

Pimpinella

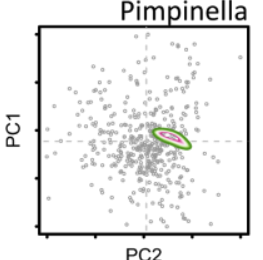

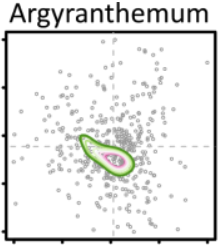

Crambe

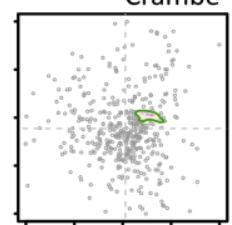

Limonium

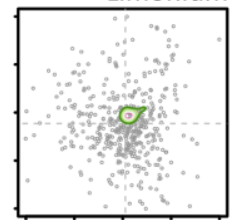

Polycarpaea

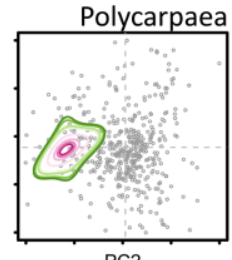

Asparagus

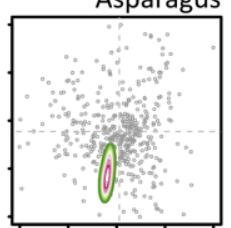

Descurania

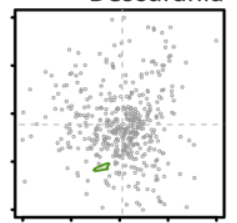

Lotus

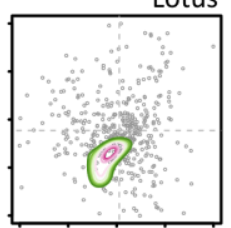

Sideritis

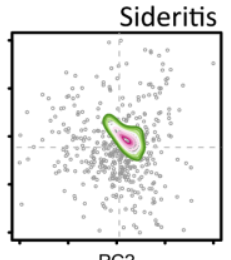

Sonchus

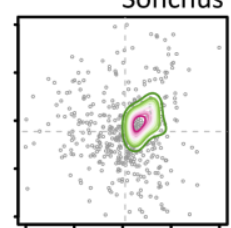

Echium

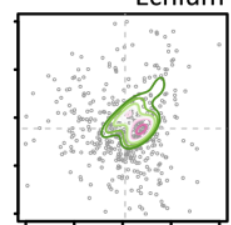

Micromeria

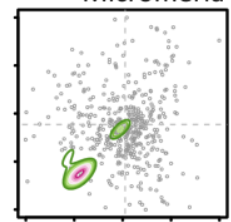

Teline

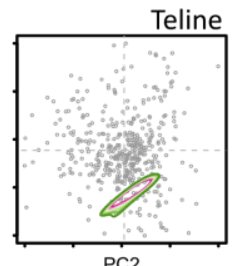

Bystropogon

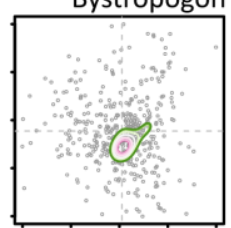

Euphorbia

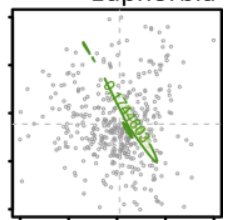

Pericallis

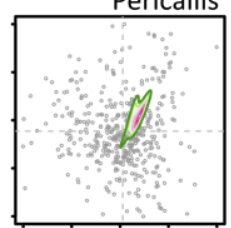

Tolpis

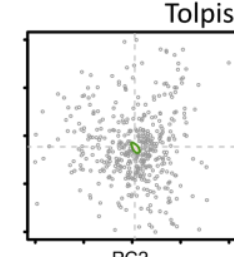

Figure 4. Functional trait spaces for 21 major radiated lineages in Tenerife, based on eight plant functional traits: Leaf area (LA $\left.\mathrm{mm}^{2}\right)$, leaf dry matter content $\left(\mathrm{LDMC} \mathrm{mg} \mathrm{g}^{-1}\right)$, leaf mass per area (LMA $\mathrm{g} \mathrm{m}^{-2}$ ), leaf Nitrogen content $\left(\mathrm{N}_{\text {mass }} \mathrm{mg} \mathrm{g}^{-1}\right)$, leaf thickness $\left(\mathrm{L}_{\text {th }} \mathrm{mm}\right)$, maximum plant height $(\mathrm{H} \mathrm{m})$, stem specific density (SSD $\mathrm{mg} \mathrm{mm}^{-3}$ ) and seed mass (SM $\mathrm{mg}$ ).
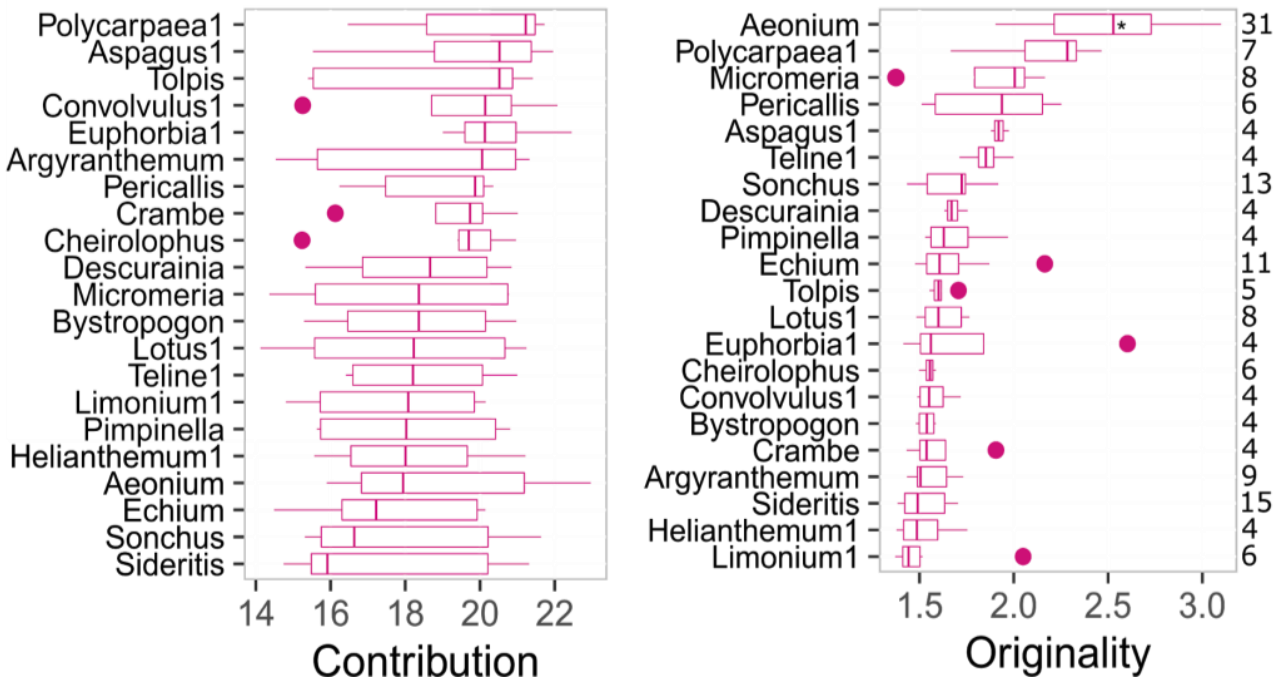

Figure 5. Functional contribution and originality for 21 major radiated plant lineages present in Tenerife (lineages containing more than three species). Asterisk "*" in panels indicate that groups have significantly contributed or have original values to the island trait space. Significance tests were done using Kruskal-Wallis, with alpha level 0.05. 
Section IV. Trait data collection

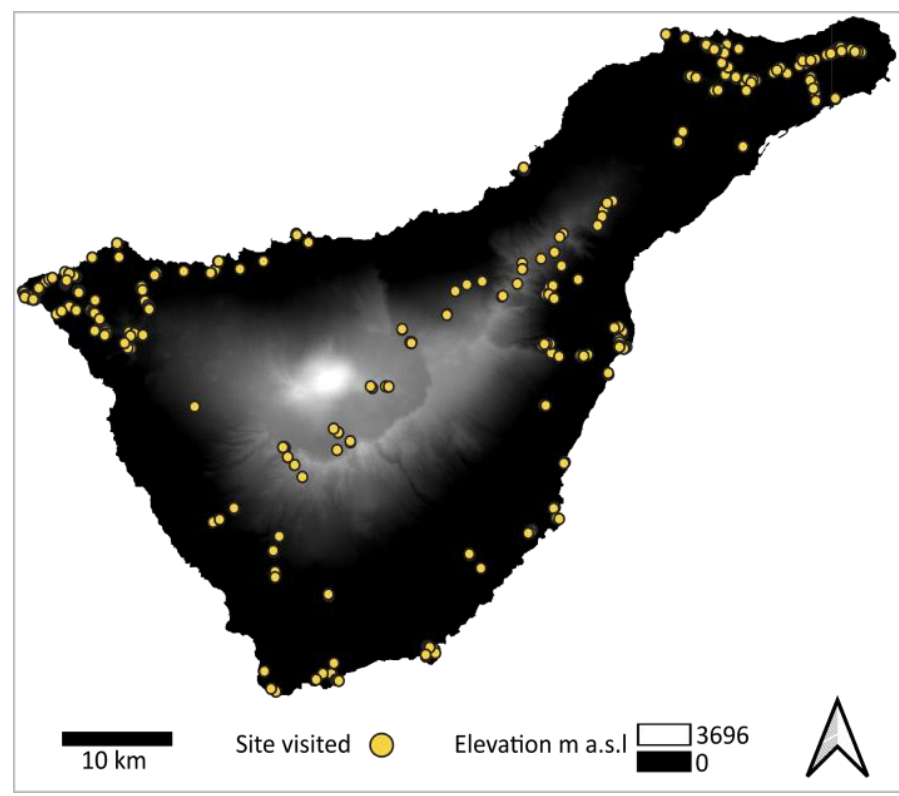

Figure 6. Tenerife map displaying about 500 different sites visited during the fieldwork campaign in 2017 and 2018 where plant material to quantify the eighth plant functional traits were collected. 


\section{Supplementary material Chapter III}

\section{Patterns and drivers of plant functional diversity across spatial scales on an oceanic island}

Appendix S1. Fieldwork-related information

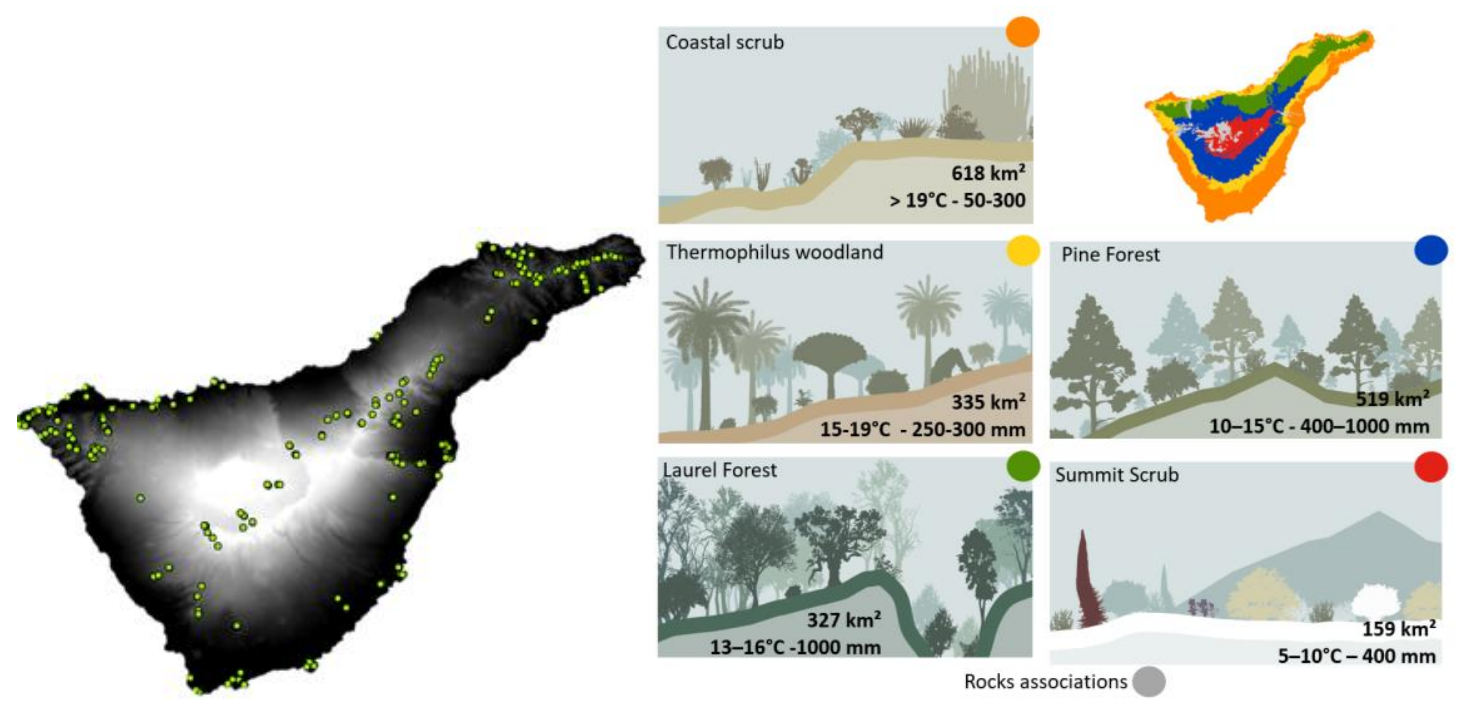

Figure 1. Tenerife elevation map with the sites visited to collect plant functional traits were collected on Tenerife (green dots) on the left side. More than 500 different sites were visited, covering all vegetation types and nearly all Tenerife's elevational gradient from sea level to 2700 $m$ a.s.l Tenerife Vegetation types on the right site. Cartoons course https://www3.gobiernodecanarias.org/medusa/ecoescuela/recursosdigitales/files/formidable/P isos-Tenerife.pdf 
Appendix S2. Trait data and species occurrence data

Table 1. Validation of trait value imputation. Out of Bag (OOB) scores indicated, the lower the value the better the random forest algorithm performed. Note: phylogenetically informed trait values had always lower OOB scores, except for SLA predicted values.

\begin{tabular}{|c|r|r|r|}
\hline $\begin{array}{r}\text { Imputed } \\
\text { trait }\end{array}$ & $\begin{array}{r}\text { OOB error from phylogenetically } \\
\text { informed traits }\end{array}$ & $\begin{array}{r}\text { OOB error from non-phylogenetically } \\
\text { informed (naive) traits }\end{array}$ & Difference \\
\hline LA & 58692693.97 & 62477812.18 & -3785118.2 \\
\hline LDMC & 977.16 & 1135.34 & -158.18 \\
\hline SLA & 242.65 & 171.52 & 71.13 \\
\hline LMA & 1107.54 & 1164.09 & -56.55 \\
\hline Lth & 0.48 & 0.58 & -0.1 \\
\hline$N_{\text {mass }}$ & 31.61 & 40.68 & -9.08 \\
\hline Cmass $_{\text {SM }}$ & 1252.81 & 1451.73 & -198.91 \\
\hline SM & 2334.71 & 2443.22 & -108.51 \\
\hline SSD & 0.02 & 0.02 & 0 \\
\hline$H$ & 4.84 & 6.93 & -2.09 \\
\hline
\end{tabular}
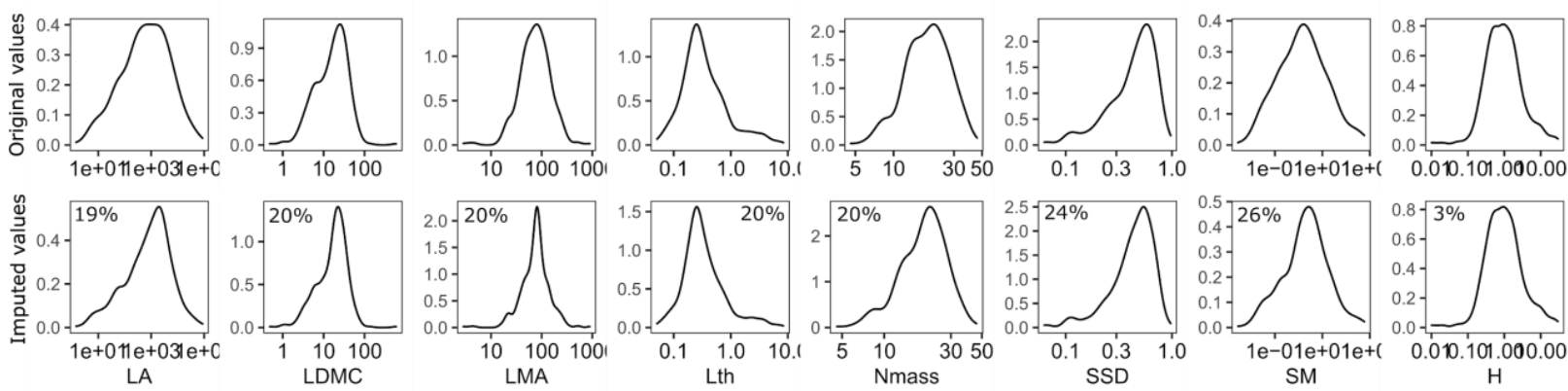

Figure 2. Density distribution of the original true and imputed trait values for each trait. The percentages values correspond to the amount of trait imputed of the total of 436 native plant species. 


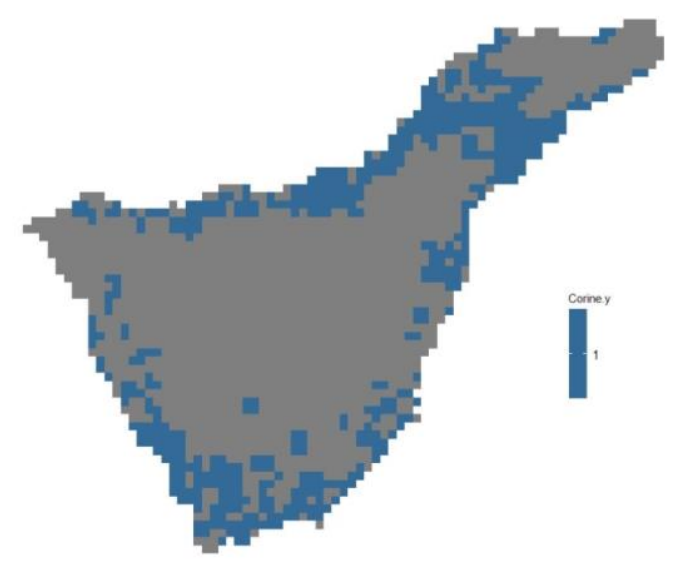

Figure 3 . We removed 535 cells from $1 \mathrm{~km}^{2}$ grain size data (blue squares). These cells were located in urban places, either cities and industrial areas This information is from Banco de Datos de Biodiversidad Atlantis 3.1 at www.biodiversidadcanarias.es and the urban cell information from Corine land cover legend (2018), where urban cells in the legend are 1.

a
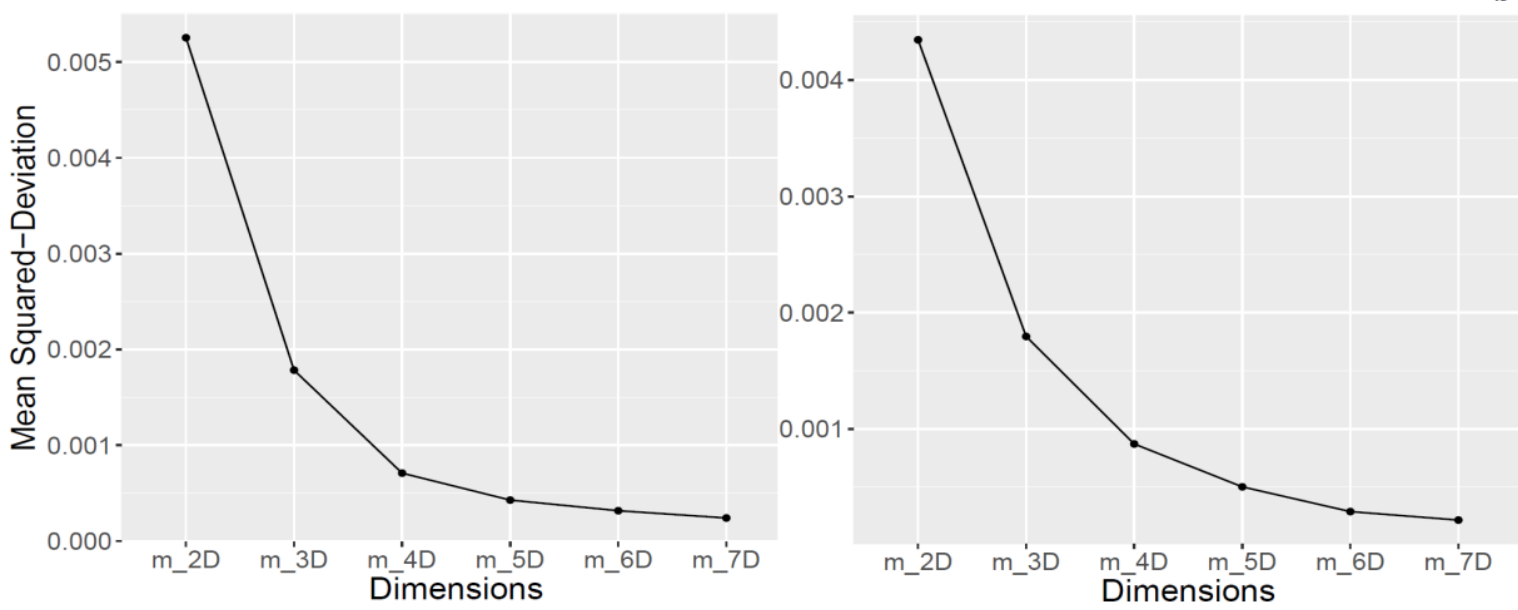

Figure 4. Assessment of the number of dimensions required to build the distance matrix that reflects functional dissimilarity between the species. The assessment included 434 native seed plant species and eight plant functional (see methods). For both sets of data, i.e., (a) plots and (b) cells five dimensions were required to build the distance matrix. Note that from the 6th dimension Mean Squared-Deviation is very low. This assessment is based on the Maire et al 2015 approach. 
a

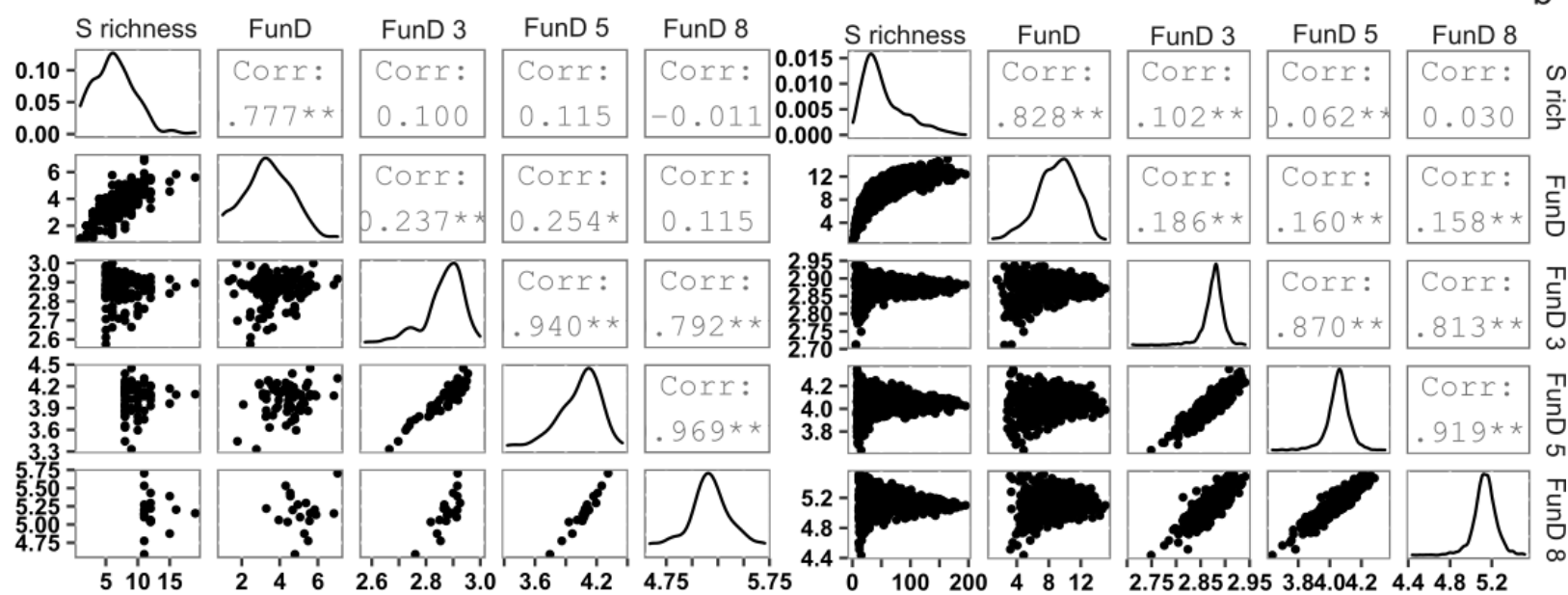

Figure 5. Density distribution and correlation analysis between species richness and functional diversity metrics. Observed functional diversity values (FunD) and three different functional diversity estimations were rarefied to control for species richness, using three different minimum numbers of species, i.e., three, five and eight species: FunD 3, FunD 5, and FunD 8, respectively. Spearman's correlation coefficients for (a) plot data $100 \mathrm{~m}^{2}$ and for (b) cell data $1 \mathrm{~km}^{2}$.

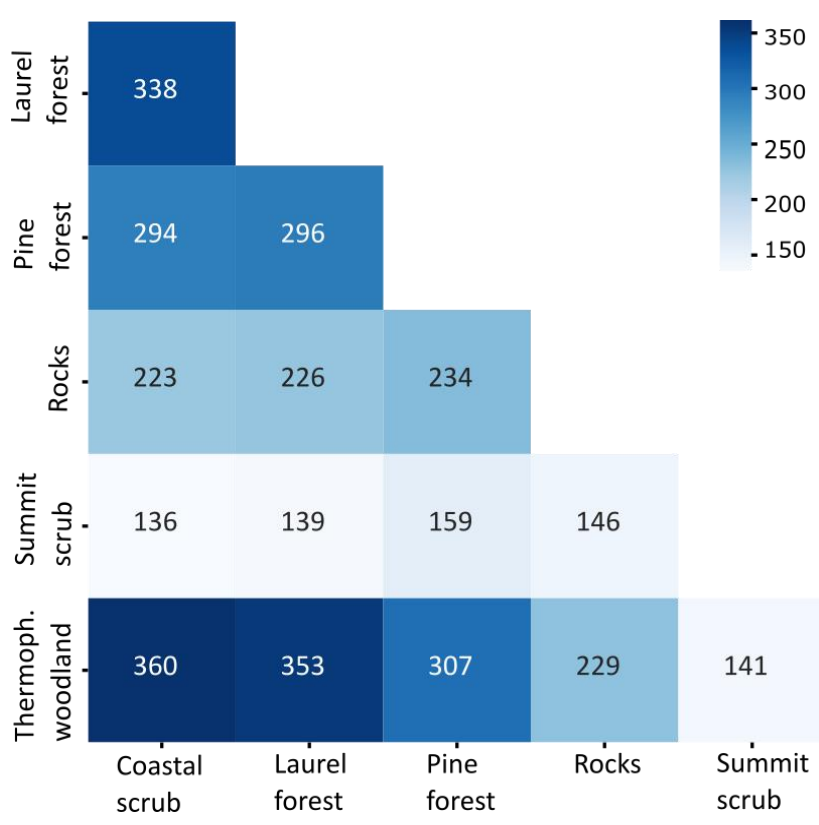

Figure 6. Number of species shared across vegetation types for local spatial grain $1 \mathrm{~km}^{2}$. 
Appendix S3. Taxonomic diversity and statistical analysis
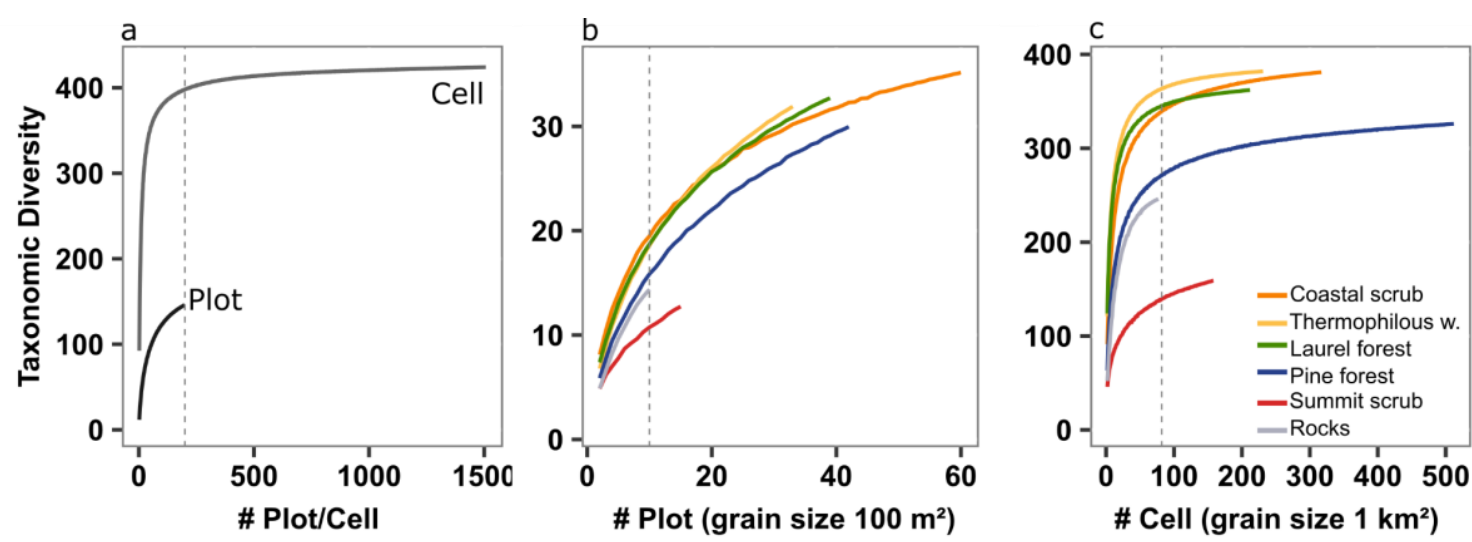

Figure 7. Taxonomic diversity accumulation curves of native plant communities on Tenerife at two spatial grains, plots $\left(100 \mathrm{~m}^{2}\right)$ and cells $\left(1 \mathrm{~km}^{2}\right)$, across the entire island (a) and per vegetation type at each grain ( $b$ and $c)$. Dotted vertical lines illustrate the largest amount of accumulated sampled plots or cells defined given the smallest number of plots and cells contained in the rocks vegetation types.
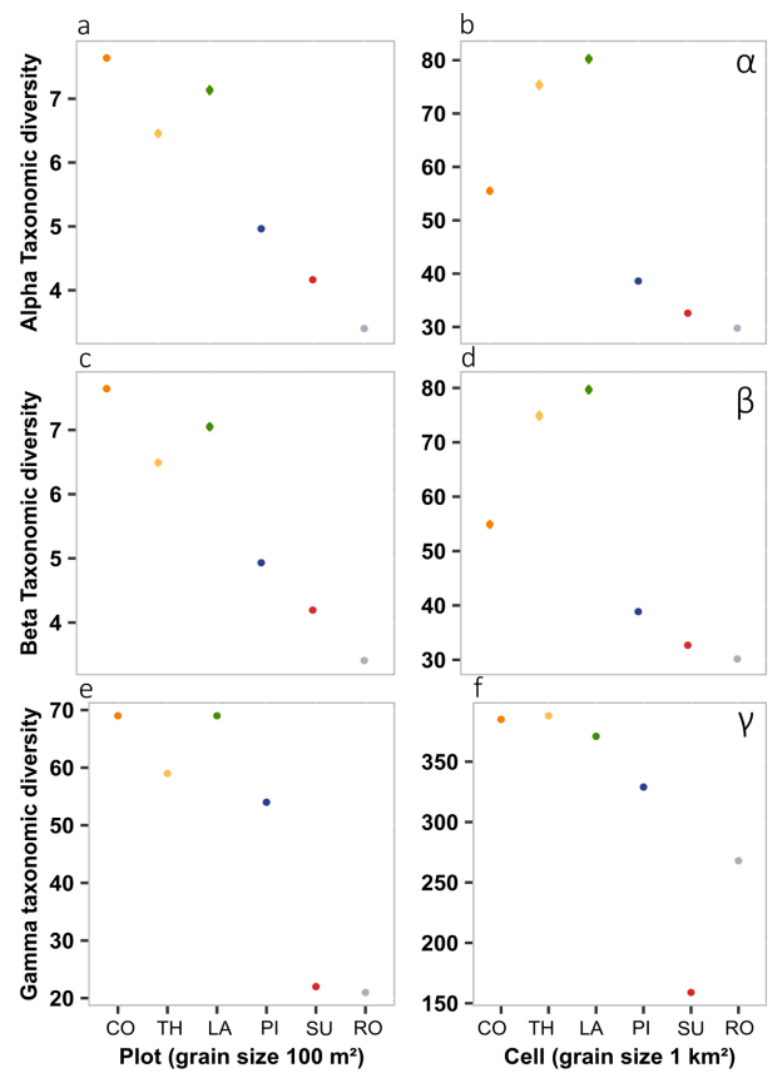

Figure 8. Taxonomic diversity patterns of Tenerife vegetation types from within local (alpha) and regional (gamma) spatial scales (a, b, c, e) and across local spatial scales (beta) (c, d) for two spatial grains, $100 \mathrm{~m}^{2}$ and $1 \mathrm{~km}^{2}$. Vegetation types are arranged by Tenerife elevational gradient, 
a

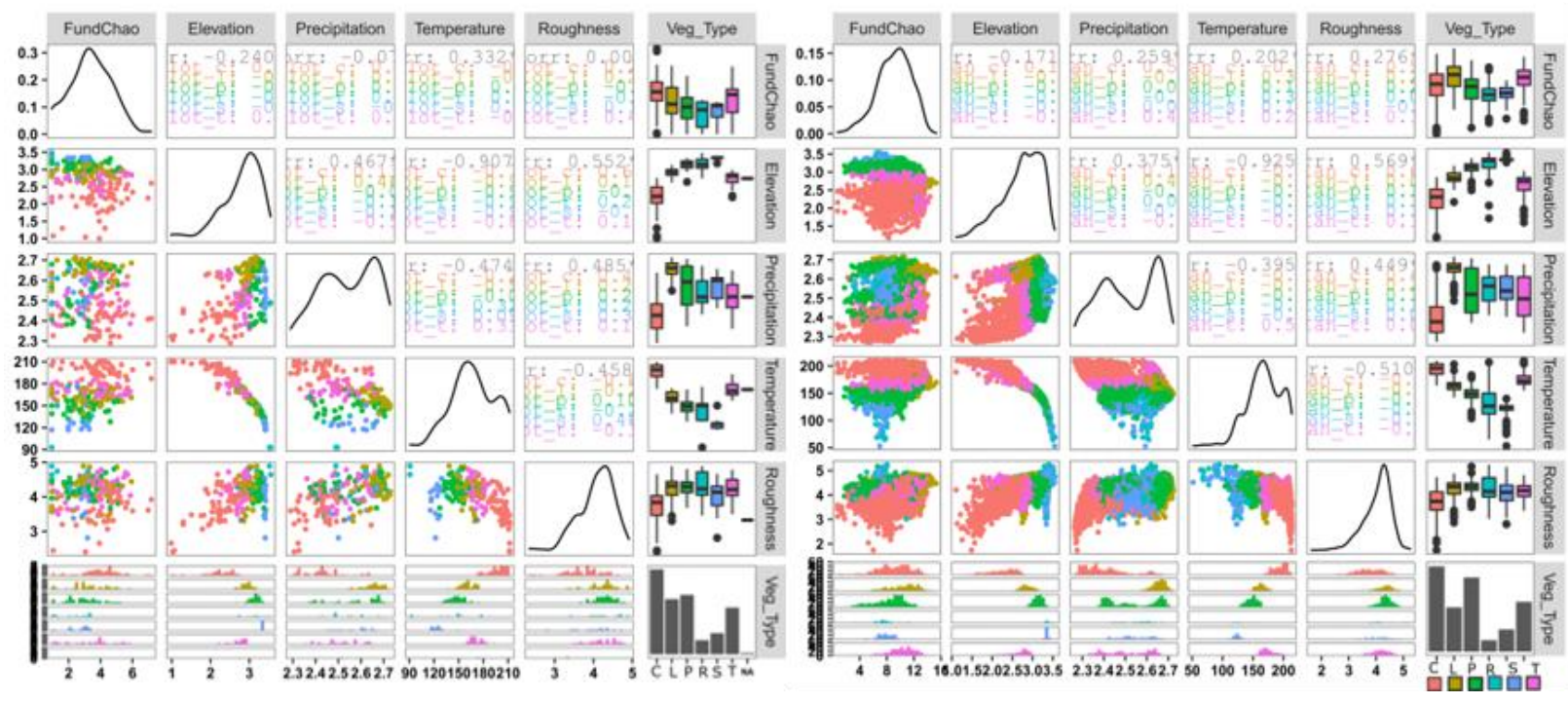

Figure 9. Density distribution and correlation analysis between the predictor variables used in the analysis. Spearman's correlation coefficients for (a) plot data $100 \mathrm{~m}^{2}$ and for (b) cell data $1 \mathrm{~km}^{2}$.
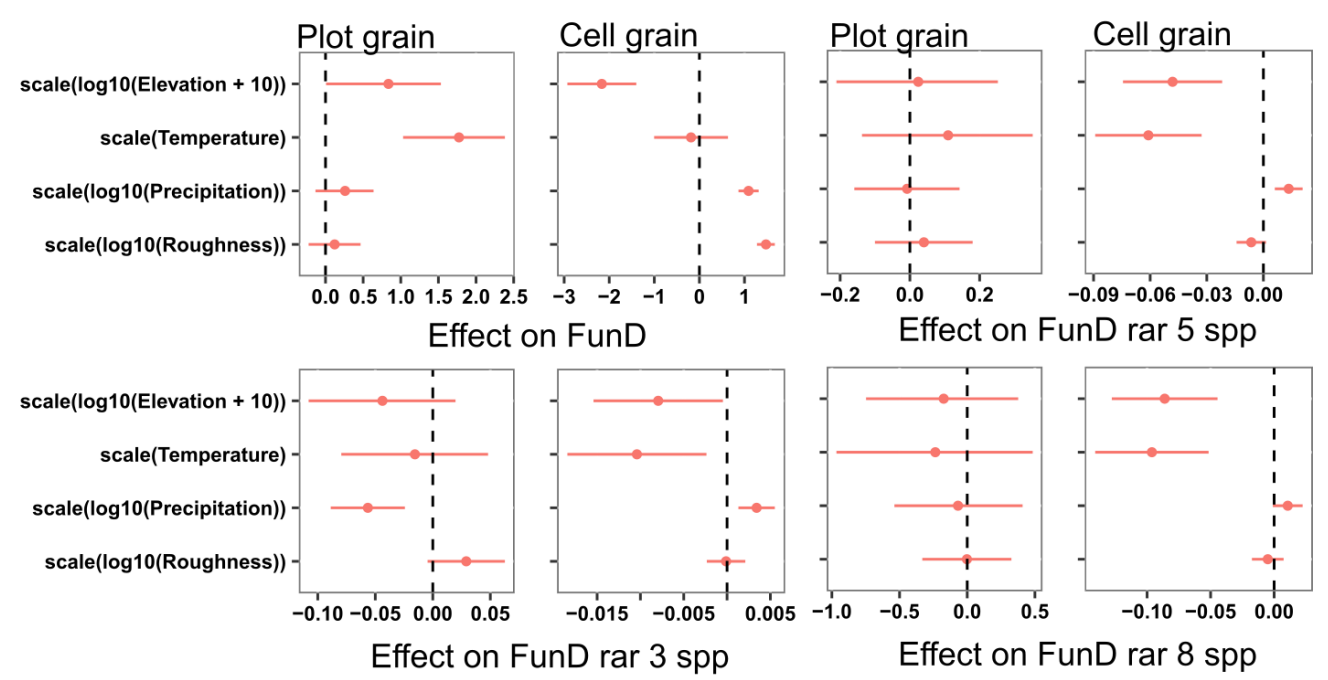

Figure 10. Evaluation functional diversity standardization at plot $100 \mathrm{~m}^{2}$ and cell grain $1 \mathrm{~km}^{2}$, using different number to control for species richness. Where, observed functional diversity values is FunD. The three different standardizations used three, five and eight species: FunD rar 3 spp, FunD rar 5 spp, and FunD rar 8 spp, respectively. 


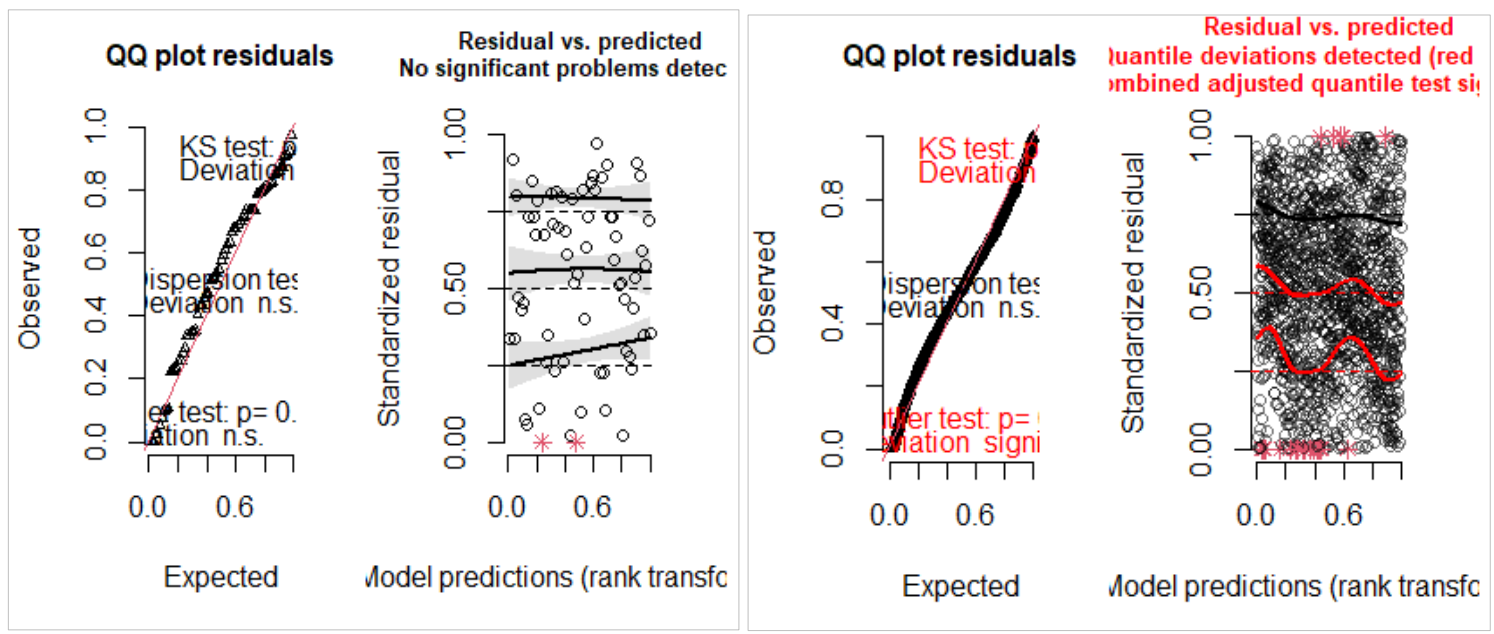

Figure 11. Residuals diagnostics for the generalized linear mixed models fitted using the gamma family and log link function. Functional diversity (the response variable) in response to mean annual precipitation, mean annual temperature, elevation, and roughness. On the left residual diagnostics for models where functional diversity estimates were at $100 \mathrm{~m}^{2}$. On the right residual diagnostics for models where functional diversity estimates at $1 \mathrm{~km}^{2}$. 


\section{Supplementary material Chapter IV}

\section{Environmental heterogeneity dynamics drive plant diversity on oceanic islands}

Appendix section 2: Archipelagos included in the analysis

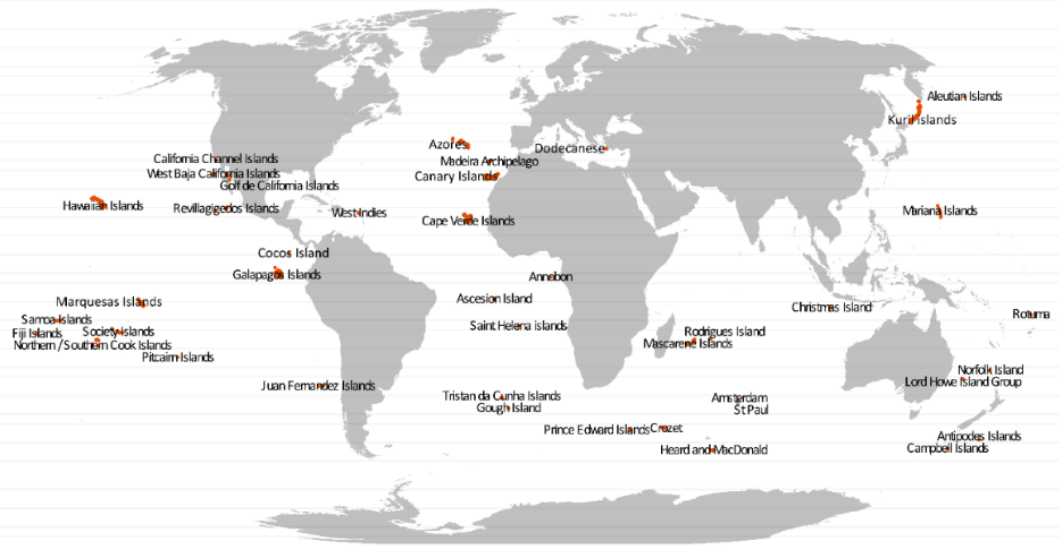

Figure S2.1. Map displaying the 41 archipelagos analyzed in this study.

Appendix section 3: Assessment of the environmental heterogeneity (EH) quantification for 135 oceanic islands and analysis of the effect of the spatial scale on EH.
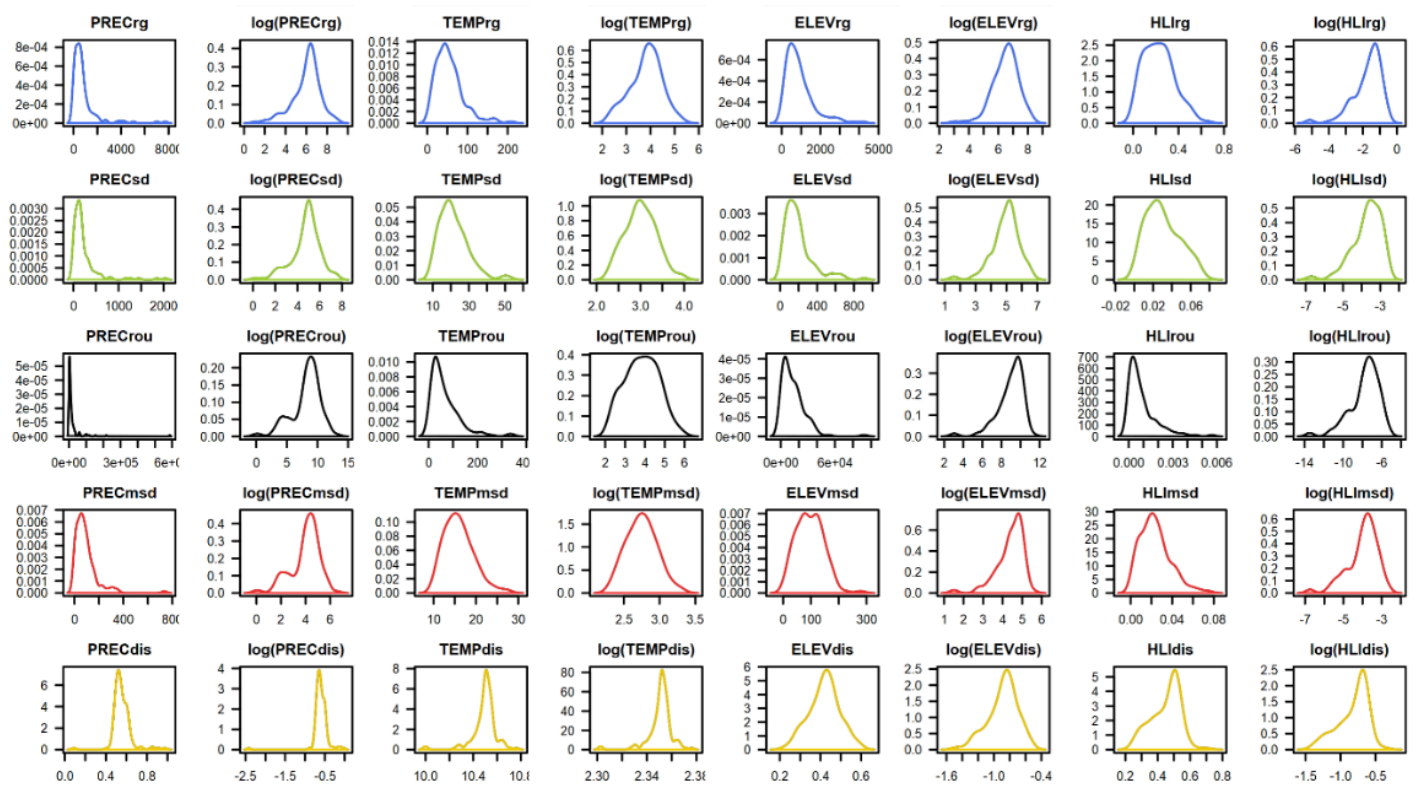

Figure S3.2. Density distribution for the $20 \mathrm{EH}$ metrics calculated. The majority of EH metrics showed a skewed distribution. Thus, all EH metrics were log-transformed using natural logarithm function (here 'log' refers to natural logarithm) to achieve normality for analysis. 


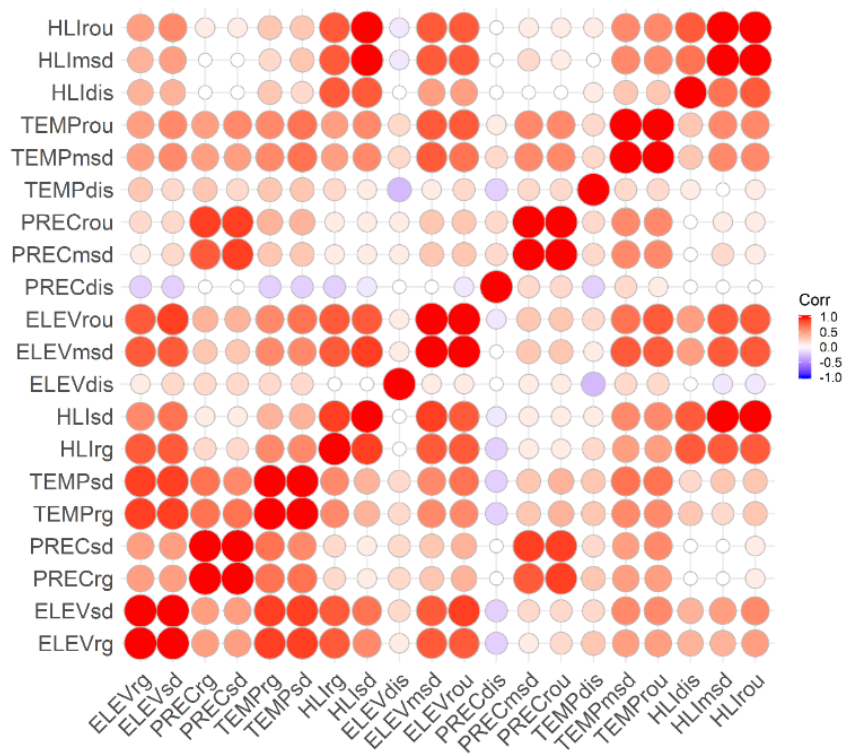

Figure S3.3. Pairwise correlations among the $20 \mathrm{EH}$ metrics calculated for the 135 oceanic islands investigated in this study. Colors (red - positive, blue - negative) and circles size indicate the magnitude and direction of Pearson's correlation coefficients. The EH metrics were named by referring first to the EH component abbreviation in uppercase, followed by the calculation method abbreviation in lower case, e.g. ELEVrou and PRECrg (see Figure 1 in main text for clarification). Strong correlations were observed among whole-island metrics and moving-window metrics (roughness and standard deviation), as well as among temperature (TEMP) and elevation (ELEV) heterogeneity. Correlation analysis was done with $\mathrm{EH}$ metrics log-transformed.

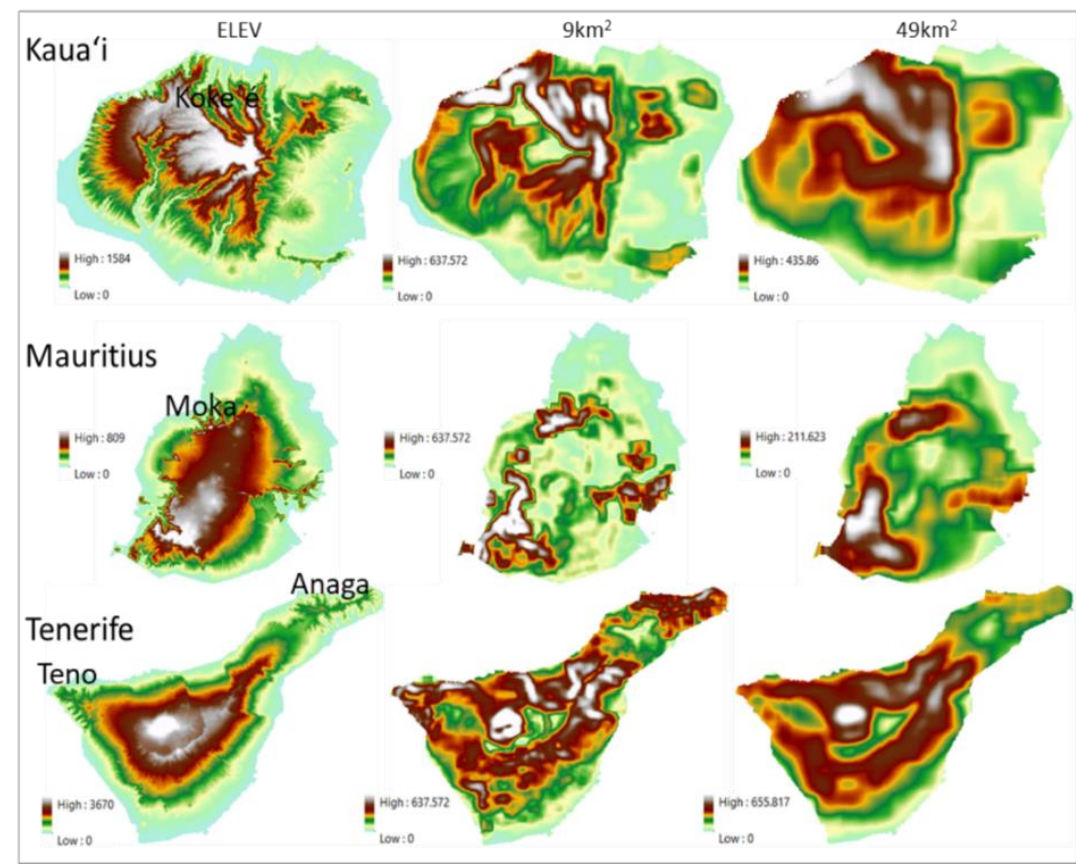

Figure S3.4. Exemplification of EH captured using an intermediate window size $\left(9 \mathrm{~km}^{2}\right)$ and larger window size $\left(49 \mathrm{~km}^{2}\right)$ for three oceanic islands: Kaua'i, Mauritius, and Tenerife and their respective mountain ranges, Koke'é, Moka, Anaga and Teno. The maps display elevation in $\mathrm{m}$ a.s.l. (i.e., ELEV at $250 \mathrm{~m}$ ) on the left side, and two heterogeneity rasters produced using neighborhood analysis 
computed using standard deviation within the moving-windows. Note, $9 \mathrm{~km}^{2}$ window size attributed large standard deviation values to landscape features, where mountain ranges and island ravines are located, while the $49 \mathrm{~km}^{2}$ window size tended to diffuse such features.

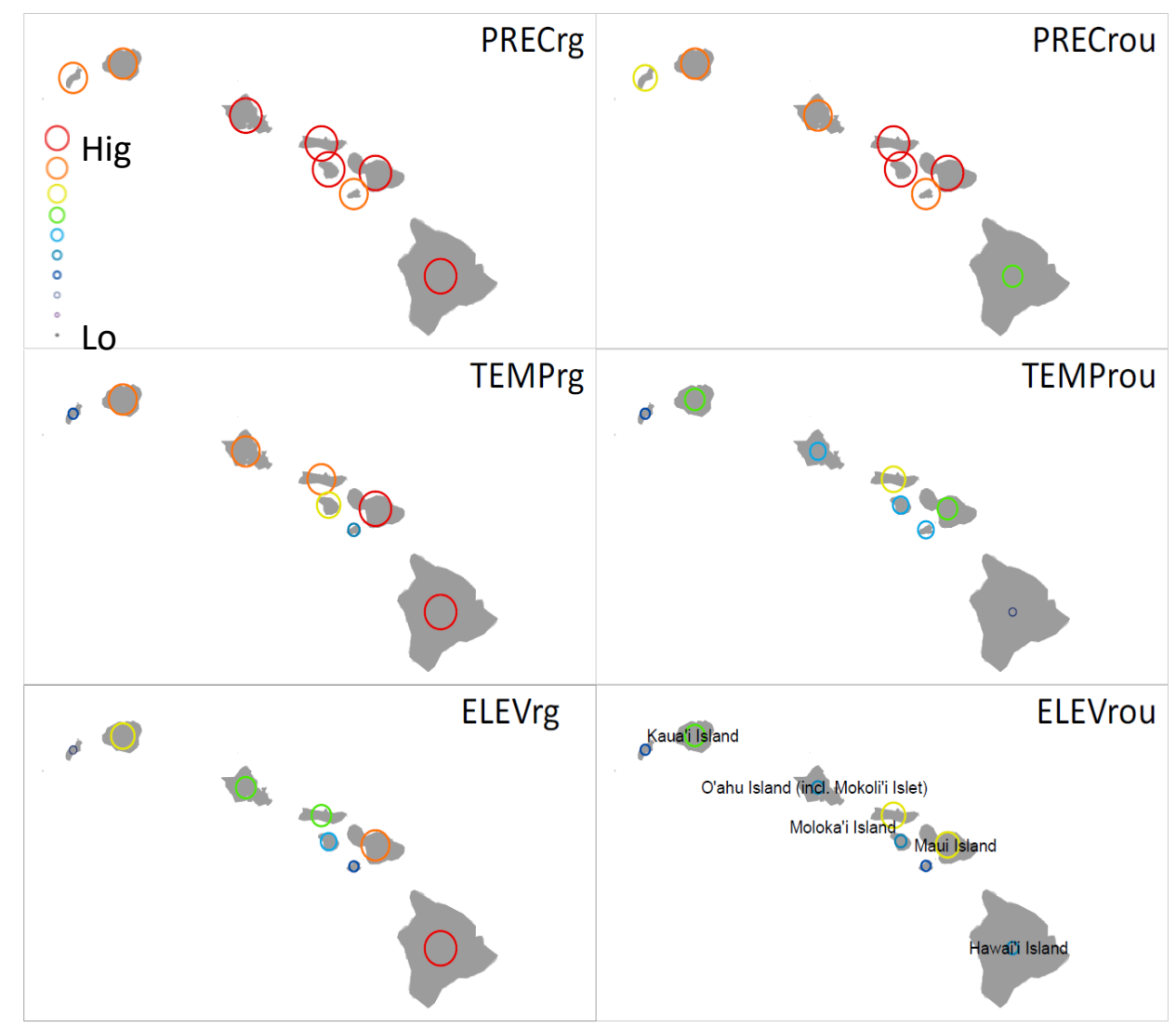

Figure S3.5. Exemplification of how EH metrics captured different aspects of EH using the Hawaiian archipelago. Whole-island metrics that used range $(r g)$ are displayed on the left side and movingwindow metric that used roughness (rou) on the right side. Different colors circles indicate the level of EH. Note that the islands received different values depending on the types of EH metric used. 


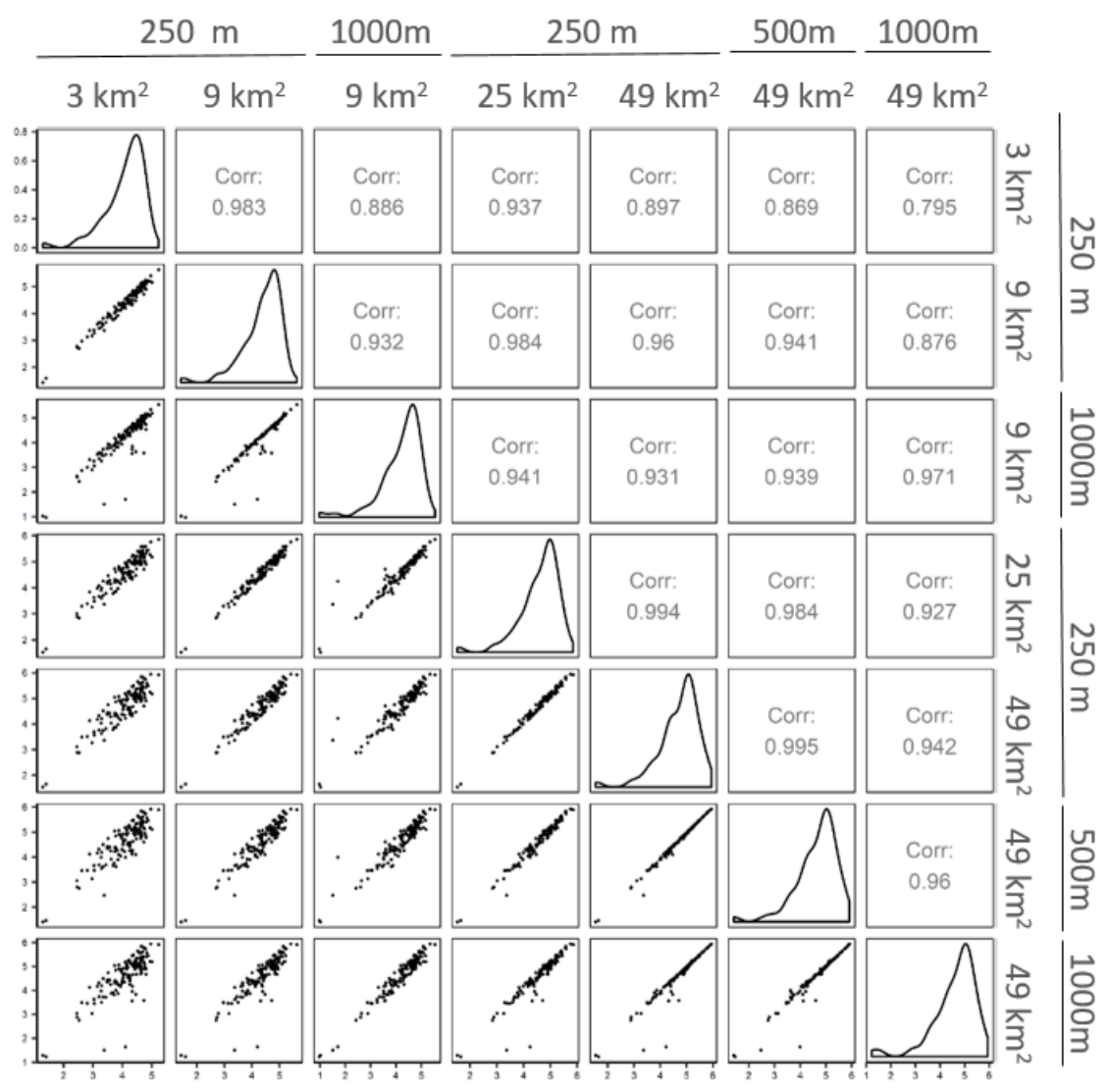

Figure S3.6. Effects of using different moving window sizes and spatial grains on the EH quantification. Four different window sizes $\left(3,9,25,49 \mathrm{~km}^{2}\right)$ and three different spatial grains (250, 500 and $1000 \mathrm{~m}$ ) were compared based on elevation (ELEV; $\mathrm{m}$ a.s.l. at $250 \mathrm{~m}$ spatial grain). The spatial grains 500 and $1000 \mathrm{~m}$ were aggregated from ELEV, using raster resampling technique. The analysis is based on Pearson's correlation values. 
Appendix section 4: $\mathrm{EH} \sim \mathrm{ATT}^{2}$, $\mathrm{EHATT}^{2}$ and $\mathrm{ATT}^{2}$ models evaluation

Table S4.1. Effect of log-transforming island age in the $\mathrm{EH} \sim \mathrm{ATT}^{2}$ models to evaluate the environmental heterogeneity $(\mathrm{EH})$ trend over time (see methods for more detail on the model formula). The $\mathrm{EH} \sim \mathrm{ATT}^{2}$ models were fitted using LMM and evaluated using Akaike's information criterion (AIC), where lower AIC values $(\triangle A I C>2$ ) indicate higher statistical support for a given model. Marginal (i.e., fixed effects) and conditional (i.e., fixed plus random effects) $R^{2}$ values are reported for each model. In the formulas 'In' refers to natural logarithm, 'EH' to a EH metric (logtransformed) and ' $\mathrm{A}$ ' and ' $\mathrm{T}$ ' to island area and age, respectively. Model comparison is done by pairs (grey, white) and the majority of the models produced lower AIC values when the island age terms (i.e., $\mathrm{T}$ and $\mathrm{T}^{2}$ ) were log-transformed.

\begin{tabular}{|c|c|c|c|}
\hline Model & AIC & $\begin{array}{l}\mathrm{R}^{2} \\
\text { marginal }\end{array}$ & $\begin{array}{l}\mathrm{R}^{2} \\
\text { conditional }\end{array}$ \\
\hline ELEVdis $\sim \ln A \ln T \ln T^{2}$ & 394.88 & 0.065 & 0.236 \\
\hline ELEVdis $\sim \ln A T^{2} T^{2}$ & 402.43 & 0.058 & 0.231 \\
\hline ELEVmsd $\sim \ln A \ln T \ln T^{2}$ & 350.56 & 0.150 & 0.568 \\
\hline ELEVmsd $\sim \ln A T T^{2}$ & 358.88 & 0.139 & 0.544 \\
\hline ELEVrg $\sim \ln A \ln T \ln T^{2}$ & 269.67 & 0.523 & 0.769 \\
\hline ELEVrg $\sim \ln A T^{2} T^{2}$ & 280.37 & 0.516 & 0.751 \\
\hline ELEVrou $\sim \ln A \ln T \ln T^{2}$ & 347.21 & 0.161 & 0.579 \\
\hline ELEVrou InA T T ${ }^{2}$ & 355.58 & 0.150 & 0.556 \\
\hline ELEVsd $\sim \ln A \ln T \ln T^{2}$ & 305.81 & 0.403 & 0.692 \\
\hline ELEVsd $\sim \ln A T^{2} T^{2}$ & 314.74 & 0.396 & 0.671 \\
\hline HLIdis $\ln A \ln T \ln T^{2}$ & 299.81 & 0.012 & 0.741 \\
\hline HLIdis $\sim \ln A T^{2} T^{2}$ & 306.49 & 0.010 & 0.743 \\
\hline $\mathrm{HLImsd} \sim \ln A \ln T \ln T^{2}$ & 321.42 & 0.046 & 0.619 \\
\hline HLImsd $\sim \ln A T^{2} T^{2}$ & 323.42 & 0.066 & 0.634 \\
\hline HLIrg $\ln A \ln T \ln T^{2}$ & 280.12 & 0.181 & 0.753 \\
\hline HLIrg $\sim \ln A T^{2} T^{2}$ & 286.90 & 0.178 & 0.750 \\
\hline HLIrou $\ln A \ln T \ln T^{2}$ & 317.48 & 0.025 & 0.636 \\
\hline HLIrou $\sim \ln A T^{2} T^{2}$ & 320.54 & 0.039 & 0.645 \\
\hline $\mathrm{HLIsd} \sim \ln \mathrm{A} \ln T \ln \mathrm{T}^{2}$ & 315.55 & 0.046 & 0.662 \\
\hline HLIsd InA T T ${ }^{2}$ & 320.66 & 0.050 & 0.662 \\
\hline PRECdis $\sim \ln A \ln T \ln T^{2}$ & 397.36 & 0.095 & 0.103 \\
\hline PRECdis $\sim \ln A T^{2} T^{2}$ & 403.03 & 0.100 & 0.108 \\
\hline PRECmsd $\sim \ln A \ln T \ln T^{2}$ & 299.24 & 0.051 & 0.757 \\
\hline PRECmsd $\sim \ln A T^{2} T^{2}$ & 317.76 & 0.021 & 0.732 \\
\hline PRECrg $\sim \ln A \ln T \operatorname{In} T^{2}$ & 279.55 & 0.303 & 0.804 \\
\hline PRECrg $\sim \ln A T^{2} T^{2}$ & 302.82 & 0.264 & 0.775 \\
\hline PRECrou $\sim \ln A \ln T \ln T^{2}$ & 297.95 & 0.053 & 0.762 \\
\hline PRECrou $\sim \ln A T^{2} T^{2}$ & 316.28 & 0.024 & 0.738 \\
\hline PRECsd $\sim \ln A \ln T \ln T^{2}$ & 283.55 & 0.238 & 0.797 \\
\hline PRECsd $\sim \ln A T^{T} T^{2}$ & 306.82 & 0.198 & 0.765 \\
\hline TEMPdis $\sim \ln A \ln T \ln T^{2}$ & 392.77 & 0.131 & 0.184 \\
\hline TEMPdis $\sim \ln A T^{2} T^{2}$ & 408.94 & 0.062 & 0.079 \\
\hline TEMPmsd $\sim \ln A \ln T \ln T^{2}$ & 352.33 & 0.122 & 0.580 \\
\hline TEMPmsd $\sim \ln A T^{2} T^{2}$ & 370.51 & 0.068 & 0.530 \\
\hline TEMPrg $\sim \ln A \ln T \operatorname{In} T^{2}$ & 243.91 & 0.588 & 0.830 \\
\hline
\end{tabular}




\begin{tabular}{|c|c|c|c|}
\hline TEMPrg $\sim \ln A \mathrm{~T}^{2}$ & 264.99 & 0.562 & 0.802 \\
\hline TEMProu $\sim \ln A \ln T \ln T^{2}$ & 348.88 & 0.137 & 0.608 \\
\hline TEMProu $\sim \ln A T^{2} T^{2}$ & 366.72 & 0.086 & 0.561 \\
\hline TEMPsd $\sim \ln A \ln T \ln T^{2}$ & 292.64 & 0.467 & 0.730 \\
\hline TEMPsd $\sim \ln A T^{2} T^{2}$ & 308.46 & 0.441 & 0.699 \\
\hline
\end{tabular}

Table S4.2. Effect of log-transforming EH metrics in the EHATT${ }^{2}$ to predict number of native and single-island endemics species of vascular plants. Models were fitted using GLMM with Poisson distribution error and evaluated based on Akaike's information criterion (AIC), where $\triangle \mathrm{AIC}>2$ indicates higher statistical support. The majority of the models produced lower AIC values when the EH metric was log-transformed. 'In' refers to the natural logarithm.

\begin{tabular}{|c|c|c|c|}
\hline $\begin{array}{l}\text { Log-transformation } \\
\text { comparison of EH metric in } \\
\text { the } A T^{2} \text { model to predict } \\
\text { number of native species }\end{array}$ & $\begin{array}{l}\text { Statistical } \\
\text { support } \\
\text { AIC value }\end{array}$ & $\begin{array}{l}\text { Log-transformation } \\
\text { comparison of EH metric in } \\
\text { the } \mathrm{ATT}^{2} \text { models to predict } \\
\text { number of single-island } \\
\text { endemics }\end{array}$ & $\begin{array}{l}\text { Statistical } \\
\text { support } \\
\text { AIC value }\end{array}$ \\
\hline ELEVdis & 1571.8 & ELEVdis & 666.2 \\
\hline InELEVdis & 1571.8 & InELEVdis & 666.3 \\
\hline ELEVmsd & 1565.7 & ELEVmsd & 657.4 \\
\hline InELEVmsd & 1562.2 & InELEVmsd & 655.0 \\
\hline ELEVrg & 1571.2 & ELEVrg & 665.8 \\
\hline InELEVrg & 1562.7 & InELEVrg & 658.8 \\
\hline ELEVrou & 1569.7 & ELEVrou & 662.7 \\
\hline InELEVrou & 1563.1 & InELEVrou & 656.7 \\
\hline ELEVsd & 1571.3 & ELEVsd & 665.4 \\
\hline InELEVsd & 1564.9 & InELEVsd & 657.6 \\
\hline HLIdis & 1567.8 & HLIdis & 666.1 \\
\hline InHLIdis & 1565.2 & InHLIdis & 665.8 \\
\hline HLImsd & 1568.9 & HLImsd & 660.3 \\
\hline InHLImsd & 1566.5 & InHLImsd & 657.1 \\
\hline HLIrg & 1571.5 & HLIrg & 663.6 \\
\hline InHLIrg & 1570.3 & InHLIrg & 664.1 \\
\hline HLIrou & 1570.4 & HLIrou & 663.3 \\
\hline InHLIrou & 1567.8 & InHLIrou & 659.3 \\
\hline HLIsd & 1571.1 & HLIsd & 661.6 \\
\hline InHLIsd & 1569.1 & InHLIsd & 660.5 \\
\hline PRECdis & 1571.0 & PRECdis & 666.3 \\
\hline InPRECdis & 1570.9 & InPRECdis & 666.0 \\
\hline PRECmsd & 1557.4 & PRECmsd & 663.8 \\
\hline InPRECmsd & 1560.6 & InPRECmsd & 663.2 \\
\hline PRECrg & 1561.7 & PRECrg & 665.3 \\
\hline InPRECrg & 1558.8 & InPRECrg & 663.8 \\
\hline PRECrou & 1563.7 & PRECrou & 664.1 \\
\hline InPRECrou & 1561.1 & InPRECrou & 663.0 \\
\hline PRECsd & 1564.0 & PRECsd & 666.1 \\
\hline InPRECsd & 1560.7 & InPRECsd & 664.1 \\
\hline TEMPdis & 1571.1 & TEMPdis & 665.7 \\
\hline InTEMPdis & 1571.1 & InTEMPdis & 665.7 \\
\hline TEMPmsd & 1561.1 & TEMPmsd & 660.2 \\
\hline
\end{tabular}




\begin{tabular}{|l|l|l|l|}
\hline InTEMPmsd & 1560.2 & InTEMPmsd & 657.7 \\
\hline TEMPrg & 1568.7 & TEMPrg & 664.6 \\
\hline InTEMPrg & 1559.8 & InTEMPrg & 657.2 \\
\hline TEMProu & 1564.9 & TEMProu & 664.0 \\
\hline InTEMProu & 1561.3 & InTEMProu & 655.5 \\
\hline TEMPsd & 1566.0 & TEMPsd & 664.4 \\
\hline InTEMPsd & 1561.5 & InTEMPsd & 660.0 \\
\hline
\end{tabular}

Table S4.3. Statistical support for including environmental heterogeneity (EH) in the $A T^{2}$ model in the framework of the General Dynamic Model (GDM) and absolute model fit assessment $\left(R^{2}\right.$ values). The $\mathrm{ATT}^{2}$ and $\mathrm{EHATT^{2 }}$ models were fitted using GLMMs with Poisson error, including each EH metric separately. Model comparison was based on Akaike's information criterion (AIC), where $\triangle A I C>2$ indicates higher statistical support. The $A T^{2}$ model without an environmental variable is used as reference $(\triangle A I C=0)$. The AIC values of $A T T^{2}$ models for native species and single-island endemics were 1569.7 and 664.6, respectively. In all models, island area (A) and age (T) as well as the EH metrics were log-transformed. $R^{2} m$ and $R^{2} c$ correspond to marginal (fixed effects) and conditional (random effects) effects, respectively.

\begin{tabular}{|c|c|c|c|c|c|c|c|}
\hline $\begin{array}{l}\text { EH metric } \\
\text { included } \\
\text { in the } \\
\text { ATT }^{2} \\
\text { model to } \\
\text { predict } \\
\text { number } \\
\text { of native } \\
\text { species }\end{array}$ & $\begin{array}{l}\text { Statistical } \\
\text { support: } \\
\triangle \text { AIC }\end{array}$ & $R^{2} m$ & $\mathrm{R}^{2} \mathrm{C}$ & $\begin{array}{l}\text { EH metric } \\
\text { included } \\
\text { in the } \\
\mathrm{ATT}^{2} \\
\text { model to } \\
\text { number } \\
\text { of single- } \\
\text { island } \\
\text { endemics }\end{array}$ & $\begin{array}{l}\text { Statistical } \\
\text { support: } \\
\triangle \mathrm{AIC}\end{array}$ & $\mathrm{R}^{2} \mathrm{~m}$ & $R^{2} C$ \\
\hline PRECrg & 10.93 & 28.53 & 99.70 & ELEVmsd & 9.61 & 31.52 & 99.97 \\
\hline TEMPrg & 9.95 & 27.51 & 99.71 & TEMProu & 9.07 & 33.76 & 99.97 \\
\hline TEMPmsd & 9.55 & 27.67 & 99.70 & ELEVrou & 7.95 & 31.38 & 99.97 \\
\hline PRECmsd & 9.17 & 29.27 & 99.69 & HLImsd & 7.49 & 29.85 & 99.97 \\
\hline PRECsd & 9.05 & 28.24 & 99.70 & TEMPrg & 7.39 & 31.89 & 99.97 \\
\hline PRECrou & 8.67 & 29.20 & 99.69 & ELEVsd & 7.03 & 30.73 & 99.97 \\
\hline TEMProu & 8.49 & 27.68 & 99.70 & TEMPmsd & 6.93 & 32.95 & 99.97 \\
\hline TEMPsd & 8.29 & 27.51 & 99.71 & ELEVrg & 5.81 & 30.51 & 99.97 \\
\hline ELEVmsd & 7.58 & 27.70 & 99.70 & HLIrou & 5.34 & 29.87 & 99.97 \\
\hline ELEVrg & 7.06 & 27.68 & 99.70 & TEMPsd & 4.60 & 30.77 & 99.97 \\
\hline ELEVrou & 6.66 & 27.63 & 99.70 & HLIsd & 4.12 & 29.66 & 99.97 \\
\hline ELEVsd & 4.84 & 27.48 & 99.70 & PRECrou & 1.64 & 31.89 & 99.97 \\
\hline HLIdis & 4.55 & 27.28 & 99.71 & PRECmsd & 1.40 & 31.66 & 99.97 \\
\hline HLImsd & 3.23 & 27.51 & 99.70 & PRECrg & 0.80 & 31.50 & 99.97 \\
\hline HLIrou & 1.96 & 27.44 & 99.70 & PRECsd & 0.53 & 31.39 & 99.97 \\
\hline HLIsd & 0.66 & 27.18 & 99.70 & HLIrg & 0.49 & 29.96 & 99.97 \\
\hline $\mathrm{ATT}^{2}$ & 0.00 & 27.30 & 99.69 & $\mathrm{ATT}^{2}$ & 0.00 & 29.62 & 99.97 \\
\hline HLIrg & -0.51 & 27.17 & 99.70 & TEMPdis & -1.13 & 29.71 & 99.97 \\
\hline PRECdis & -1.14 & 27.28 & 99.69 & HLIdis & -1.18 & 28.93 & 99.97 \\
\hline TEMPdis & -1.33 & 27.29 & 99.69 & PRECdis & -1.43 & 30.60 & 99.97 \\
\hline ELEVdis & -2.00 & 27.30 & 99.69 & ELEVdis & -1.71 & 29.90 & 99.97 \\
\hline
\end{tabular}



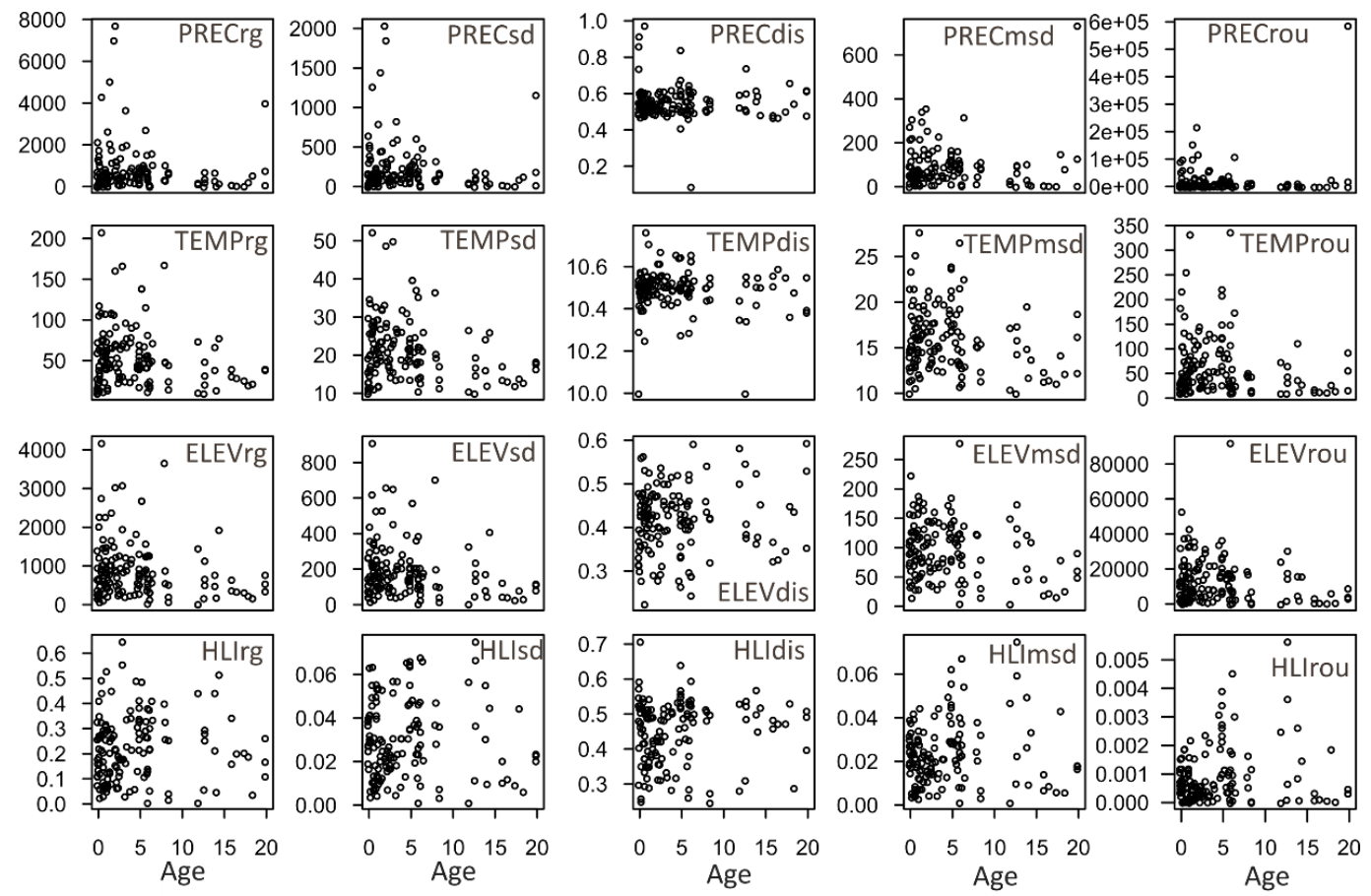

Figure S4.7. Univariate relationships between island age and EH metrics. Original values of Island age and EH metrics are displayed. This data was used to fit EH ATT ${ }^{2}$ models, as well as EHATT ${ }^{2}$ and $\mathrm{ATT}^{2}$ models.

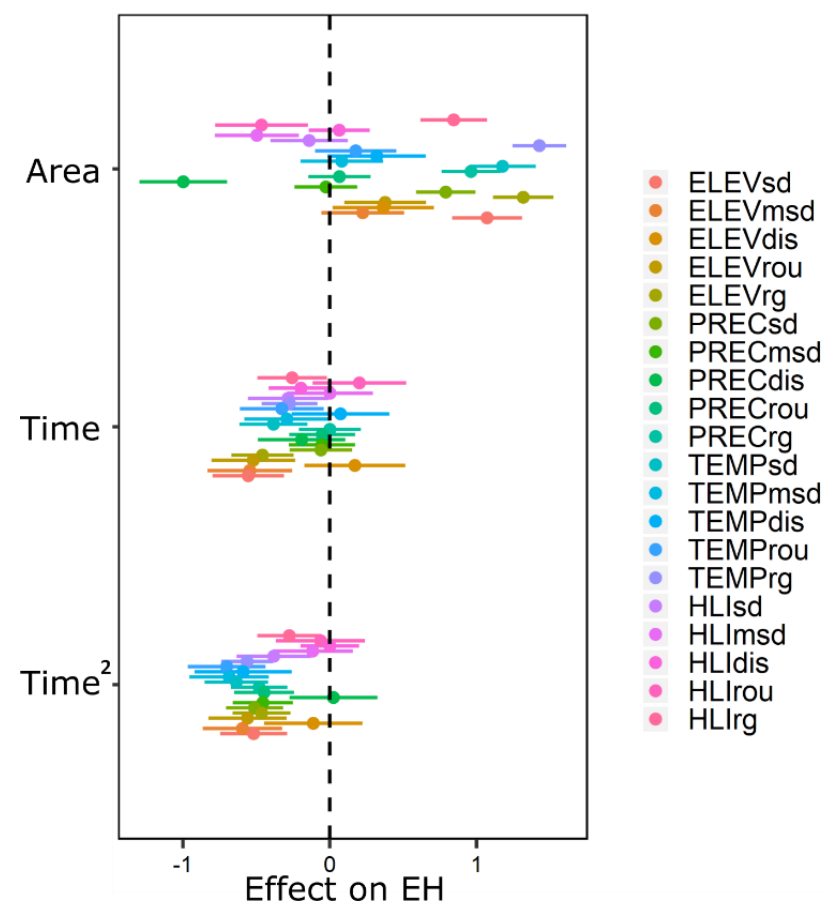

Figure S4.8. Effects of island area and age on environmental heterogeneity (EH). Coefficient estimates (dots) and confidence intervals spanning 95\% (bars) obtained after fitting LMM using the formula: EH metric ATT ${ }^{2}$. The colors correspond to a different EH metric set as response variable. The dashed line marks zero effect of a model coefficient on the response variable. 
Coefficient estimates were automatically scaled by 2 times their standard deviation for direct comparison.

(a)

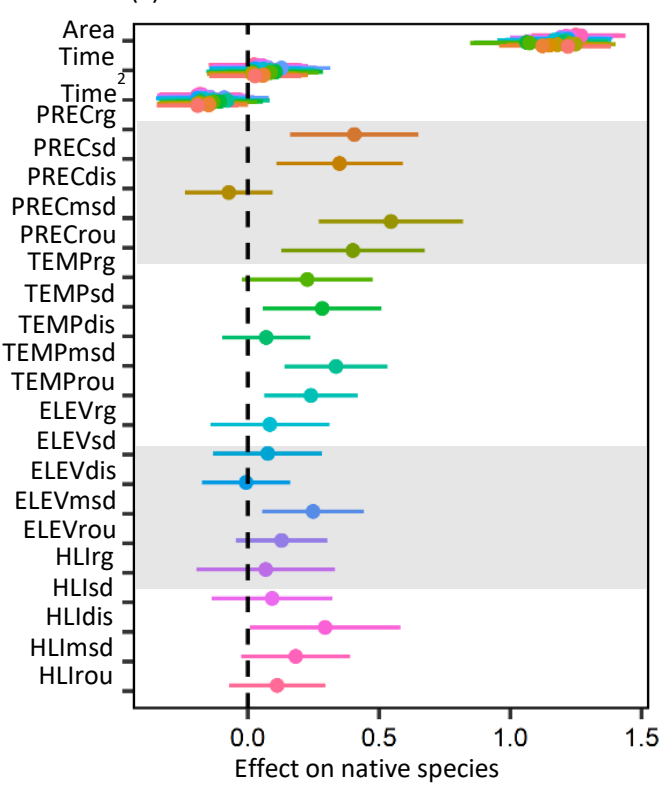

(b)

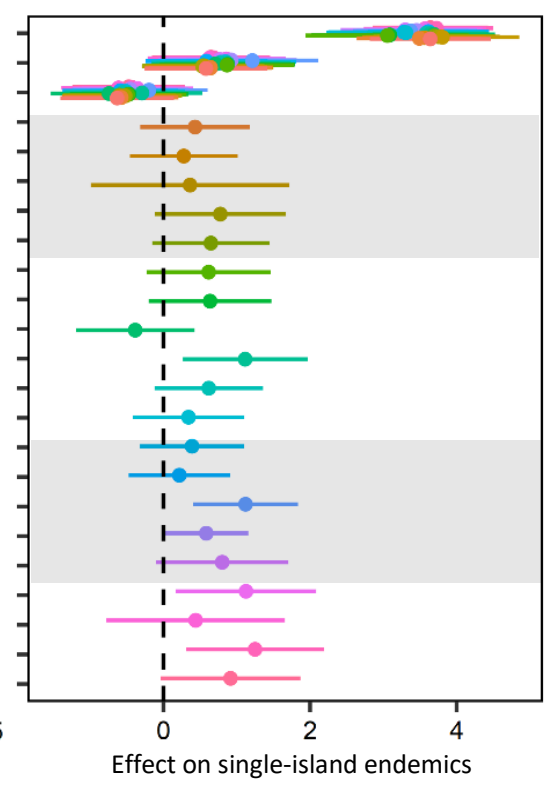

Figure S4.9. Effects of including EH metrics without log-transformation in the models to predict (a) number of native and (b) number of single-island endemic species of vascular plants. Coefficient estimates (dots) and 95\% confidence intervals (bars) from models fitted using generalized linear mixed-effects models (with Poisson distribution error) with $\mathrm{ATT}^{2}$ and EHATT${ }^{2}$. The colored dots and bars correspond to a particular model depending on the EH metric included. Note that without the log-transformation the majority of the EH metrics showed non-significant to zero effect on the response variables. 
Appendix section 5: Temporal trends of vascular plant diversity over island age.

Table S5.4. Effect of excluding $\mathrm{T}^{2}$ from the EHATT${ }^{2}$ and $\mathrm{ATT}^{2}$ models that predict number of native and single-island endemic species of vascular plants. The ATT' ${ }^{2}$ and EHATT${ }^{2}$ models were fitted using GLMM with Poisson error, including each EH metric separately. Evaluation of the $\mathrm{T}^{2}$ term exclusion is based on Akaike's information criterion (AIC), where $\triangle \mathrm{AIC}>2$ indicate higher statistical support. Note that, the majority of the models produced lower AIC values when the $T^{2}$ term was removed.

\begin{tabular}{|l|l|l|l|l|l|}
\hline $\begin{array}{l}\text { EH metric } \\
\text { included in } \\
\text { models for } \\
\begin{array}{l}\text { Native } \\
\text { species }\end{array}\end{array}$ & $\begin{array}{l}\text { AIC for model } \\
\text { EHAT }\end{array}$ & $\begin{array}{l}\text { AIC for model } \\
\text { EHATT }^{2}\end{array}$ & $\begin{array}{l}\text { EH metric } \\
\text { included } \\
\text { in models } \\
\text { for single- } \\
\text { island } \\
\text { species }\end{array}$ & $\begin{array}{l}\text { AIC for model } \\
\text { EHAT }\end{array}$ & $\begin{array}{l}\text { AIC for model } \\
\text { EHATT }^{2}\end{array}$ \\
\hline ELEVdis & 1573.31 & 1569.76 & & 665.27 & 664.61 \\
\hline ELEVmsd & 1561.03 & 1562.19 & ELEVmsd & 653.09 & 65.32 \\
\hline ELEVrg & 1561.53 & 1562.70 & ELEVrg & 657.07 & 658.80 \\
\hline ELEVrou & 1562.24 & 1563.11 & ELEVrou & 654.92 & 656.66 \\
\hline ELEVsd & 1564.13 & 1564.93 & ELEVsd & 655.82 & 657.58 \\
\hline HLIdis & 1569.09 & 1565.21 & HLIdis & 666.15 & 665.79 \\
\hline HLImsd & 1568.58 & 1566.53 & HLImsd & 656.45 & 657.12 \\
\hline HLIrg & 1572.94 & 1570.27 & HLIrg & 664.08 & 664.12 \\
\hline HLIrou & 1570.07 & 1567.80 & HLIrou & 658.77 & 659.27 \\
\hline HLIsd & 1570.69 & 1569.11 & HLIsd & 659.72 & 660.49 \\
\hline PRECdis & 1574.52 & 1570.90 & PRECdis & 666.03 & 666.04 \\
\hline PRECmsd & 1559.73 & 1560.60 & PRECmsd & 661.38 & 663.21 \\
\hline PRECrg & 1557.50 & 1558.84 & PRECrg & 662.06 & 663.81 \\
\hline PRECrou & 1560.33 & 1561.09 & PRECrou & 661.12 & 662.97 \\
\hline PRECsd & 1559.40 & 1560.71 & PRECsd & 662.40 & 664.08 \\
\hline TEMPdis & 1573.90 & 1571.09 & TEMPdis & 667.17 & 665.74 \\
\hline TEMPmsd & 1558.68 & 1560.21 & TEMPmsd & 655.79 & 657.68 \\
\hline TEMPrg & 1557.89 & 1559.81 & TEMPrg & 655.26 & 657.22 \\
\hline TEMProu & 1559.71 & 1561.28 & TEMProu & 653.58 & 655.53 \\
\hline TEMPsd & 1559.78 & 1561.47 & TEMPsd & 658.25 & 660.00 \\
\hline & & & & & \\
\hline
\end{tabular}


(a)

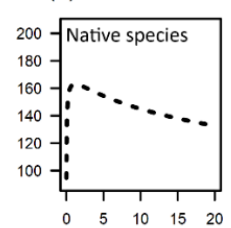

(f)

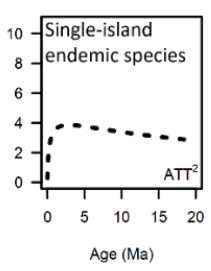

(b)

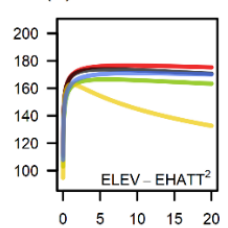

(g)

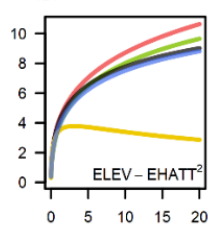

(c)

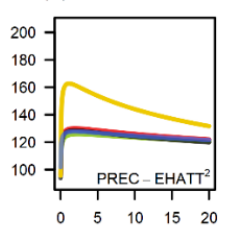

(h)

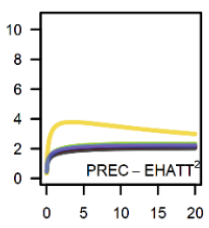

Age (Ma) (d)

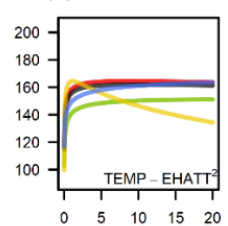

(i)

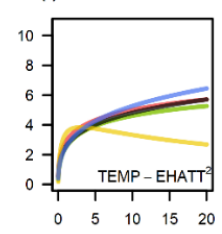

Age (Ma)

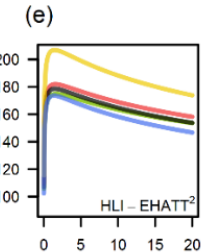

(j)

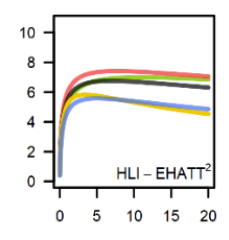

Age (Ma)

Figure S5.10. Temporal trends of species richness and endemism of insular vascular plants. The trends correspond to model predictions based on 135 oceanic islands. The ATT $^{2}$ and EHATT ${ }^{2}$ models were fitted using GLMM with Poisson error, including each EH metric separately. Temporal trends of number of native (a: $\mathrm{ATT}^{2}$ and b-e: EHATT ${ }^{2}$ models) and single-island endemics species (f: $\mathrm{ATT}^{2}$ and g-j: $\mathrm{EHATT}^{2}$ models) are arranged per EH component. The different color lines correspond to the method used to calculate EH.

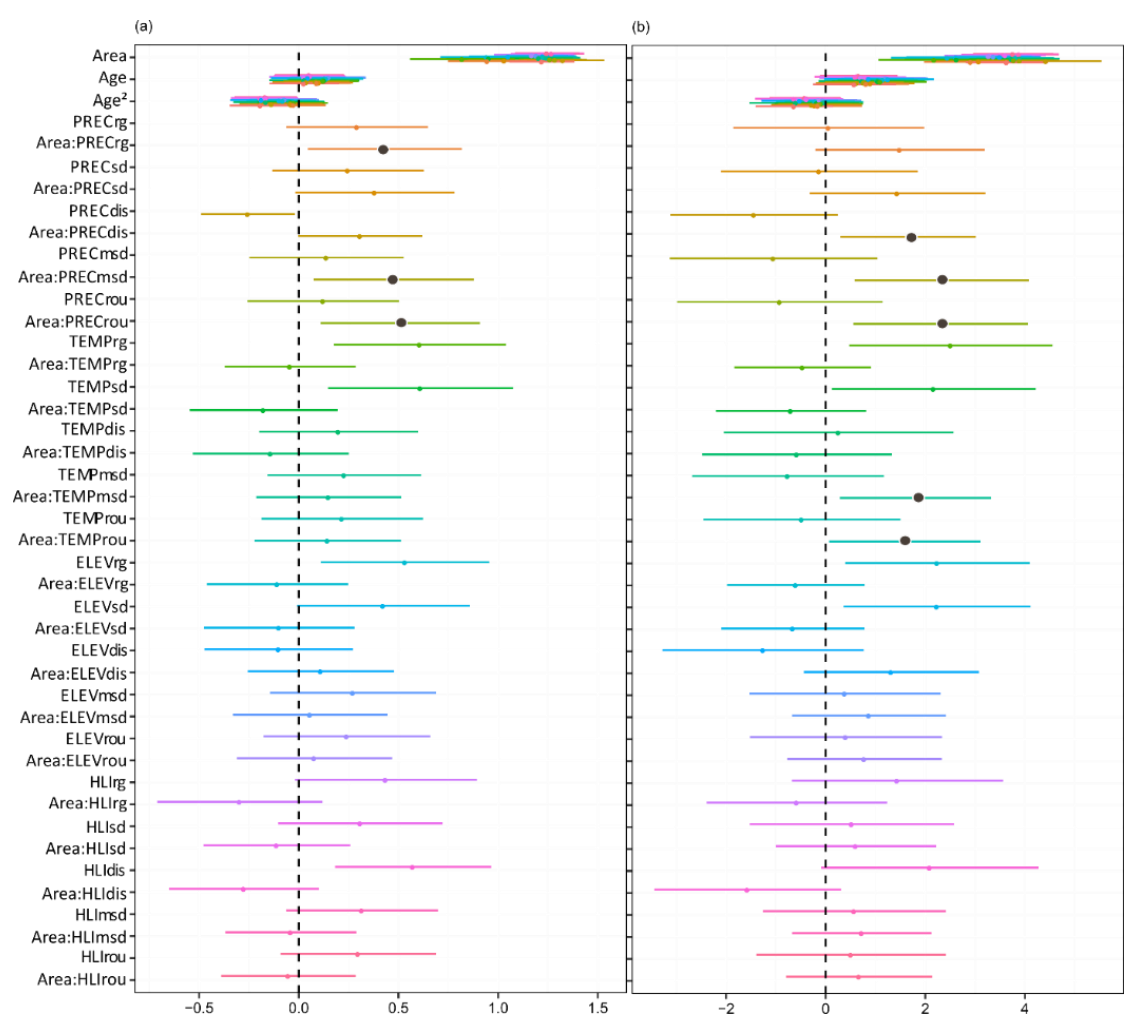

Figure S5.11. Effects of the interaction between island area and EH in the EHATT' ${ }^{2}$ model predicting (a) number of native and (b) number of single-island endemic species of vascular plants. Coefficient estimates (dots) and 95\% confidence intervals (bars) from models were fitted using generalized linear mixed-effects models with Poisson distribution error. The colored dots and bars correspond to a particular model depending on the EH metric included. Significant interactions are highlighted with black coefficient dots. 


\section{ACKNOWLEDGMENTS}

I want to thank all the great people that supported and encouraged me through the PhD process. I thank my great mentor, Prof. Dr. Holger Kreft, who always supported me, taught me how to be rigorous, critical and creative in my work, and who also gave me great advice. One of the best being "do not go extinct" after talking about how much hard-work finishing the PhD involves. I thank Dr. Patrick Weigelt and Dr. Dylan Craven who have also been incredible mentors. Patrick, spent hours teaching me how to " $\mathrm{R}$ " and shared ideas and thoughts about statistics, islands and plants. Dylan spent many hours discussing with me my results; he shared with me new methods and great ideas that helped improving my PhD overall.

I thank my colleagues and friends from the Department Biodiversity, Macroecology \& Biogeography. Special thanks to Dr. Amanda Taylor and Dr. Nathaly Guerrero, my great female mentors, who supported me professionally and emotionally during my $\mathrm{PhD}$, and who being critical to my work made it always better. I also thank my friends Marie Ryan, Wilhelmine Bach and Dr. Cristian Koning for their support proofing parts of my thesis. Special thanks to my Mexican LatinAmerican colleagues, Dr. Lety Monge, Dr. Vale Guzman and Thalita Arruda, whos hardwork and good-vibes always inspired me. I also thank all the great people from the different corners of the world I got to meet working in the Göttingen lab. This is a great place to work and I will always keep its people very close to my heart.

I also want to thank the Tenerife crew; whose support was key to successfully finish my field and lab work. Special thanks to Prof. Dr. José María Fernández Palacios for his biogeographical advice about the canary plants. Thanks to Dr. Rüdiger Otto, who showed me the entire flora of Tenerife and guided me through the sampling of (almost) all Tenerife plants.

My PhD work was financed by the RTG 1644 "Scaling problems in statistics" and by the Department Biodiversity, Macroecology \& Biogeography, University of Göttingen. Special thanks to Dörte Dede and Dr. Barbara Strauss who were always very kind and diligent helping me with the organization and coordination of the fieldwork I conducted. I thank Silke Marks for helping me dealing with the administrational issues. I also thank Prof. Dr. Kerstin Wiegand for her nice comments and supporting me with the RTG reports. 
I especially thank my parents and family. My dad Carlos Barajas whose love for science always inspired me and made me wonder about the intricacies of nature. My Mom Luz Marina Barbosa, who taught me hard-work and constantly challenged me. I most especially thank my husband Bjørn Øst Hansen, who's my partner, friend and mentor. He taught me how to be efficient during my PhD and whose great ideas (almost) always work. Bjørn's company and support made possible the realization of my PhD, his love is the engine of my success. 


\section{AUTHOR CONTRIBUTION}

\section{Chapter II Assembly of functional diversity of an oceanic island flora}

Martha Paola Barajas-Barbosa, Dylan Craven, Patrick Weigelt, Pierre Denelle, José María Fernández-Palacios, Rüdiger Otto, Sandra Díaz, Jonathan Price and Holger Kreft.

HK conceived the idea of this study and MPBB further developed the idea. MPBB collected and measured plant trait data and performed the analysis. PD supported the analysis. DC and PW supported the interpretation of results. RO supported plant trait data collection. MPBB let the writing with major contribution from all co-authors.

This chapter is a manuscript in preparation. Target journal: Nature

\section{Chapter III Plant functional diversity on an oceanic island varies across spatial scales}

Martha Paola Barajas Barbosa, Dylan Craven, Patrick Weigelt, Rüdiger Otto, Joshua Erkelenz ${ }^{1}$, Amanda Taylor ${ }^{1}$, Dagmar Hanz ${ }^{4}$, Pierre Denelle ${ }^{1}$, José María Fernández Palacios ${ }^{3}$ Manuel Steinbauer ${ }^{5}$ and Holger Kreft ${ }^{1}$

HK, MPBB and DC conceived the idea. MPBB collected and measured plant trait data, prepared species distribution data and performed the analysis. DC supported interpretation of results. JE supported data cleaning and preparation for the analysis. PW and AT supported statistical analysis. RO supported plant trait data collection. DH prepared of species distribution data. MPBB let the writing with major contribution from all co-authors.

This chapter is a manuscript in preparation. Target journal: Ecology letters

\section{CHAPTER IV Environmental heterogeneity dynamics drive plant diversity on oceanic islands}

Martha Paola Barajas-Barbosa ${ }^{1 *}$, Patrick Weigelt ${ }^{1}$, Michael Krabbe Borregaard ${ }^{2}$, Gunnar Keppel ${ }^{1,3}$, Holger Kreft ${ }^{1,4}$

HK, MPBB and PW conceived the idea. MPBB performed the analysis. PW supported the analysis and interpterion of results. MPBB let the writing with major contribution from all co-authors.

This chapter is published in the Journal of Biogeography. https://doi.org/10.1111/jbi.13925 


\title{
DOKTORANDEN-ERKLÄRUNG \\ DER GEORG-AUGUST-UNIVERSITÄT GÖTTINGEN
}

\author{
Name: Martha Paola Barajas Barbosa \\ Anschrift: Vor dem Hospitaltore 2, 04103, Leipzig.
}

Ich beabsichtige, eine Dissertation zum Thema „Diversity of oceanic island floras: a functional and taxonomic approach along gradients of environmental heterogeneity and across spatial scales " an der Georg-August-Universität Göttingen anzufertigen.

Dabei werde ich von Herr Prof. Dr. Holger Kreft betreut.

Ich gebe folgende Erklärung ab:

1. Die Gelegenheit zum vorliegenden Promotionsvorhaben ist mir nicht kommerziell vermittelt worden. Insbesondere habe ich keine Organisation eingeschaltet, die gegen Entgelt Betreuerinnen und Betreuer für die Anfertigung von Dissertationen sucht oder die mir obliegenden Pflichten hinsichtlich der Prüfungsleistungen für mich ganz oder teilweise erledigt.

2. Hilfe Dritter wurde bis jetzt und wird auch künftig nur in wissenschaftlich vertretbarem und prüfungsrechtlich zulässigem Ausmaß in Anspruch genommen. Insbesondere sind alle Teile der Dissertation selbst angefertigt; fremde Hilfe habe ich dazu weder unentgeltlich noch entgeltlich entgegengenommen und werde dies auch zukünftig so halten.

Des Weiteren ist mir bekannt, dass Unwahrhaftigkeiten hinsichtlich der vorstehenden Erklärung die Zulassung zur Promotion ausschließen bzw. später zum Verfahrensabbruch oder zur Rücknahme des erlangten Grades berechtigen.

Leipzig, $\quad 16.04 .2021$

(Ort, Datum, Unterschrift) 
DOKTORANDEN-ERKLÄRUNG DER GEORG-AUGUST-UNIVERSITÄT GÖTTINGEN 